University of San Diego

Digital USD

1999-03-01

\title{
Diversity, Collaboration, Reflective Practice, and Technology in Professional Education Programs: Strategic Choices for Higher Education
}

Caren L. Sax EdD

University of San Diego

Follow this and additional works at: https://digital.sandiego.edu/dissertations

Part of the Leadership Studies Commons

\section{Digital USD Citation}

Sax, Caren L. EdD, "Diversity, Collaboration, Reflective Practice, and Technology in Professional Education Programs: Strategic Choices for Higher Education" (1999). Dissertations. 658.

https://digital.sandiego.edu/dissertations/658

This Dissertation: Open Access is brought to you for free and open access by the Theses and Dissertations at Digital USD. It has been accepted for inclusion in Dissertations by an authorized administrator of Digital USD. For more information, please contact digital@sandiego.edu. 
DIVERSITY, COLLABORATION, REFLECTIVE PRACTICE, AND TECHNOLOGY IN PROFESSIONAL EDUCATION PROGRAMS:

STRATEGIC CHOICES FOR HIGHER EDUCATION

\author{
by
}

Caren L. Sax

A dissertation submitted in partial fulfillment of the requirements for the degree of Doctor of Education

University of San Diego

March 1999

Dissertation Committee

William Howe, Ph.D., Chair

Paula Cordeiro, Ed.D.

Fred McFarlane, Ph.D. 
Copyright $@$ by Caren L. Sax

Reproduced with permission of the copyright owner. Further reproduction prohibited without permission. 


\begin{abstract}
Today's postsecondary students are entering American institutions of higher education (IHEs) with different experiences, expectations, and learning needs than students of previous generations. Calls for more diverse campuses, advanced technology, and lifelong learning are maintaining pressure on IHEs to adjust to new demands for a more encompassing vision as traditional approaches are no longer adequate. The challenges are tremendous; the responses must be extensive and reflective if higher education is to achieve its goals of preparing students for productive and meaningful lives.
\end{abstract}

This study investigated student experiences in a yearlong professional education program that was focused by four strategic choices identified by a college of education in a large southwestern university: diversity, collaboration, reflective practice, and technology. Specifically, the content of student journals and transcripts of group discussions were analyzed for indications of changes in awareness and examples of application during their internship experiences. Qualitative research methods were used to address the following questions: 1) How, if at all, did the students' awareness of the four strategic choices change over time?; and 2) How, if at all, did the students apply the four strategic choices during their internships?

Data were analyzed using a modified version of the constant comparative approach of developing theory. Three subprocesses, e.g., data reduction, data display, and conclusion drawing/verification, were employed to identify patterns of attitude change over time, and indications of progress through stages of awareness, understanding, and application. As patterns emerged, new relationships and explanations 
were discovered. Findings indicated that changes in awareness occurred and that students applied what they learned in their internships. This study demonstrated that infusing strategic choices into the coursework of a professional education program helped encourage students to challenge their own beliefs and clarify their own values. In addition, the use of a cohort structure and seminar class facilitated the creation and maintenance of a learning community. Finally, coordinating the goals and activities of the coursework and internship experiences helped to reinforce effective models for teaching and learning. Based on these findings, implications were offered for professional education programs and for administrators and faculty engaged in IHE reform. 


\section{PREFACE AND ACKNOWLEDGMENTS}

\section{Sometimes when I consider what tremendous consequences come from little}

\section{things, I am tempted to think there are no little things. (Bruce Barton)}

When I read this quote on a handmade card in a little shop in Boston, I was impressed with the simplicity yet intensity of the message. Reflecting on all the "little" opportunities, experiences, and decisions that have brought me to this milestone, I never realized the tremendous consequences that were in store for me. Recognizing prospects and pursuing them at the right time has always paid off for me, so when faced with the unique opportunity to begin this doctoral program, I knew the timing was perfect. Professionally, I needed to take the next step. Personally, I needed the challenge. Yet none of this would have happened without the support and encouragement I have received from more people than I can possibly name here.

The members of my dissertation committee, Drs. Bill Howe, Paula Cordeiro, and Fred McFarlane, have each provided me with a model of leadership and scholarship that inspired me to think differently about changes in higher education. I discovered a wealth of information through their recommendations and am proud to have included their insights in my dissertation.

I also want to acknowledge the students in my study who so generously shared their hopes, fears, and reflections on becoming teachers. I am confident that they will be, in their own words, "Teachers who Really Do Care!" I cannot thank them enough for allowing me to follow and analyze their progress and for trusting me to share their stories accurately. 
Finding a doctoral program that not only enabled me, but encouraged me to stay true to my values, was no little thing. Finding within that program a group of fellow students who also valued challenging the status quo was a tremendous consequence. Together we discovered the strength of becoming a learning community. Sharing the inevitable ups and downs of academic demands while attempting to balance them with career and family responsibilities created a bond and provided mutual support. I am honored to be your colleague and your friend.

There are people who inspire, people who encourage, people who push ... I am fortunate to have had all of these kinds of people in my life. Ian Pumpian has inspired me for 20 years to do more than I could have ever imagined. Thanks for inviting me to San Diego. I have never worked so hard in my life and at the same time, felt so rewarded. Had I not come to San Diego, I would not have met Doug Fisher. His confidence in me has never wavered and his expectations have pushed me to complete amazing accomplishments. They are part of my San Diego family who have signed up for the long haul. I am grateful to them and to my other friends at Interwork Institute who have helped me to balance work and school and still maintain some sanity.

Finally, it is certainly no little thing to have support and encouragement from family and friends who reach from coast to coast and beyond. My personal network is far-reaching and includes people who have known me forever. My focus has been narrow and intense these past few years, so I appreciate the tolerance and understanding they have offered when I was not available for anything beyond work or school. Most of all, I want to thank my husband, Chris, who knew what he was getting into and went there anyway. I could not have done it without your patience and unconditional love. 


\section{TABLE OF CONTENTS}

\section{ABSTRACT}

PREFACE AND ACKNOWLEDGMENTS ii

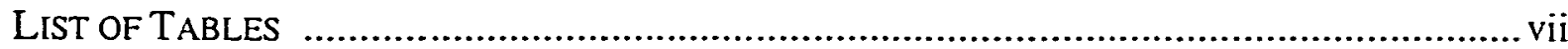

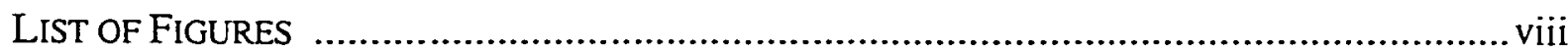

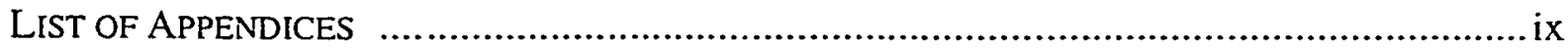

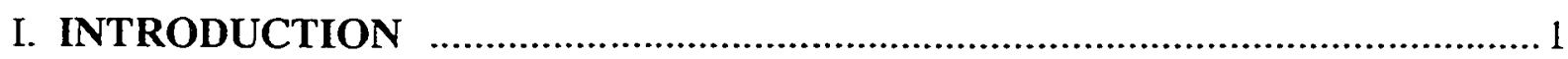

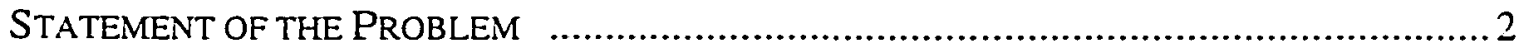

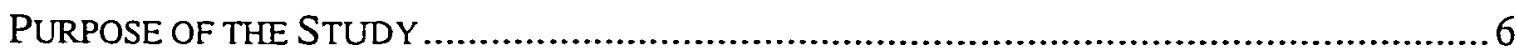

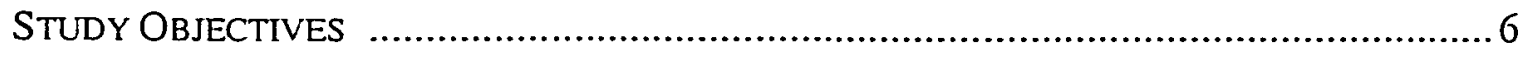

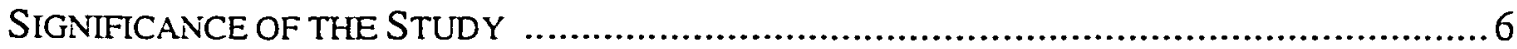

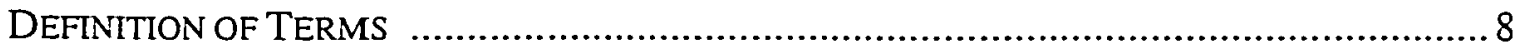

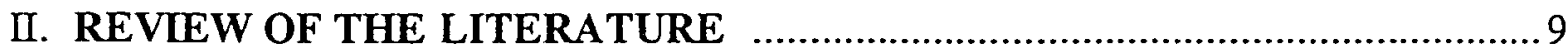

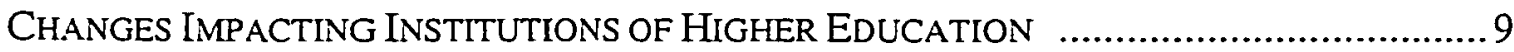

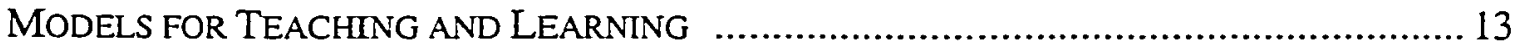

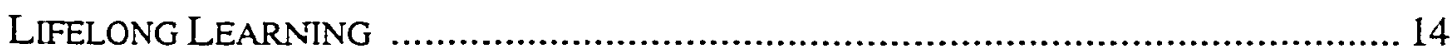

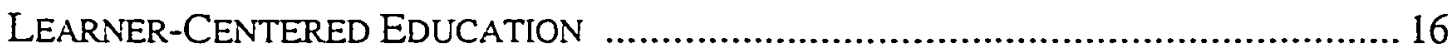

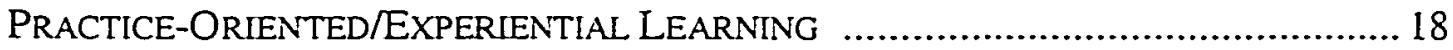

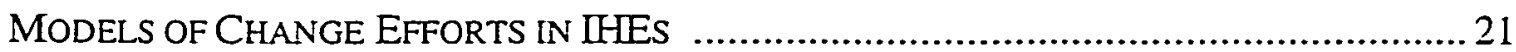

SWU-COE: CREating A New Conceptual Framework for Change ................ 28

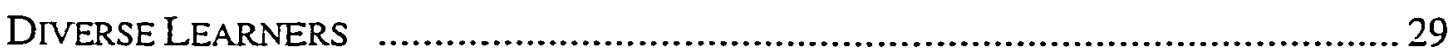

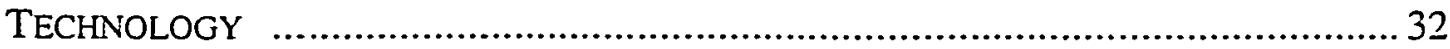

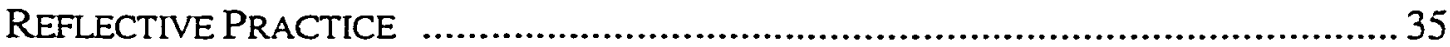




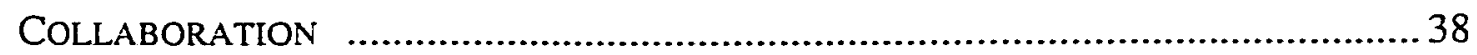

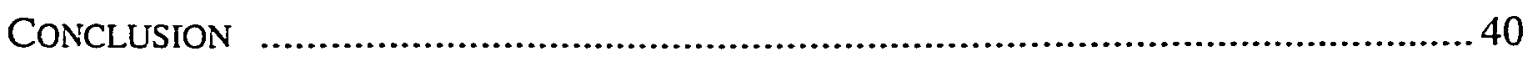

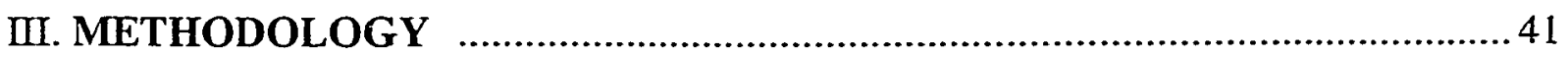

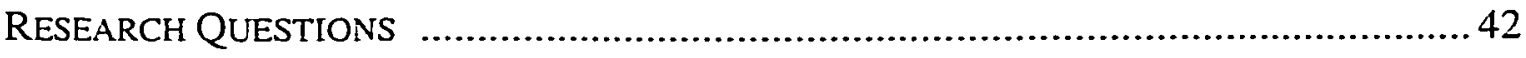

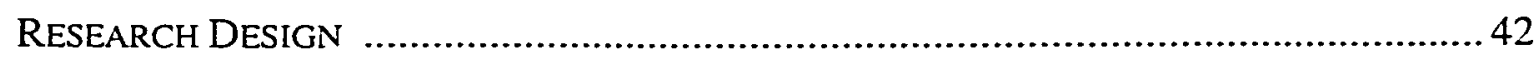

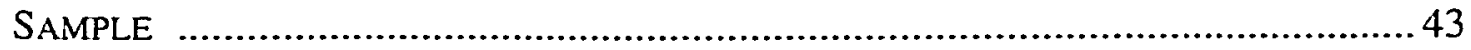

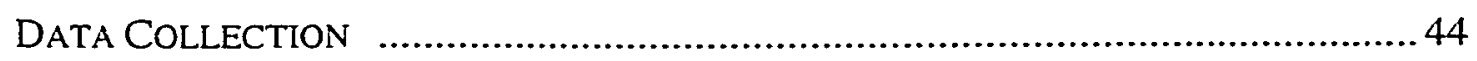

DATA ANALYSIS

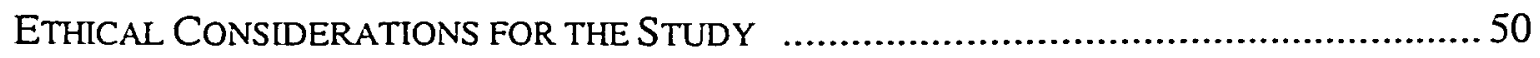

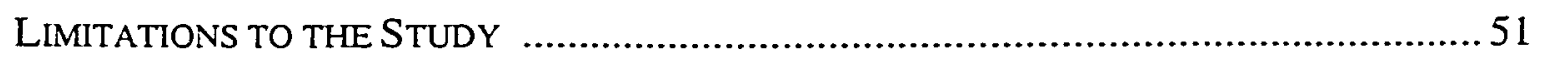

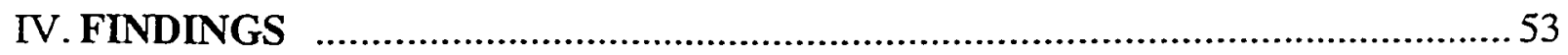

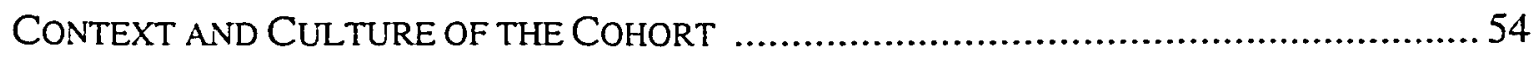

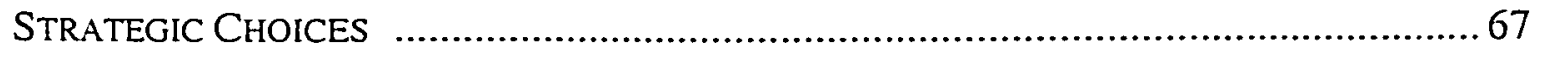

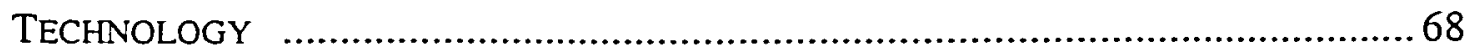

COLLABORATION

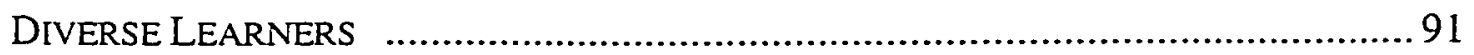

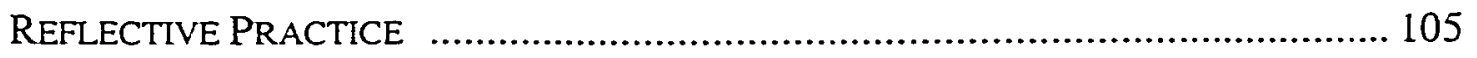

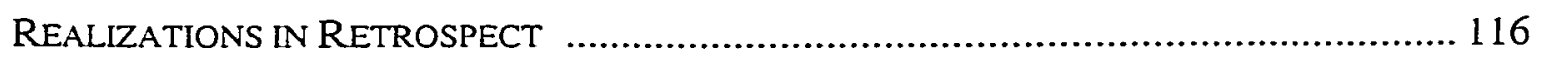

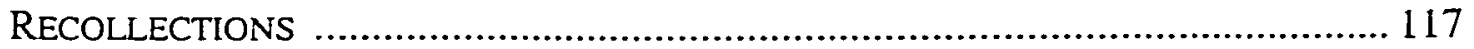

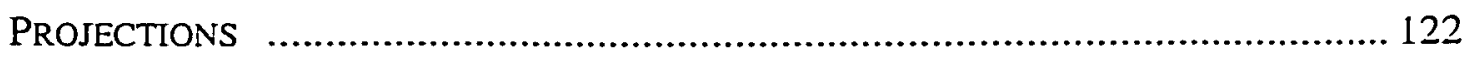

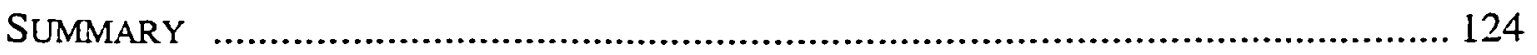

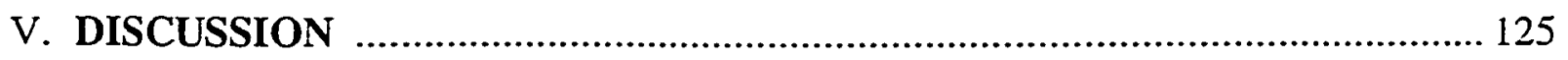

QUESTION 1: ChangeS IN AWARENESS .......................................................... 126 


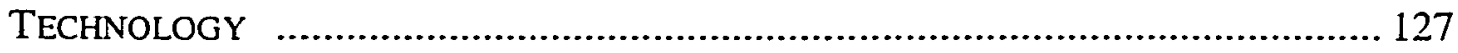

DIVERSE LEARNERS

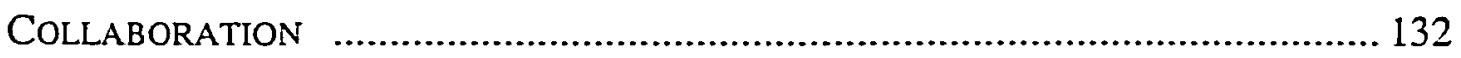

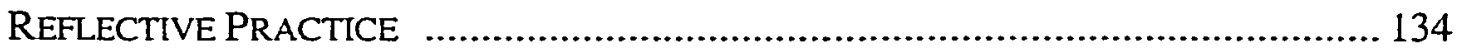

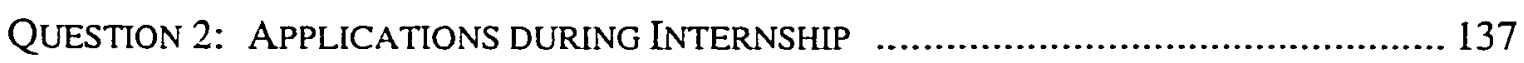

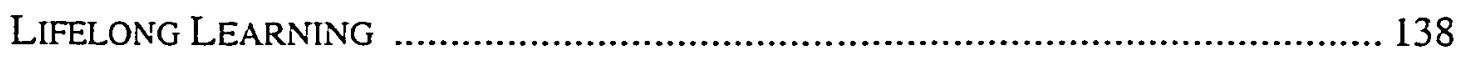

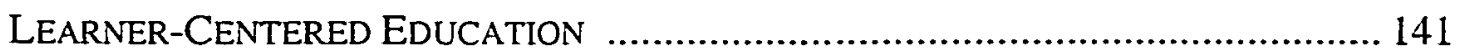

PRACTICE-ORIENTED/EXPERIENTIAL LEARNING ............................................ 143

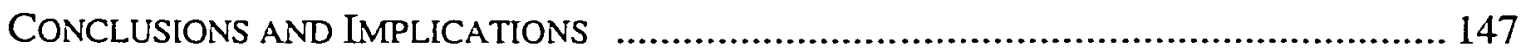

RECOMMENDATIONS FOR FUTURE RESEARCH ……......................................... 151

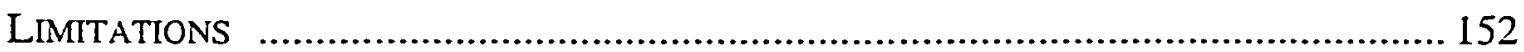

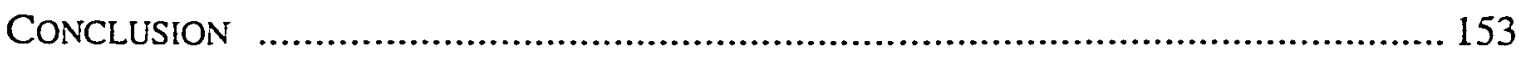

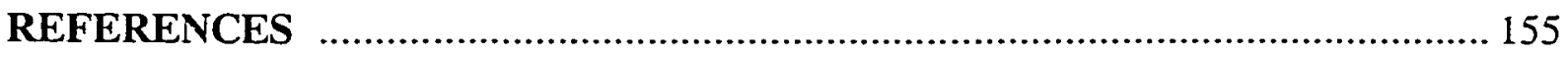

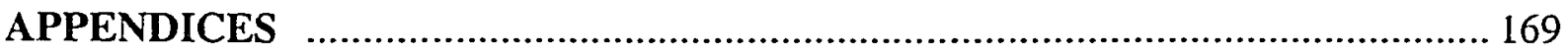




\section{LIST OF TABLES}

TABLE 1: PlaCEMENTS ACCORdING TO GRADE LEVELS ....................................... 44 


\section{LIST OF FIGURES}

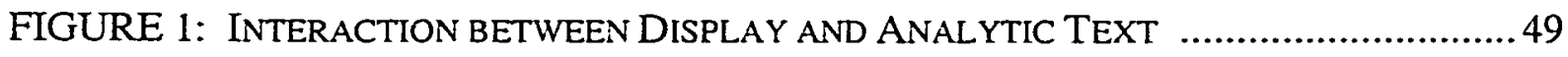

FIGURE 2: CREATING A LEARNING COMMUNITY .........................................59

FIGURE 3: CHECKPOINTS FOR AWARENESS AND APPLICATION ...............................69

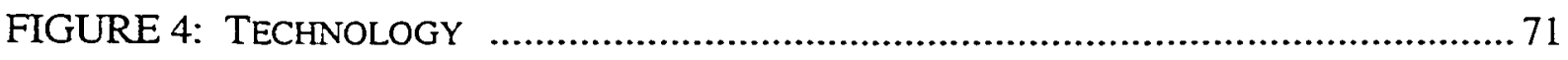

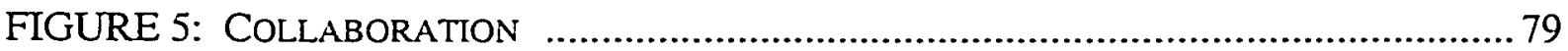

FIGURE 6: MEETING THE NEEDS Of DIVERSE LEARNERS $\quad$.................................. 92

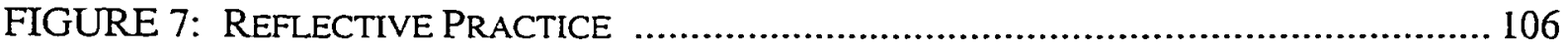

viii 
LIST OF APPENDICES

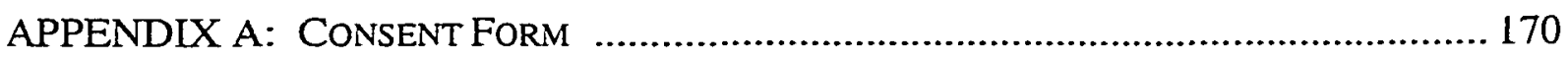

APPENDIX B: STUDENT JouRNAL WRITING PROMPTS ......................................... 173

APPENDIX C: STUDENT GROUP DISCUSSION QUESTIONS ......................................... 174 


\section{CHAPTER ONE}

\section{INTRODUCTION}

The aim of higher education is not only to prepare students for productive careers, but also to enable them to live lives of dignity and purpose; not only to generate new knowledge, but to channel that knowledge to humane ends; not merely to study government, but to help shape a citizenry that can promote the public good. Thus, higher education's vision must be widened if the nation is to be rescued from problems that threaten to diminish permanently the quality of life. (Boyer, 1990, p. 77)

Reports and exposés from within and outside institutions of higher education (IHEs) support Boyer's appeal for a "wider vision" (Academy for Educational Development, 1991; Association of American Colleges, 1985; Boyer, 1987; Goodlad, 1990; Holmes Group, 1990). Many of these reports acknowledge that while some change has occurred, the very nature of institutions and how teaching and learning is approached needs to be further examined. Moreover, today's students are entering United States IHEs with different experiences, expectations, and learning needs than students of previous generations (Chaffee, 1998; Sacks, 1996). Calls for more diverse campuses, advanced technology, and lifelong learning are maintaining pressure on IHEs to adjust to new demands for a wider perspective (Knowles, 1990; Morey \& Kitano, 1997). 
In facing newly framed choices and different contexts, leaders in higher education must strike a balance between the needs and preferences of students, and the priorities and traditions of institutions. In attempting to obtain this balance, effective leadership must address the needs of all stakeholders (Darling-Hammond, 1996; Fullan, 1993) so that change is a collaborative effort. The challenges are tremendous; the responses must be extensive and reflective if higher education is to achieve the aims that are clearly in demand.

\section{Statement of the Problem}

Demographics at colleges and universities are changing radically. The proportion of students age 25 and older has increased steadily since the mid-1980s and is expected to continue past the year 2000 (US Department of Education, 1993). More students in this age group and in the overall IHE population are enrolling on a part-time basis, due to increased costs and other factors (Lucas, 1994). Furthermore, the number of students from traditionally underrepresented groups (e.g., older females, non-white students, students with disabilities) is also on a steady increase (Lucas, 1994). Students from these groups enter IHEs with a range of unique needs: beginning a second career later in life, speaking a primary language other than English, and/or requiring physical and academic accommodations (Morey \& Kitano, 1997). Moreover, graduate enrollment is increasing at a faster rate than enrollment for undergraduates (Lucas, 1994). This population includes greater numbers of students who are computer-literate and who are accustomed to accessing information from home or from other locations (Thornburg, 1994). Such students claim to be "impatient with traditional classroom practice" (p. 42), and expect to access their learning through technology and to integrate technology into their learning. 
These examples suggest a very different profile of today's postsecondary student as compared to students from pre-World War II who were predominantly male, white, and of middle or upper-class status (Lucas, 1994).

Given these changes, herein lies the problem: traditional higher education approaches are no longer effective in responding to today's students and their unique needs (Boyer, 1987; Braskamp \& Wergin, 1998; Levine, 1993; O’Brien, 1998). In order to address this problem, a new vision of higher education is emerging. This vision aims for more than improving existing systems; rather, it offers new ways of thinking that include attention to the content and form of the curriculum as well as to the delivery of instruction (Boyer, 1990; Tierney, 1998; Young, 1997). Administrators and faculty in US colleges and universities are deliberating on how best to assess and respond to the newly defined needs of students, as well as to the changing political, economic, and social contexts that contribute to those needs (Braskamp \& Wergin, 1998; Coate, 1995). One aspect of these deliberations has focused on how to reconceptualize and balance the primary goals of IHEs: research, teaching, and service (Boyer, 1987; Tierney, 1998).

During the first half of this century, all three goals were addressed with the implication that they were of equal importance. After World War II, the balance shifted to a greater emphasis on research (Glassick, Huber, \& Maeroff, 1997). The 1990s have brought a renewed commitment to teaching (Boyer, 1993; Glassick, Huber, \& Maeroff, 1997) and initial considerations about the role of service through social partnerships (Braskamp \& Wergin, 1998). This recent discussion about placing more emphasis on teaching and service provided the impetus for faculty at many IHEs to reflect and reexamine how they are designing and delivering professional education programs. A 
number of states have responded with commitments to reform. For example, the Maryland Redesign addressed the recommendations of most of the national reform initiatives through their emphasis on field experience development and efforts to recruit traditionally underrepresented groups (Clemson-Ingram \& Fessler, 1997). Similarly, initiatives in Illinois and North Dakota provided the impetus to revamp existing professional education programs to order to improve performance assessments and learning outcomes, consistent with recommended national professional standards (Wise, Leibbrand, \& Williams, 1997). Further, the administrators and faculty at College of Education at one large southwestern state university (referred to here as Southwestern University or SWU) undertook a similar challenge to create a new way of designing and delivering professional education programs.

During the 1996-97 academic year, Southwestern University's College of Education (SWU-COE) faculty reexamined the mission, vision, and guiding principles of the College through a process of inquiry and consensus decision making. Faculty and administrators had participated in workshops held every three to four years during the previous decade to review and reflect on SWU's professional education programs. These sessions resulted in the identification of four strategic choices to guide the direction of the College: responding to and serving the needs of diverse learners; strengthening linkages with the community and the University to promote collaboration both within and outside the programs; utilizing reflective practice as a vehicle for linking theory to practice; and maximizing the use of technology as a tool for both communication and instruction. Each of these strategic choices has been well documented as a critical element of professional education programs (Boyer, 1987; Braskamp \& Wergin, 1998; Dewey, 
1933; Fullan, 1993; Matthews, 1997; Schön, 1983, 1987; Sergiovanni, 1994; Young, 1997). These values-based choices, central to the vision and mission of the COE, were designed to permeate the professional education programs in the following departments: Administration, Rehabilitation, and Postsecondary Education; Counseling and School Psychology; Educational Technology; Policy Studies in Language and Cross-Cultural Education; Special Education; and the School of Teacher Education (COE Policy File, 1997). Each department was responsible for customizing goals and directions to reflect its specialty. Toward that end, administrators and faculty in each department began examining course content, instructional strategies, assessment procedures, and classroom interactions in light of the four strategic choices.

By reviewing and redesigning each of these dimensions of teaching and learning, their goal was to "transform" courses to better meet the needs and expectations of their students. Transformed courses "challenge traditional views and assumptions; encourage new ways of thinking; and reconceptualize the field in light of new knowledge, scholarship, and ways of knowing" (Morey \& Kitano, 1997, p. 23). However, as the strategic choices were only purposefully implemented in the 1997-98 academic year, the impact on students could not be fully examined until they at least finished that school year. While an examination of the entire College of Education program was beyond the scope of this study, exploring the experiences of one group of students could provide insight for SWU's College of Education, other COEs, as well as IHEs with professional education programs. Investigating how students perceived and experienced these choices, and in turn, applied this knowledge from their "transformed" courses to their internship settings contributes to the knowledge base of professional education program 
design. Furthermore, lessons learned from these students are useful for higher education leaders engaged in change, helping inform them of how theory can be translated into practice.

Purpose of the Study

The purpose of the study was to investigate how the newly conceptualized strategic choices in a professional education program impacted students. Specifically, this study focused on one group of post-baccalaureate students in a year-long professional education program to determine how they experienced coursework focused by the four COE strategic choices and how they applied what they learned to their field of study. Analyzing the perceptions of their experiences, expressed via journal writing and interviews, provided implications for IHE educators and administrators engaged in organizational change.

\section{Study Objectives}

The objectives of this study were twofold: 1) to explore students' perceptions of their experiences with the four strategic choices and how they applied these choices to their professional education practice; and 2) to identify implications for educators and administrators related to the translation of theory to practice.

\section{Significance of the Study}

The transformation of programs and coursework in higher education requires long-term commitment, continuous reexamination, and effective leadership that is supportive of organizational change. The College of Education (COE) used in this study engaged in a systemic change process for more than ten years, initially identifying one of its strategic choices as "serving the needs of the diverse learner" (Morey \& Kitano, 1997, 
p. xi). Beginning in 1996, the College of Education administration and faculty organized their educational and organizational priorities to focus not only on diverse learners, but also on collaboration, reflective practice, and the use of technology. At this time, faculty began to "transform" their courses to "challenge traditional views and assumptions; encourage new ways of thinking; and reconceptualize the field in light of new knowledge, scholarship, and ways of knowing" (p. 23). Further, they explored the power structures in their classrooms, considered instructional methods that might better capitalize on students' experience, and looked for assessments to promote student selfevaluation.

As this was the first year that a comprehensive change had been implemented across the College of Education, the impact on students had yet to be determined. Therefore, an examination of how these theoretical underpinnings successfully or unsuccessfully translated into practical applications has potential to add to the knowledge base for other professional education programs. Understanding how students learned and applied these value-based choices is useful for university administrators, graduate and academic deans, faculty members, and other directors and coordinators of academic and professional development programs as they respond to the changing needs of their students. More specifically, this research provided insight into the following: 1) how students perceived and experienced the four strategic choices; 2) how they applied the choices to their own professional practices; and 3) how this information might inform educators and administrators in higher education so that they may better meet the changing needs of students. 


\section{Definition of Terms}

The four strategic choices are briefly defined here, and will be elaborated upon and given contextual reference in the review of the literature. These definitions are adapted from those listed in the standards manual published by the National Council for Accreditation of Teacher Education (NCATE) (1995).

Collaboration: Communication with peers, professional educators, and others for purposes of planning, problem solving, maximizing resources and expertise; assumes interdependence, equity, and shared rules.

Diverse learners: Refers to the wide range of individuals and populations who have observable and demonstrable physical, cognitive, and behavioral differences.

Reflective practice: A mode that links thought and action with reflection. It involves thinking about and critically analyzing one's actions with the goal of improving one's professional practice.

Technology: Computers, multi-media equipment, distance communication, etc. that are used to deliver instruction, facilitate interaction, access resources, and expand opportunities for expression, communication, and learning. 


\section{CHAPTER TWO}

\section{REVIEW OF THE LITERATURE}

This chapter provides a critical review of the literature in four areas. The first section describes how institutions of higher education have changed in the past 350 years, shifting the balance among the major foci of teaching, research, and service. The second section provides models for teaching and learning as a context for how some of these changes have been implemented, including lifelong learning, learner-centered education, and practice-oriented or experiential learning. Included in each of these models are summaries and results of studies related specifically to teacher education. The third section critiques research of IHE reform efforts in professional education programs, again with a major focus on teacher education. The last section describes the strategic choices created by the College of Education in this study: diverse learners, technology, reflective practice, and collaboration. These choices, or organizational themes are also summarized in the context of today's IHEs, and more specifically, their significance in professional education programs.

\section{Changes Impacting Institutions Of Higher Education}

In 350 years of American higher education, social change has affected how IHEs balance the work of teaching, research, and service (Tierney, 1998). Given the fluctuation of economic resources, changes in population demographics, and impact of 
societal and political forces at any given time in history, the focus on each of these components has shifted accordingly. Change, particularly in the 1990s, has been characterized by a less certain financial environment and increased governmental criticism of research universities (Geiger, 1993). At the same time, the 1990s ushered in renewed commitment to teaching, and a revived debate on the functions expected of faculty (Boyer, 1993). The new definition of work in higher education, or "scholarship" as Boyer termed it, recognized a wider range of talent in IHEs. In the Carnegie Foundation report, $\underline{\text { Scholarship Reconsidered, Boyer (1990) and his colleagues claimed }}$ that the work of the professoriate must include discovery, integration, application, and teaching. Boyer (1993) summed up this new vision:

Scholarship, then, means more than engaging in original work; it also means stepping back from one's own investigations, looking for connections, building bridges between theory and practice, and communicating one's knowledge effectively to students. (p. 330)

One of the most visible changes in higher education is the rapid increase in numbers. More students are entering universities and colleges than ever before. Enrollment in public institutions increased 26\% from 1978 to 1991 , and is expected to increase at least another 14\% between 1991 and 2003 (Lucas, 1994). Along with the increase, the profile of the "typical" student is also changing. For example, the age distribution of college students has clearly shifted. While the number of students 18 to 24 years of age increased by $8 \%$ ( 7.2 to 7.8 million) from 1983 to 1991 , the proportion of students in this age bracket fell almost $4 \%$ in that time span. Students 25 years of age and older increased from 5.1 million to 6.2 million, a growth of almost $23 \%$ during the 
same time period. Graduate enrollment between 1978 and 1991 has increased at a faster rate than that of undergraduate enrollment, i.e., $30 \%$ at the graduate level compared with $26 \%$ for undergraduates. More part-time students are attending college, up 34\% between 1978 and 1991. While women have outnumbered men on college campuses since the $1950 \mathrm{~s}$, the percentage of females age 35 or older grew from $3.4 \%$ to $6.3 \%$, a trend likely to continue in the coming years (Lucas, 1994).

Another example of significant demographic change is the increase of ethnic diversity in IHEs. Between 1980 and 1990, the proportion of White, non-Hispanic students declined, while the proportion of students identified as African-American, Hispanic, Asian/Pacific Islander, and American Indian/Alaskan Native grew (Carter \& Wilson, 1994). In addition, students with disabilities now represent about $10.5 \%$ of college enrollment, including those with visual or hearing impairments, learning disabilities, physical disabilities, communication disorders, or emotional disabilities (Wilson, 1992). This population is also expected to increase as technology helps open doors, both literally and figuratively (Shapiro, 1993).

In addition to remarkable demographic changes, societal changes are impacting IHEs. Possibly the most profound change affecting our society since the Industrial Revolution and the national railway system is the transformation brought about by the information-technology revolution (Foa, Schwab, \& Johnson, 1996). Technology is likely to have a significant impact on the job market as well as on the training and education that will be required for those jobs (Rifkin, 1995). In addition, as technology capabilities expand, the gap will widen between those who have access to technology and those who do not (Thomburg, 1994). In response, "educational institutions will need to 
play a vital role in restoring dignity to citizens who lack resources and the ability to utilize telecommunication systems" (Reed, 1997, p. 60).

Widening economic gaps among US citizens may also directly and indirectly impact how IHEs provide appropriate education. Poverty, as well as related issues of unemployment, school violence, and changes to family and community structures, contributes to social fragmentation (Braskamp \& Wergin, 1998), and too often "higher education fails to assist surrounding communities to address and re-shape their destiny" (Reed, 1997). Historically, IHEs have played important societal roles by preparing leaders and responding to national problems (Boyer, 1990). Today, higher education has a unique opportunity to do so again. As Bellah and his colleagues (1992) claim in The Good Society, education "pulls us into the common world or it fails altogether" (p. 176). In other words, the demand for redefining higher education includes not only academic reexamination, but also a redefinition of "education for citizenship" (p. 177). IHE constituencies, e.g., families, business leaders, community advocates, state legislators, professional associations, federal government agencies, are "asking the academy to link work and school and to become more active partners in addressing and solving our social ills" (Braskamp \& Wergin, 1997, p. 63). Policy makers are addressing all levels of education, P - 16 (preschool to senior year in college) to join as partners. Higher education must then become the "forum for critical community dialogues, by advancing practice-based knowledge and policies as well as upholding the creation of theory-based knowledge, and by utilizing faculty expertise in new ways" (p. 64).

Given the complex interdependence of all facets of society, additional shifts in the political, environmental, and social arenas cannot help but impact higher education and 
how it serves its constituents and customers. The message remains the same: higher education must change to meet the needs of all its stakeholders.

\section{Models For Teaching And Learning}

Dating back to one of the most significant educational publications in the 1980s, A Nation at Risk, (National Commission on Excellence in Education, 1983), skepticism about education has grown. While that report targeted public schools (K-12), higher education responded with its own reports and recommendations for improvement (Academy for Educational Development, 1991; Association of American Colleges, 1985; Boyer, 1987; Carnegie Forum on Education and Economy, 1986; Education Commission of the States, 1986; Goodlad, 1990; Holmes Group, 1990). Findings from these major reform reports, particularly in the area of professional education, identified needs in the following areas: schools of education modeling what they advocate; improvements in professional training reflecting an understanding of learning processes; commitment to continued research; strengthening and integrating clinical experiences; recruitment of underrepresented populations; and willingness to extend beyond the walls of the university to collaborate with other stakeholders (Guest, 1993). Efforts during the remainder of the 1980 s focused on identifying problems and organizing resources to deal with them. During the 1990s, attention turned to assessment, teaching, and the improvement of undergraduate education (Boyer, 1993). Currently, American universities and colleges are reconceptualizing not only how to teach, but how to engage students as active participants in the learning process (O'Brien, 1998). Research on learning principles and adult learning styles is abundant (APA, 1992; Knowles, 1990), but applying it to the needs of today's students can be challenging. 
Debates about models of teaching and learning can be traced to ancient Greece and Rome, when different conceptions of education competed for acceptance. While Plato and Aristotle and their successors placed a priority on reason and the arts of reasoning that framed the "philosophic" tradition, the Romans preferred the "rhetorical" tradition, defined by a commitment to oration or the arts of speech and language (Lucas, 1994). Focus on one or the other of these traditions has shifted back and forth over the centuries, and by the mid-1800s, dominant American universities dedicated their time and efforts to specialized research and advanced professional studies, and "installed experimental science as a new knowledge paradigm" (p. 313). Many universities in the twentieth century place humanities at the bottom of the status hierarchy, social science disciplines at the next level up, and physical, biological, and mathematical sciences at the top of the hierarchy (Lucas, 1994). Whatever the priority, the history of curricular change over time within colleges and universities cannot be divorced from societal forces and changes. The following examples represent some of the dominant models of teaching and learning utilized in today's institutions of higher education.

Lifelong learning. As early as 1931, Alfred North Whitehead proposed that "Education must now be defined as a lifelong process of continuing inquiry. And so the most important learning of all - for both children and adults - is learning how to learn, acquiring the skills of self-directed inquiry" (as cited in Knowles, 1990, p. 167). His insights were based on the increasingly rapid cultural changes that people were experiencing in their lifetimes. Moreover, if humans were going to be prepared to continually face new situations and conditions, they must be educated to do so. Some forty years later, Edgar Faure and his associates on the International Commission on the 
Development of Education, observed that "education was preparing men for a type of society which does not yet exist" (as cited in Knowles, 1990, p. 168), reaffirming the concept of lifelong learning. Many other educational thinkers followed suit, offering the support of such approaches as "innovative learning" versus "maintenance learning" (Botkin, Elmandjra, \& Salitza, 1979) and "systems theory and holistic thinking" (Capra, 1983). Knowles (1990) proposed a complex system of lifelong learning in the context of a learning community that suggested identifying new roles and competencies for learners and instructors, as well as tapping other potential learning resources in a community.

Lifelong, or continuous learning, has also been a dominant theme in teacher education reform reports and recommendations. For example, the Holmes Group proposed that teachers be committed to continuous learning for themselves, their students, and their colleagues as a fundamental principle of teacher education (Griffin, 1991). Toward this end, teachers must be supported and encouraged to develop professionally by having "time to plan, to confer, to observe teaching by other teachers, to discuss practice, to read and write, to travel, and to reflect and inquire" (Sykes, 1990, p. 90). One avenue for continuous professional growth is through teacher-initiated research, either on an individual or collaborative basis. Action research, in particular, provides opportunities for teachers, administrators, and other members of the school community to influence and direct reform initiatives (Calhoun, 1994). Numerous studies linking action research to school reform efforts provide evidence that this type of participatory inquiry is an effective process for both improving schools and supporting continuous professional growth (Glickman, 1993; Joyce, Wolf, \& Calhoun, 1993). 
Learner-centered education. "The focus on individuality, on the personal benefits and the utility of education, has a rich tradition in American higher education" (Boyer, 1987, p. 67). Given this interest in meeting the individual interests of students, it might seem logical that education be learner-centered. History tells us otherwise. In the mideighteenth century, lecturing by instructors was the latest method that was seen as an improvement over recitation, "a process in which students repeated from memory, often verbatim, textbook assignments" (p. 149). At that time, lectures typically consisted of instructors reading the material and students copying what was said. By the end of the 1980s, lecture was still the most preferred method, according to the Carnegie Foundation's extensive studies of undergraduate education (Boyer, 1987). Lecturing is an example of the "banking" concept of education (Freire, 1970). A banking approach to education positions the teachers as the depositors and the students as depositories. The danger, Freire argued, is that "knowledge is [seen as] a gift bestowed by those who consider themselves knowledgeable upon those whom they consider to know nothing" (p. 58). This unidirectional approach in which the control of information belongs to the instructor, does little to motivate most learners.

A learner-centered approach is more likely to address motivational questions, as well as issues of power and control. With the advancement of technology and increase in teaching by distance communication modes, research is emerging about learner-centered education. "Teaching through discussion relies on a learner-centered approach, whether the participants meet face to face, or on the computer screen. It rests on principles of collaborative learning and egalitarian relationships" (Rohfeld \& Hiemstra, 1995, p. 1). Studies have indicated that placing students in the center of the learning process 
encourages active participation, increased self-esteem, and improved interpersonal relationships (Jones \& Young, 1997). Further, enabling students to become more active in guiding the learning process may uncover "the hidden power faculty exert when they claim responsibility for guiding and teaching knowledge" (p. 100).

Using a learner-centered approach in teacher education is helpful in assessing and meeting today's students' needs as they enter credential programs. In their research on the professional development of student teachers, Rodriguez and Sjostrom (1998) compared a sample of traditional and nontraditional adult teacher candidates. The nontraditional student teachers included adults who were over 25 years of age with varied life experiences (e.g., prior work experience, parenting, military service, postsecondary training). The authors collected and analyzed data simultaneously over two 16-week semesters, during which they accessed weekly journal reflections, in-class observations, and interviews. Their findings suggested that overall, nontraditional students were more analytical as they described their experiences, more self-initiating and self-directed in assuming responsibilities, and more self-confident about their goals and capabilities early in their student teaching experience. Their research also indicated that because such marked differences emerged in how the two groups of teachers developed, teacher educators as well as university supervisors and cooperating teachers should "employ a developmental perspective in which student teachers pass through stages of growth as they mature professionally" (p. 184). Further, teacher preparation programs must "customize their roles and coaching techniques to address the differences in maturation levels and how [different] groups process the experience" (p. 185). By becoming more learner-centered, teacher education faculty as well as the teacher candidates can "act as 
learners about their own teaching as they strive for personal and professional growth" (p.186).

Practice-oriented/experiential learning. If, as Boyer (1990) claimed, higher education has a responsibility "to help shape a citizenry that can promote the public good" (p. 77), then IHEs must provide the opportunity for students to learn through practical experience. One avenue for experiential learning is through volunteerism or service learning. The Carnegie Foundation's 1984 national survey of undergraduates indicated that about half of the students participated in some kind of service activity during college (as cited in Boyer, 1987). Surveys administered to students at Kent State University suggested that "about 90 percent of student volunteers said service-learning experience was as valuable or more valuable to them than classroom work" (as cited in Boyer, 1987, p. 216). It was also reported that volunteering often had an impact on students' motivation and ability to take on increased responsibility as an adult.

Providing experiential activities as an integral component of coursework is another way to ensure that students have opportunities to construct knowledge in a real context (Morey \& Kitano, 1997). These activities may range from participating in a "cultural plunge" in order to more fully experience life in a culture that is different from one's own, to role playing and attending field trips to better associate how theories and philosophies are implemented in communities. Designing curriculum, assignments, and assessments that integrate some level of real experience requires a re-evaluation of the criteria for success in any given course (Gay, 1997).

A third example of the use of practice-oriented learning is through internships or similar field practica, typically used in professional education programs. Students learn 
more than technical skills when placed in a practicum. They learn "conventions, constraints, languages, and appreciative systems, their repertoire of exemplars, systematic knowledge, and patterns of knowing-in-action" (Schön, 1987, p. 36). Apprenticeships offer the opportunity for students to benefit from the "accumulated experience of others" (p. 37). These experiences also create an atmosphere in which the apprentice can assume responsibilities for real projects without adding the full weight of pressures and responsibilities that are assumed by their mentors. Providing meaningful field experiences requires that IHEs do more than placement. Many innovative programs incorporate a number of strategies to enhance experiential learning. For example, cohorts are often organized to help establish a learning community (Bullough \& Gitlin, 1995). In addition, coaching can be provided in a variety of formats, providing students with the experience of collaborative inquiry (Schön, 1987). Finally, reflection as it is integrated with practice, such as in the form of action research, provides an ongoing learning experience that connects inquiry with understanding, and understanding with the need for improvement and lifelong learning (Bullough \& Gitlin, 1995).

Relating issues about experiential learning to teacher education programs, Guyton and McIntyre (1990) summarized research focused on specific aspects of student teaching. They noted the lack of a theoretical framework or clear set of goals regarding the design and implementation of field experience components of teacher education. They also identified a number of problems encountered in many programs, many of which related to the importance of the student teaching context. Often the cooperating teachers were not prepared for the responsibilities of educating and supervising their student teachers, nor were they certain of their roles or expectations in a student teacher 
triad (i.e., student, cooperating teacher, university supervisor). Garland and Shippy (1991) described a research-based supervisory program that addressed this need. Their program represented an approach that offered preparation for cooperating teachers in both theoretical knowledge and practical skills. The research indicated that this was an effective strategy for enhancing the skills of the cooperating teachers as well as improving the context for the student teachers.

In another study related to experiential learning, Harthern and Rolle (1991) surveyed $166 \mathrm{~K}-12$ teachers in two westem Georgia school systems. Specifically, they studied teachers' perceptions of where and when they developed understanding of and competency in 18 identified teaching skills. The researchers indicated that the generalizability of the study may have been affected by the specific factors of the region (i.e., the majority of the teachers had their education, training, and teaching experiences only in that geographic region). Their findings, however, were consistent with other research on teacher preparation programs. "Work experiences and/or practicum experiences as part of these programs need particular attention since teachers perceive these types of experiences as being most helpful in developing both understanding of and competency in these [teaching] skills" (p. 55). In addition, this study adds support to the thinking that competencies are developed in stages, not only in the student teaching experience, but also throughout the professional careers of teachers (Davis \& Zaret, 1984). Clearly, further research is warranted to determine the competencies that are most appropriate for student teachers to achieve at each stage of their professional development. 


\section{Models Of Change Efforts In IHEs}

There is no shortage of literature outlining the problems with higher education nor with documenting the need for changes in how IHEs address teaching and learning. As mentioned earlier in this review, the bulk of writing in professional education reform literature offers important insights on a range of issues that could be improved with careful reexamination and a commitment to change. More specifically, the research and recommendations that apply to teacher education reform are highlighted in this section.

At the forefront of these efforts was the series of reports from the Holmes Group (1986; 1990; 1995), a consortium of 96 US research universities committed to making their teacher education programs more rigorous and connected. In meetings held between June 1988 and September 1989, the Holmes Group curriculum committee agreed that seven principles should guide teacher education: 1) foundation of a comprehensive liberal studies education; 2) commitment to continuous learning for themselves and their students; 3) active involvement in designing curriculum; 4) understanding of a school's organization and dynamics; 5) preparation for effective leadership; 6) awareness of diversity issues and ability to create learning opportunities for all students; and 7) understanding of how the classroom learning community is part of the larger community (Griffin, 1991).

The first report, Tomorrow's Teachers (Holmes Group, 1986), supported the professionalization of teachers. One recommendation toward reaching this goal was to eliminate undergraduate teacher education programs (Futrell, 1987). The report also argued for the establishment of Professional Development Schools (PDSes) as a vehicle for coordinating theory and practice. Of equal importance to its recommendations, the 
Holmes Group offered a renewed image of teachers as "active agents in the teaching process and not simple conduits transmitting skills, behaviors, or attitudes to a group of children through prescribed materials" (Feinberg, 1987, p.366).

The second report, Tomorrow's Schools (1990), focused more specifically on Professional Development Schools and how they could be established to promote collaboration, professional development, restructured roles and practices, and educational research (Labaree \& Pallas, 1996). Expanding on the 1986 version, this second report offered even stronger support for teachers becoming partners in educational research (Johnson, 1990).

The third recommendation by the Holmes Group (1995), published as Tomorrow's Schools of Education, addressed how IHE faculty could respond to the increasingly complex needs of the public education system as they attempted to prepare educators for a new era of declining resources and increased competition. The report recommended that emphasis be placed on strengthening the connections between schools of education and the rest of the university, as well as with other partners in the teaching profession (e.g., teachers, administrators, education specialists) (Murray, 1996). The comments and suggestions generated by the series of reports by the Holmes Group were consistent with a number of other reports published during the same time period, including the Carnegie Forum on Education and Economy's (1986) A Nation Prepared: Teachers for the $21^{\text {st }}$ century, and John Goodlad's (1990) Teachers for our Nation's Schools.

More than ten years after the Holmes Group was first conceived, a study was commissioned by the Ford Foundation to evaluate the impact of this consortium's efforts, 
and more importantly, to determine new directions for the next decade of teacher education reform. In a report entitled, The Rise and Stall of Teacher Education Reform, Fullan, Galluzzo, Morris, \& Watson (1998) addressed these issues through the following questions: "How appropriate were the goals of the Holmes Group? What progress have member institutions made with the Holmes Group agenda? What impact has the Holmes Group had on the field of teacher education beyond its own member institutions?" (pp. 49-51). Overall they claim that "the field of education is significantly better off because of the work of the Holmes Group and its success in bringing national attention to reform in teacher education" (p. 52). In addition to the reports they published, the Holmes Group was responsible for: bringing teacher education reform issues to the forefront; promoting partnerships between schools and universities, especially through the creation of PDSes; emphasizing the importance of adding minority representation to the faculty of schools and universities; and helping to raise the status of teacher training programs in general. Five national efforts are already underway to revitalize the activities that seemed to "stall" in the past five years: the Holmes Partnership; the National Commission on Teaching and America's Future (NCTAF); the Reauthorization of Title V (Higher Education Act); the National Partnership for Excellence and Accountability in Teaching; and the National Research Center on Policy and Teaching Excellence. These groups are attempting to build on the acquired knowledge. For example, the Holmes Group became the Holmes Partnership, refocusing its efforts on six goals that promote the establishment of new partnerships on local and national levels. In addition, the National Commission on Teaching and America's Future has set what they describe as an "audacious" goal: "by they year 2006, America will provide all students in the country with what should be 
their educational birthright: access to competent, caring, and qualified teachers" (p. 58). Underlying all these efforts is "the question of whether or not society wants good teachers enough to advance the cause of teaching and teacher education" (p. 55).

Despite this wealth of information, the number of empirical studies of professional education reform is small in comparison to the majority of books and articles that consist primarily of expert opinion and anecdotes (Clemson-Ingram \& Fessler, 1997). Clemson-Ingram and Fessler, two Johns Hopkins University Education Division directors, have been associated with a systems change effort that incorporated national higher education reform recommendations to guide its development known as the Maryland Redesign. Although final results of this project are not yet available, information on the process is clearly consistent with research on change efforts. The Redesign employed a process that was public, participatory, and based on a vision that valued "innovation, diversity, risk taking, and dialogue" (p. 15). The expectation is that this process will result in better prepared teachers who will be engaged in continued professional development as well as in a systemic approach to school improvement.

Linda Darling-Hammond (1996), executive director of the NCTAF, concurred that research data on professional education are limited. She stated that "attempts across the country are still embryonic and scattered rather than systemic, but the possibilities for rethinking teacher preparation ... are greater than they have ever been" (p. 10). DarlingHammond's (1994) research focused primarily in the area of PDSes as an alternative to traditional teacher education programs that are all too often underfunded and inconsistent in quality. Much of this research was based on her earlier work in which she focused on expanding the essence of professionalism as related to teachers' roles and responsibilities. 
A critical area of study fundamental to the area of change efforts in professional education is the examination of attitudes and beliefs of students. A number of research studies have been published about preservice education that focus on identifying the belief systems of students as they enter professional education programs (Calderhead \& Robson, 1991; Guillaume \& Rudney, 1993; Hollingsworth, 1989). Results of this research emphasized the importance of teacher educators understanding that student beliefs affect the way students internalize course materials, theories, and strategies. Within this realm, Kagan (1992) focused specifically on the self-image of students in teacher education programs. She reviewed 40 learning-to-teach naturalistic and qualitative studies between 1987 and 1991 and found that preservice programs failed to address the need for students to develop their self-images as teachers. Her research indicated that developing a strong self-image appeared to be a prerequisite for a student to acquire teaching skills, and therefore should be emphasized in professional education programs.

Maria Tatto (1998), a teacher educator/researcher, investigated the influence of teacher education on teachers' values and beliefs and found a paucity of empirical evidence in this area. In her own study, Tatto hypothesized that "constructivist-oriented teacher education emphasizing participatory learning and reflection will have more influence on teacher education students' views than conventionally oriented teacher education" (p. 67). She collected data from nine teacher education programs (not intended to be a representative sample) and "examined the relationship between teacher education and changes in knowledge, skills and dispositions of experienced and prospective teachers who participated in different approaches to teacher education" ( $\mathrm{p}$. 
67). Tatto examined patterns of change in teacher education students' views as related to professional norms in the field and to program norms among faculty. The results of her study suggested two challenges for teacher educators and others interested in reform. First, the data indicated that there was a lack of professional norms across teacher education programs. Second, she found that programs identified as internally coherent seemed to graduate individuals who demonstrated beliefs similar to their faculty. The question of how to make programs more coherent without devaluing the individuality and diversity that exists among faculty indicated the need for further research. The author advocated for the development of shared understandings or norms within professional education programs that might encourage graduates to "become more critical and reflective in their practice" (p. 77). Her study also helped to support the need for further research into how the beliefs of student teachers translated into practice.

Maxson and Sindelar (1998) took a different approach as they attempted to identify the images, ideas, and knowledge or "implicit theories" (p. 5) that students brought with them as they entered an elementary teacher education program. They were also interested in "how and if those images changed as a result of coursework designed to challenge and clarify those images" (p. 6). Maxson and Sindelar investigated this aspect of professional education as part of a systematic study of an elementary education program, PROTEACH, at the University of Florida. PROTEACH emphasized "the philosophy of reflective teaching and a belief that knowledge is socially constructed by teachers and students" (p. 7). Data collected and analyzed in this study included two written exercises completed by 12 students enrolled in two concurrent sections (six from each) of a required course in the program. A case study format was used to identify 
themes and patterns in the data. Maxson and Sindelar found that less than half of the students in their studies entered the program with "clear images" of themselves as future teachers. This finding differed from the results of a number of other studies that demonstrated that the majority of beginning students entered programs with such images (Bullough \& Stokes, 1994; Calderhead \& Robson, 1991; Kagan, 1992). The PROTEACH data suggested that two basic types of students entered teacher preparation programs: those who have an image of themselves as a teacher, and those who have conflicted or emergent images. Their results were based on a limited number of students and provided little information on how students' beliefs changed over time or about what factors influenced students to adopt new ideas and methods. Further research is warranted to investigate not only students' beliefs, but also how those beliefs evolve and generalize to practice in the classroom.

While empirical studies of professional education reform research appear to be somewhat limited, the research that exists emphasizes the need for a better understanding of how students internalize and practice what they have learned. This study investigated how, if at all, a group of students understood and incorporated a values-based framework into the concepts and practice of teaching in order to add to the professional education literature.

\section{SWU-COE: Creating A New Conceptual Framework For Change}

Many of today's organizations, whether educational, commercial, or governmental, frame their mission, vision, and values in ways that encourage their members' input and support (Drucker, 1989; Senge, 1990; Wheatley, 1994). Such shared perspectives both drive and transcend daily activities and higher goals that are worth 
pursuing on a personal as well as on an organizational level (Bardwick, 1996; Bergquist, 1993). Some organizations identify guiding principles, others articulate outcomes. Southwestern University, identified in this study, has been actively engaged in creating such shared vision with all its stakeholders. Recent efforts to open dialogue among its internal and external partners demonstrated SWU's commitment to creating a community of learners by focusing on a number of mutually agreed upon themes. Consistent with themes identified by the national reform reports, SWU has targeted goals in the following areas: global and international opportunities, social justice, technology, diversity, connectivity, communication, and academic excellence and research.

Similarly, SWU's College of Education initiated planning that included reconceptualizing its goals and directions for professional education programs. The College of Education was well positioned to build on efforts that began a decade earlier when the need for creating effective learning environments for a multicultural and multilingual population became more clear (Morey \& Kitano, 1997). Inspired by the establishment of new goals created through the shared vision process, as well as by updated National Council for Accreditation of Teacher Education (NCATE) standards, the strategic choices for the program were focused by the four strategic choices noted earlier: diverse learners, technology, reflective practice, and collaboration. Each of the choices has been well documented as a critical element of professional education programs. They are summarized in the following sections in the context of higher education, and how they relate to the changing profile and needs of today's students, particularly those in professional education programs. 


\section{Diverse learners.}

By the year 2000 about $30 \%$ or more of all students in the public schools will be from minority groups. While the number of such students graduating from high school is increasing, the percentage of those enrolling in higher education is going down. If our sense of nationhood is to be strengthened, if a generation of new citizens is to be brought into the mainstream of American life, colleges and universities must recommit themselves to the task of equality and of opportunity for all. (Boyer, 1987, p. 39)

The meaning of diversity has widened considerably in the past three decades. In the early 1960s, Congress originally framed the Civil Rights Act to promote equal treatment for ethnic minorities. By the time the Act became law in 1964, protection against unfair discrimination was expanded to include nationality, religion, and sex (Kozol, 1991). Today's definition of diversity, as it relates to equity and other social justice questions, encompasses far more dimensions. On the federal level, legally recognized aspects of diversity include age and disability. At the state and local levels, views of diversity extend to prohibiting discrimination on the basis of sexual orientation, height, weight, physical mannerisms, marital status, even behavioral considerations (Ghorpade, 1998). This more inclusive view of diversity has a number of implications in the context of higher education, i.e., its relationship to admissions, student population, curriculum, general education requirements, assessment strategies, and shared values.

Most IHEs want to increase the diversity of their student enrollment (Young, 1997), utilizing affirmative action as well as active recruitment. Many of today's 17- to 22-year old students are more underprivileged than elite, more ethnically diverse and 
economically disadvantaged than the "privileged" youth who have typically dominated college campuses. Students who define themselves by distinct characteristics, e.g., ethnicity, disability, nationality, are an expanding population on today's campuses (Matthews, 1997). The struggle lies in deciding who is rejected while increasing the diversity of those who are accepted.

Examination of the curriculum, and in particular the general education course requirements, may indicate if the policies of an IHE actively promote diversity versus accommodating it in a more passive manner. As Young (1997) claims in describing an egalitarian community college curriculum, "Diverse programs make the college more accessible to students, and accessibility, in turn, increases the diversity of students" ( $p$. 63). The reality of diversity calls for an abandonment of traditional stereotypes about who people are, what they can do, and why they choose certain courses of action.

After students are accepted on a campus, they may require further support and/or accommodations in order to succeed. The sensitivity to such considerations is another indication of active or passive acceptance of diversity (Levine, 1993). Resources may include designated offices (e.g., minority affairs, disabled student services), accessibility of services (e.g., interpreters, note-takers), and individualized alternatives for assessment procedures (e.g., longer test-taking time, oral versions of exams).

The manner in which diversity is addressed on campuses in general is likely to establish a powerful example for how diversity issues may or may not be addressed within specific programs. In other words, "diversity should permeate the total campus environment" (Kitano, 1997, p. 16). Efforts to increase awareness of diversity issues have resulted in a number of recommendations for practices that are consistent with the 
current multicultural knowledge base. These include, but are not limited to, creating and implementing content and materials, instructional strategies, objectives, assessment procedures, and evaluation that all take cultural characteristics and student experiences into consideration (Kitano, 1997). In the process, some time must be devoted to identifying and confronting beliefs (of both instructors and their students) about social conditions that contribute to the problems faced by diverse learners as well as their own commitment to teaching these learners.

Ross and Smith (1992) presented case studies of six preservice teachers to assess the student teachers' perceptions of the influence that coursework, their own background experiences, contrasting field experiences, and their initial beliefs on entering the program had on the development of their perspectives on these issues. Ross and Smith's data suggested that placing students in contrasting classrooms (i.e., traditional "transmission" teaching approach vs. constructivist and interactive practices), and then helping them reflect on these experiences in the context of coursework and their own belief systems, may have challenged their attitudes and practices with diverse learners. The authors, in trying to understand preservice teachers' thinking about these issues, presented the following questions:

Will students sustain the changes in attitudes initiated during the teacher education program? Will they continue to grow in their ability to see the perspectives of diverse learners? Will their knowledge influence what they do in classrooms as they teach diverse learners? (p. 102) 


\section{Technology.}

If we allow the information superhighway to bypass education -- even for an interim period -- we will find that the information rich will get richer while the information poor get poorer with no guarantee that everyone will be on the network at some future date. (Thomburg, 1994, p. 8)

Rapid advances in technology are shaping a new world in which lifelong learning means survival and where self-directed learners will have the advantage over others who rely on more traditional ways of learning (Thornburg, 1994). Technology affects how instruction is delivered, how students access education, and how resources are made available. Historically, technological innovations were introduced slowly and too often perpetuated traditional curricula. New ways of utilizing technology may transform not only the way the curriculum is delivered but how the learning takes place, emphasizing the skills necessary in today's world where people change careers five to eight times (Reich, 1992).

One vision of higher education's future is that the physical campus will no longer be necessary (Sacks, 1996). Some predictions indicate that distance education via the Internet will replace traditional instructional interactions and that only small residential colleges and research universities might be in business in another 50 years (Matthews, 1997). Clearly, "the virtual university is emerging to challenge the dominant paradigm of higher education by providing universal access to online courses and degrees" (Owston, 1997 , p. 28). One of the benefits of enrolling in an online course is a flexible time schedule. That is, students who cannot meet traditional time schedules due to work and/or family obligations have the option to log on the computer at their convenience 
(Fisher \& Sax, in press). Typical lectures can be transformed into multimedia productions, augmented by the seemingly endless resources available via the Internet. The benefits appear to be numerous; however, many questions remain regarding other aspects of accessing education in this manner.

Meyen, Lian, and Tangen (1998), in a series of articles on the development and delivery of instruction online using the Internet and the World Wide Web, identify a number of issues grouped under the following categories: 1) valuing online instruction; 2) creating acceptable conditions (quality standards); 3) creating institutional policies; 4) examining educational equity; and 5) considering the future (p. 54). Supporters and opponents, both adamant in their beliefs about the value of such instruction, range from those who have embraced the technology, to those who see it as a passing fad, to those who view it as inferior to traditional instruction.

Looking at technology in the context of "Generation X" attending college, Sacks (1996) suggests that professors must learn to apply new technologies that reinforce postmodern arrangements. He sees little need for professors to merely disseminate information that can be accessed more easily and quickly via the computer and the Internet. Rather, he sees their role emerging as an "expert consultant" who has two main responsibilities:

1) guiding students in the use of information-gathering tools, i.e., helping them learn how to learn; and 2) helping students imagine new ways of looking at knowledge, while prodding them to appreciate subtle complexities about a discipline not obtainable from machines and databases. (p. 180) 
Additional aspects of technology merit consideration in higher education, including the role of technology in facilitating communication across all levels of the institution and in developing partnerships with business for purposes of technology and information transfer (Braskamp \& Wergin, 1998). Finally, as technology becomes an integral part of IHEs, the concern about technology access cannot be overlooked. Jones and Young (1997) address electronic technologies as part of the hidden curriculum that may perpetuate existing barriers for students who cannot afford, or who cannot otherwise access, the technology. On the other hand, technology can also level the playing field, that is, "in cyberspace, no one knows if you are old, young, brown, red, female, male, rural, urban; if you're typing from a wheelchair, or from a kitchen late at night" (Matthews, 1997, p. 75).

Technology is also changing the way that schools of teacher education consider instruction, beyond offering more coursework online or requiring students to access the Internet for class assignments. If public school teachers must have the knowledge, skills, and comfort level to implement technology effectively into their classrooms (Bradshaw, 1997), then teacher educators have some responsibility for addressing this issue at the preservice level. A survey conducted in 1996 by the American Association of Colleges for Teacher Education (AACTE) and The National Council for Accreditation of Teacher Education (NCATE) showed that only $45 \%$ of school of education faculty regularly used computers, televisions, and VCRs as interactive instructional tools and $53 \%$ occasionally used some electronic technology to present information in class. NCATE hopes to increase the numbers of faculty members who integrate technology into teacher training programs by requiring schools of education to meet new technology standards for 
accreditation after the year 2000 (Zehr, 1997). The new standards are designed "to move technology from the periphery to the center of teacher education" (p. 25). The majority of states require that prospective teachers complete a minimum amount of technology training in order to be licensed. By 2000 , a number of states, including California, will require teachers to demonstrate basic competency in the use of computers in the classroom in order to receive a teaching credential (Zehr, 1997).

Reflective practice.

Knowing others is intelligence;

Knowing yourself is true wisdom.

Mastering others is strength;

Mastering yourself is true power.

(Lao-tzu, in Mitchell, 1988, p. 33)

From the ancient sages to the modern corporations of America, understanding oneself is the starting point for wisdom and leadership. Linking self-knowledge to the impact it has on one's relationships with others, as well as bridging reflective thought to action, is essential for meeting the rapidly changing challenges of today's world. John Dewey $(1933)$ and Donald Schön $(1983,1987)$ are often referenced in discussions of reflective practice. Dewey's views of reflective thinking were closely related to, even embedded in, the decision-making process. He noted that reflection begins in doubt, hesitancy, or surprise; that is, when facing conflict, professionals try to bring rationality to the situation. "To reflect is to look back over what has been done so as to extract the net meanings which are the capital stock for intelligent dealing with further experiences" (Dewey, 1933, p. 87). Schön's work on reflective practice and its use in professional 
development helped to identify the importance of self-reflection as well as "reflection-inaction." Reflection-in-action entails thinking about what one is doing often while doing it, as well as "reflect[ing] on the understandings which have been implicit in [one's] action, understandings which he surfaces, criticizes, restructures, and embodies in further action" (Schön, 1983, p. 50). Schön also noted that reflection is more of a sense making process, in which professionals must "make sense of an uncertain situation that initially makes no sense" (p. 40). In so doing, they must identify important aspects of a particular situation, construct a context for understanding, and ultimately question their own assumptions (Ashbaugh \& Kasten, 1995).

Reflective practice is a useful tool in a number of disciplines. For example, action research clearly integrates reflective practices (Calhoun, 1993; Glickman, 1992, 1993; Stringer, 1996). As participants in the action research cycle gather information and execute activities, they must take time to reflect on the process as well as the results in order to proceed to the next stage. Because the process is rarely linear, reflection is an essential component for moving from one cycle to the next (Stringer, 1996). Evaluators often rely on reflective practices as well. As Patton (1997) described in his evaluation of a wilderness program that proposed to turn college administrators into leaders in experiential education, “One doesn't learn from experience; one learns from reflection on experience" (p. 95). Reflection is also considered to be an important element of leadership (Bennis, 1989; Dreher, 1996; Kouzes \& Posner, 1987; Rost, 1993). For example, Rost (1993) described leadership scholars as thinking men and women who benefited from "the more or less automatic actions that result from countless previous experiences upon which they have reflected" (p. 185). Whether referring to the 
clarification of personal values or the development of organizational insight, reflective practices help to promote the understanding of self and others.

A range of strategies and techniques, e.g., journaling, meditation, coaching, have been incorporated as tools for effective reflection in the context of professional development (Morey, 1997; Patton, 1997; Schön, 1987). In particular, teacher educators have written extensively about the use of reflection as a strategy for improving teaching practices (Clift, Houston, \& Pugach, 1990), translating theory to practice (Boyd, Boll, Brawner, \& Villaume, 1998), and developing as a professional (Guillaume \& Rudney, 1993; Rodriguez \& Sjostrom, 1998). Using reflection for improving teaching practices is primarily geared toward credentialed teachers, typically those who have already accumulated years of experience. The other studies quoted here target preservice or student teachers. For example, Boyd, Boll, Brawner, and Villaume (1998) examined the ways that universities and elementary school sites assisted preservice teachers to develop attitudes of a reflective professional, specifically in how they translated language and literacy theory into practice. Rodriguez and Sjostrom (1998) studied the use of critical reflection in professional development as they compared traditional and nontraditional adult student teachers. Guillaume and Rudney (1993) examined the changing perceptions of a group of student teachers and what could be done to enhance their ability for reflection and inquiry. Each of these studies and others similar to them suggests not only the importance of reflective practice strategies, but also the necessity of teaching the skills and insights required to employ reflection effectively. Reflective practice provides teacher candidates a clearer perspective on how they view themselves, their work, the world, and how those views change over time. 


\section{Collaboration.}

What we need today are groups of well-informed, caring individuals who band together in the spirit of community to learn from one another, to participate, as citizens, in the democratic process. (Boyer, 1987, p. 280)

Recent literature on organizations, leadership, education, professional development, and many related topics refers to this concept of community (DarlingHammond, Bullmaster, \& Cobb, 1995; Senge, 1990; Sergiovanni, 1994). Other terms are used, depending on the context, including collaboration, teamwork, cooperative learning, coaching, and so on. A number of cliches have developed, e.g., "Collaboration is like Bigfoot, everybody talks about it but nobody has seen it," or "Collaboration means putting your money on the table and your hands behind your back," attesting to the ambiguity of the concept. According to Chrislip and Larson (1994) who are known for their research on collaborative leadership, the concept goes "beyond communication, cooperation, and coordination" (p. 5). They point to the meaning of the Latin roots, com and laborare, that is, "to work together." Indeed, their perspectives are consistent with many of the leading thinkers on change who claim that collaboration includes developing a shared vision, building trust, communicating effectively and honestly, and creating a learning community (Bergquist, 1993; Drucker, 1989; Fullan, 1993; Senge, 1990).

The essence of community lies in collaboration, with people working together and sharing responsibility that requires everyone's unique and individual talents (McKnight, 1995). For example, Bellah and his colleagues (1992) presented a sociological perspective of "the patterned ways Americans have developed for living together" (p. 4) in an attempt to identify the changes necessary for leading better lives. Etzioni (1993), 
who founded the Communitarian movement, suggested that it was time for Americans "to attend to our responsibilities, to the conditions and elements we all share, to the community" (p. 15). Institutions, organizations, and other programs that promote collaboration do not always model it themselves, as it is often easier to talk about than practice. Collaboration across a variety of disciplines is even more challenging, but may offer potential for new thinking and innovative approaches that result from the crossfertilization of ideas (Helgesen, 1995). When collaboration is viewed as essential to a system of relationships, the strength of the agreements among participants increases both individual and collective capacity (Wheatley \& Kellner-Rogers, 1996).

The need for collaboration is frequently included in the educational reform literature and often described as a necessary strategy for effecting change (Fullan, 1993), creating schools as communities (Sergiovanni, 1994), and building effective field-based teacher education programs (Darling-Hammond, 1994). Moreover, collaboration is described as one of the components necessary for successfully including students with disabilities in general education classrooms (NASBE, 1995; Sax, Fisher, \& Pumpian, 1996), and is required for expanding partnerships among schools, social and health agencies, and other community members (Dryfoos, 1994). Despite these assumptions about the need for collaboration, there appears to be little agreement on "either an operational definition or theoretical foundation of collaboration" (Welch, 1998, p. 27). In fact, some researchers claim that commonly structured student teaching placements (i.e., one student teacher with one classroom teacher) prepare teacher candidates for the "Ioneliness of the classroom, not for reflection, networking, or collegiality" (McIntyre, Byrd, \& Foxx, 1996). 
Welch (1998) explored existing definitions as well as misperceptions that accompany those definitions in order to arrive at a number of recommendations that might be useful for teacher educators. He identified the need for conceptualizing and operationalizing foundations for collaboration (i.e., establishment of a collaborative ethic that is valued and supported), skill acquisition (i.e., specific preparation for effective interaction with other professionals), and skill application (i.e., opportunities for application of these skills), if collaboration is to become more than rhetoric. He also recommended that teacher candidates have opportunities to reflect on their experiences, which is consistent with the literature cited earlier in this review.

\section{Conclusion}

This chapter provided a review of higher education reform literature, with specific examples from teacher education, in order to support the need for further research in the area of professional education program design and implementation. Particular attention was focused on the study of student beliefs and how they change over time, especially as students attempt to translate theory to practice. As IHEs redesign programs to better meet the needs of today's students, professional education programs can demonstrate the integration of the best strategies that teaching and learning models have to offer. As the empirical studies in this area appear to be limited, this study adds to the literature base and offers recommendations to leaders in higher education interested in change. 


\section{CHAPTER THREE}

\section{METHODOLOGY}

Qualitative research methods are often used when "data are not easily handled by statistical procedures" (Bogdan \& Biklen, 1992, p. 2). Qualitative research data are rich in description of people and their situations, and offer a researcher some understanding of behavior from the subject's own frame of reference. It should be noted that "qualitative researchers accept the fact that research is ideologically driven, [that is,] there is no value-free or bias free design" (Janesick, 1994, p. 212). As such, qualitative researchers must identify their own biases and understand the ethical implications that arise during the study. This study has been designed with these factors in mind. This chapter describes the research design, the research questions, and the specific methodology that were used in collecting and analyzing the data. In addition, ethical considerations for the participants and limitations to the study are addressed.

The College of Education in this study, located in the southwestern part of the United States, implemented a new vision. This vision was realized through the identification of strategic choices used to organize teaching and learning: diverse learners, technology, reflective practice, and collaboration. While an evaluation of the entire College of Education program was beyond the scope of this study, the idea of examining the impact of this new organizational and conceptual framework on students 
was feasible. Therefore, the study focused on one group of post-baccalaureate students in a yearlong professional education program to determine how they experienced coursework focused by the four choices and how they applied what they learned to their field of study. Analyzing the perceptions of their experiences, expressed via journal writing and interviews, provided implications for IHE educators and administrators engaged in similar efforts to examine their approaches to teaching and learning. The results contributed to the knowledge base of professional education program design.

\section{Research Questions}

Qualitative methods were primarily used to answer the following research questions: 1) How, if at all, did the students' awareness of the four strategic choices change over time?; and 2) How, if at all, did the students apply the four strategic choices during their internships? Descriptive data, such as frequencies of responses, are also included.

\section{$\underline{\text { Research Design }}$}

A number of characteristics of qualitative design, as described by Janesick (1994), have been considered in this study. These include: maintaining a holistic perspective; looking at relationships within a system or culture; focusing on understanding a given social setting without necessarily making predictions about that setting; demanding that the researcher stay in the setting over time; incorporating informed consent decisions and being responsive to ethical concerns; and requiring ongoing analyses of the data. Further, discovering categories, and the relationships and patterns between and among categories, added to the rich description of the data in order to deepen the understanding of the research issues. The rich description was balanced with analysis and interpretation in 
addressing the research questions (Patton, 1997). The steps of the research study, including identification of the sample, data collection, and data analysis, are as follows.

Sample. The College of Education in this study was selected for two reasons. One, the COE in this university provided a model of reform that focused on changing models of teaching and learning based on four strategic choices. Two, the researcher had access to students in this COE in her role as a faculty member of the university. Students applied to the professional education program in this COE after completing a bachelor's degree program. They were also required to meet a number of minimum requirements, such as completing specific prerequisite courses, passing an entrance exam, and attaining a specific GPA. Students typically prioritized their choices for placement based on schedules, geographical location, and cost. They were placed into cohorts according to their choices and remained together for the first year of their post-baccalaureate education. One of ten cohorts that began in fall 1997 was selected. This cohort, referred to as the Block, was a sample of convenience (Babbie, 1990) for conducting the study, as the researcher had access to the students in her role as a teacher-scholar.

The 32 students enrolled in this cohort did not know each other prior to beginning the program, with the exception of two who were related. Twenty-eight students completed the educational program (87.5\%), 25 of them female. The four who were unable to continue for the entire year were excluded from the study. Three of the students were identified as Hispanic/Latino, two students were of Pilipino descent, and 23 were Anglo. Of the 28 students, 17 entered the credential program immediately after finishing a bachelors degree program at a typical age of 22 . Of the eleven who spent years after earning their bachelors degree gaining other work experience or raising 
families, four were older than 30. Twenty-six of the students reported that they had prior experience working with children in schools, recreational programs, and other formal and informal organizations for children. They described a variety of paid and volunteer roles and many reported having more than one direct experience. Positions included instructional aide, tutor, volunteer, nanny, babysitter, music teacher, preschool teacher, camp counselor, and other supervisory roles for children in residential, academic, and recreational environments.

Students participated in two eight-week internships, one each semester. During each semester, they enrolled in coursework for the first eight weeks and an internship for the second eight weeks, thus having an opportunity to practice the skills they developed during classroom instruction and seminars. Both the school site and the grade level differed for each student the second semester to provide a contrasting environment. Every effort was also made to place students at two sites that offered a different mix of students, e.g., language, socioeconomic levels, and ethnicity. A total of 10 school sites were used, eight the first semester and six the second semester. See Table 1 for listing of grade levels. It should be noted that no significant differences existed among the cohorts, that is, students were not placed in one cohort versus another according to academic standing, experience, or demographic characteristics. Therefore, the cohort in this study may be considered representative of all other COE cohorts.

Table 1: Placements according to grade levels

\begin{tabular}{|l|c|c|c|c|c|c|c|c|c|}
\hline $\begin{array}{l}\text { Grade } \\
\text { levels }\end{array}$ & $\mathrm{K}$ & 1 & 2 & 3 & 4 & $4 / 5$ & 5 & $5 / 6$ & 6 \\
\hline $1^{\text {st }}$ Sem. & 1 & 5 & 5 & 8 & 0 & 1 & 2 & 3 & 3 \\
\hline $2^{\text {nd }}$ Sem. & 0 & 3 & 3 & 5 & 3 & 2 & 2 & 4 & 6 \\
\hline
\end{tabular}


Data collection. Data were collected in two forms: student journals and transcripts of interviews with student discussion groups. Accessing the students' perceptions of their experiences through two modes of expression (i.e., written, oral) provided triangulation of the data (Denzin, 1978). In addition, using data written throughout the one-year program provided a range of perspectives and an indication of how, if at all, their experiences changed during that time period.

1) Student journals. Each of the students in the block maintained a journal as one of the course requirements. Two open entries, based on the students' experiences, reactions, and reflections, were required each week. In addition, students were asked to write entries in their journals based on specific activities and reading assignments. For example, videos were provided during winter break and students were asked to react, in their journals, to each of the videos. A list of required entries (i.e., writing prompts) for student journals is included in Appendix B. 2) Student discussion groups. The twenty-eight students were often asked to form small groups for discussions during biweekly seminar meetings. During the last month of seminars (May, 1998), students were asked to discuss the four strategic choices in their small groups (approximately six students per group). The discussion was structured around five questions, related specifically to the application of the four choices (referred to as "core themes" by the students). The students were asked for their permission to audiotape the discussion for use as general feedback to the College of Education. They all gave verbal permission, and participated in self-selected groups. Names were not given on the tape, and students spoke in random order, offering examples and comments about their 
experiences from their internships. Each discussion lasted about 30 minutes. The composition of these questions had been informally field tested with five students from another Block who participated in similar discussions. (See Appendix $\mathrm{C}$ for list of group discussion questions.)

Data analysis. One definition of data analysis includes three subprocesses that may occur before, during, and after data collection: data reduction, data display, and conclusion drawing/verification (Huberman \& Miles, 1994; Miles \& Huberman, 1984). Data reduction refers to "the process of selecting, focusing, simplifying, abstracting, and transforming the raw data that appear in written-up field notes" (1984, p. 21). This process typically occurs continuously throughout the life of the project. The second analytical process is data display, described as "an organized assembly of information that permits conclusion drawing and action taking" (p. 21). Because qualitative data often take the form of narrative text, the sheer amount of information can be cumbersome and overwhelming. Displaying data in other forms, such as structured summaries, matrices, graphs, charts, and vignettes, can make the information more manageable and accessible. The third process in data analysis is conclusion drawing and verification, which involves a range of approaches, including comparison/contrast, notation of patterns and themes, clustering, use of metaphors, and triangulation. In other words, once conclusions are drawn, "the meanings emerging form the data have to be tested for their plausibility, their sturdiness, their 'confirmability' - that is, their validity" (p. 22). These three subprocesses were employed to help manage and focus the analysis of more than 1000 pages collected from 28 joumals and from interview transcripts of the student discussion groups. 
Given that the data already existed, a somewhat modified version of the constant comparative approach of developing theory (Glaser, 1978) was used. The researcher initially reviewed student journal data to become reacquainted with the material. Each student's journal was copied and placed in a folder. Every journal page was marked with the owner's initials and each student was given a pseudonym. Because students handwrote all the pages, a more traditional approach to data management was utilized. General storage and retrieval methods included a cross-referral and indexing system to organize the data for references to themes as well as to indications of change over time (Huberman \& Miles, 1994). This first subprocess of data reduction helped to identify possible domains and to focus and simplify the raw data. Entries representing each of the four strategic choices were highlighted with different colors, and then coded with stickon notes to indicate their relationship to "awareness" and/or "application." The journals were then reviewed again, focusing on specific time periods (e.g., beginning of first semester, beginning of student teaching, etc.) and coded accordingly. The transcripts of the group discussions were highlighted in different colors via a standard word processing software program as these data were already recorded as a computer file. These data were then "cut and pasted" electronically and coded for indications of how students applied the four strategic choices during their internships. All the data were initially coded by the researcher and a trained associate, who was given specific guidelines to ensure interrater reliability in the process.

The next subprocess, data display, resulted in a number of graphic representations that were constructed to illustrate the semantic relationship between terms found in the data (Spradley, 1980). This subprocess was applied to data that related to the following: 
four strategic choices (i.e., diversity, technology, reflective practice, and collaboration), patterns of how attitudes changed over time, and indications of progress through stages of awareness, understanding, and application. Using data displays helped the researcher make connections between the text and the displays, beginning a cycle of analysis that is represented by Figure 1 (adapted from Huberman \& Miles, 1994, p. 433). The researcher understood analysis as interactive and sequential, and as a result, allowed the data displays and the conclusions to influence each other. As more patterns emerged, new relationships and explanations were discovered. These discoveries led to the third subprocess of drawing and verifying conclusions. The researcher and the associate then reviewed the resulting domains, displays, and relationships to identify representative quotes. Refining and verifying the conclusions and identifying representative quotes were the responsibility of the researcher. Some of the tactics used for "warding off the most obvious biases included the following: checking for representativeness, checking for researcher effects (reactivity), and triangulating and weighing the evidence" (Huberman \& Miles, 1994, p. 438). These considerations were taken into account during the data analysis and verification processes in order to ensure internal validity, or "the extent to which [the research findings] are an authentic representation of some reality" (Goetz \& LeCompte, 1984, p. 210). In addition, measures for external validity, or "the degree to which such representations can be compared legitimately across groups" (p.210), were also employed when considering transferability of the findings. Two colleagues were asked to individually examine the data display and analyses in order to provide an additional measure of both internal and external validity. In addition, four students from this Block were asked to read the list of domains and representative quotes 


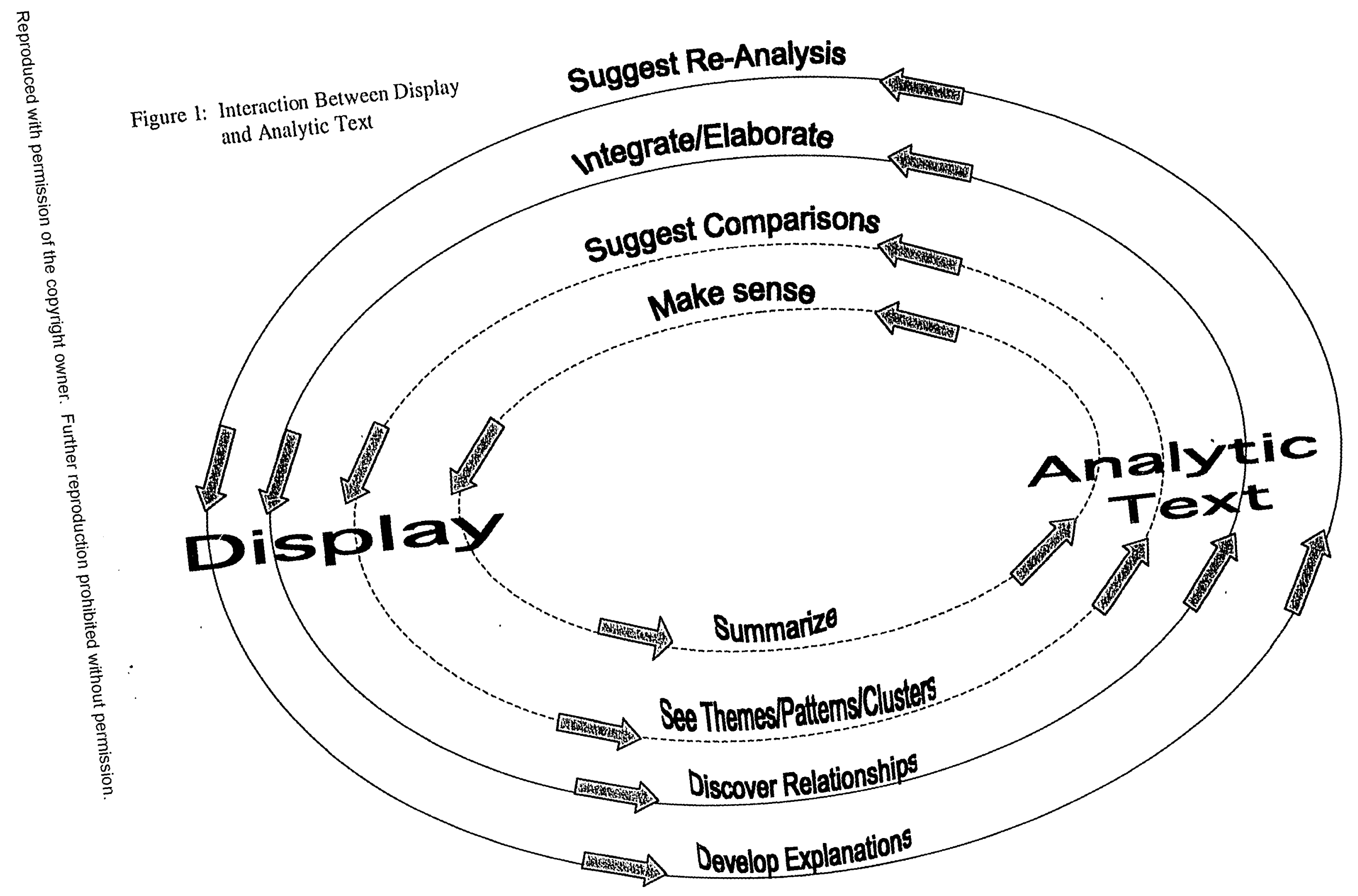


for authenticity, that is, that the conclusions represented the reality of their experiences. The colleagues as well as the students all agreed that the data were representative and that the resulting displays and analyses made sense.

Ethical Considerations for the Participants

The established procedures of the University of San Diego's Committee on the Protection of Human Subjects were followed in undertaking this study. Participation in this study presented virtually no risks for the participants. The data were gathered for another purpose, i.e., as assignments for the seminar courses in the Block. These seminars were designed as two one-unit courses, one each semester, that earned either "credit" or "no credit." Credit had already been issued by the time students were asked for their consent to access the information, and all students completed the credential program and graduated from the College of Education. After approval by the Human Subjects Committee, consent forms were mailed out the week after grades were submitted for the spring semester (see Appendix A for consent form). Return envelopes (addressed and stamped) were provided, along with a memo summarizing what was included in the consent form. Students were offered the opportunity to question the researcher on the methodology and to review the selected data.

Students" "voices" were heard in their descriptions of how they experienced and applied the four strategic choices, which have been essential components of their professional education program. Students had the opportunity to add to the knowledge base regarding the success or failure of "transforming" coursework, and to help communicate to professors and administrators the effectiveness of this approach. The benefits clearly outweighed the risks, as there was essentially no risk to the participants. 
The participants had a unique opportunity to provide feedback during the first year of implementation of a new program. Should any of them decide at some time in the future to pursue a graduate degree from the College of Education, they may directly benefit from the results, if indeed the results of this study impact how courses are designed and delivered.

\section{Limitations to the Study}

Two limitations to the study were identified. The first limitation was related to the size of the sample. The study was limited to the experiences of one cohort of students who completed a yearlong professional education program. However, the qualitative nature of the research provides rich description (Van Manen, 1990) that may be transferable to other professional education programs. Second, the research was limited to the use of existing data. Although data were collected from two sources (i.e., journals and interviews) and a member check was conducted for credibility (Lincoln \& Guba, 1985), the study did not include further contact with the participants. Nevertheless, the results of this study provide a baseline for a future investigation of the participants' perceptions after they have been employed as professionals. Interviews with and observations of the participants at least a year after employment may inform the College of Education as to how, if at all, the participants' perceptions changed over a longer period of time.

An additional limitation regarding researcher bias might be considered. Most qualitative researchers accept that "research is ideologically driven" and that "there is no value-free or bias-free design" (Janesick, 1994, p. 212). However, it is important that "the qualitative researcher early on identifies his or her biases... [so that] one can see 
easily where the questions that guide the study are crafted" (p. 212). In this study, the researcher was an instructor in the credential program. Like other qualitative researchers, she was "inescapably present" and was not "deluded that who [she was] would not make a difference in the outcomes of the study" (Jansen \& Peshkin, 1992, p. 720). Therefore, continued attention to the question of subjectivity and objectivity was rooted in this research as in any social research that uses qualitative methods. To balance this possible influence, the researcher requested that two other colleagues examine the data display and data analyses to provide an "outside" perspective that the findings did indeed appear to be an authentic representation of reality. Checking with a number of participating students after the major domains, displays, and relationships were identified provided an additional measure of authenticity. 


\section{CHAPTER FOUR}

\section{FINDINGS}

Qualitative research often results in large quantities of data, leaving the researcher with the daunting task of making sense of patterns that emerge from the words and ideas collected over time. "What is at issue is the best means to 'make sense' of the data in ways that will facilitate the continuing unfolding of the inquiry, and, second, lead to a maximal understanding of the phenomenon being studied" (Lincoln \& Guba, 1985, p. 224). It is the researcher's responsibility to "find the most effective way to tell the story" (Janesick, 1994, p. 215). This story must also be contextualized to provide a look at "the larger picture, the whole picture, beginning with a search for understanding of the whole" (p. 212).

Therefore, this chapter begins with the context and culture of the professional education cohort in this study. Farniliarity with course formats, assignments, roles and relationships, and social setting is essential to the "understanding of the whole." Findings from student journals are then presented. The two research questions are addressed as they related to each of the four strategic choices: 1) How, if at all, did the students' awareness of the four strategic choices change over time?; and 2) How, if at all, did the students apply the four strategic choices during their internships? The last section provides findings from the student group interviews. These discussions yielded a 
different perspective, that is, the students reported their overall impressions as they considered their year of professional training. In general, many of the students provided more detailed examples than they had in their journals. These discussions not only substantiated their writings, but also indicated that some students integrated a deeper and more holistic understanding of these choices into their individual belief systems.

\section{Context and Culture of the Cohort}

Shared events over a period of time, both planned and unplanned, contributed to the development of a learning community (Senge, 1990). The cohort in this study shared events on a daily basis for almost an entire year. In addition to attending all the methods classes together, students met regularly for a student teaching seminar in order to synthesize knowledge and integrate skills acquired from the coursework and teaching experiences of the multiple subject teaching credential program. All university methods classes were held at an elementary school previously designated as a partner in this professional development program. Seminar instructors offered guidance and support for students in the program by giving them a consistent point of contact throughout the year.

Seminar, a one-unit course that students attended both semesters, met weekly or biweekly when students were enrolled in methods courses (first eight weeks of each semester) as well as when they were student teaching (second eight weeks of each semester). Seminar content emphasized additional strategies for classroom management, technology integration, addressing needs of diverse learners, and facilitating reflective practices. In addition, students often discussed challenges that they encountered at their student teaching placement sites and shared successful approaches. Competencies for seminar included the development of the following: an understanding of issues relating 
to language, culture, and ethnic differences through design and implementation of appropriate classroom activities; familiarity with observation and data collection instruments for organizing classrooms and creating student support plans; experience in designing lesson plans that are sensitive to diversity issues and that provide for technology integration and collaborative learning opportunities; use of reflective journals to be shared weekly with the seminar instructor; and the creation of a portfolio and resume to demonstrate teaching abilities and experience to a potential employer.

Two weeks before students began their first semester methods courses (Reading/Language Arts and Math), they were assigned to a teacher at the host school for two days. Students witnessed and assisted in the preparation required in setting up a classroom to begin a new school year. Students in the cohort maintained the connection with this teacher on a weekly basis while enrolled in methods courses for both semesters. Faculty from this school were scheduled on a weekly basis to share their expertise on a specific topic. "Shared expertise" sessions included ideas for the first week of school, integrating technology into the curriculum, power teaching, directed drawing, storytelling, creative book reports, and creating classroom environments. Sessions were also scheduled during the second semester seminar that offered strategies for integrating the arts (music, dance, fine arts, and drama) throughout the curriculum. After the preparation days, cohort students spent the following week at their assigned schools with their cooperating (master) teachers and future students. University methods classes began the third week at the host site. Due to an increase in the student population at that school, the classroom formerly designated for the university classes was needed for children. The cohort met in the auditorium, but had access to an observation room at 
least once a week where they could watch as a teacher presented a lesson from behind a two-way mirror. As one student commented in the group interviews:

Being on site at a school, even though the situation we had was pretty interesting, I have to say that opposed to [another] block where they had to go to [the university campus] for their classes, even being in the auditorium day in and day out with all the noise, we had it better because we were on site. We were at a school, we had the kids there ready to use, especially with science it was nice to be able to pull the kids in, and with social studies the same thing, we got to use the kids and put them back in the classroom. We got to access kids - it was a nice hands-on. (Group \#4)

The cohort schedule also included one or two visits per week to their student teaching sites during the first eight weeks of the semester. These visits enabled members of the cohort to become better acquainted with their cooperating teachers and their future students and to become familiar with the classroom routine and the school schedule. By the time they began student teaching, they were prepared to design and implement lessons and assume additional teaching responsibilities. At the beginning of second semester, each student in the cohort was assigned a placement in a school and grade that differed from their first internship placement. The intent was to provide students with experiences at two schools that had different populations of children and that offered a variety of resources, supports, and approaches. Students were also scheduled for one semester in a primary grade and the other semester in an upper elementary grade level. All students were required to spend at least one semester with a teacher who possessed the Cross-Cultural Language and Academic Development (CLAD) credential or 
equivalent certification. One of the students offered this perspective on the schedule during the group interviews:

I just like the way that this program is organized because there are student teachers at my school from [another university] and they do all their methods and then they do all their student teaching and they go straight from one classroom to another classroom student teaching and they're really getting burned out. I really like having two different schools. I think that's really essential and having that time between, like having some methods, then some student teaching, some more methods and then the rest of student teaching. I liked that a lot. And I didn't realize how much I liked it until I saw what was happening to these people. (Group \#4)

In addition to discussions and activities, seminar requirements included the completion of a number of assignments that corresponded with the four strategic choices. Assignments included: submitting weekly journal entries; completing a webquest (i.e., finding relevant websites via the Internet, and providing a brief description) and a technology treasure hunt (i.e., an inventory of technology available at their assigned school sites); creating a student support plan based on the use of a wide range of positive behavioral principles and practices; implementing an activity from $\underline{\text { Activities for a }}$ diverse classroom: Connecting students (Katz, Sax, \& Fisher, 1998); and developing a professional portfolio and resume. Students were also provided with access to seven videos that demonstrated effective teaching strategies in classrooms, classroom management approaches, a panel discussion featuring students with and without disabilities discussing issues of acceptance and expectations, portfolio assessment for 
students, and strategies for working with families. Videos were distributed before winter break so that students could view them and prepare for informal presentations scheduled during second semester seminar sessions.

The culture of the cohort emerged gradually over the two semesters. Cycles of positive and negative attitudes, indications of the rise and fall of confidence levels, and the development of roles and relationships within and among the group members shaped the identity of the cohort, as illustrated in Figure 2. The initial burst of anticipation, excitement, and anxiety gave way to the feeling of being completely overwhelmed by assignments and responsibilities. The following excerpts from journal entries written during the first week reveal the positive view that the majority of students had entering the program.

This is going to be a great semester. My master teacher has made me feel right at home. I have my own desk in front of the class. He included me in decisions he was making. (Jan)

This week has just been too good to be true. I started in my classroom on Wednesday morning. Mr. S., the principal, showed me around the school and took me to my classroom making me feel welcome and at ease. I was early and when my master teacher arrived she too made me feel welcome and at ease. (Cate)

I have been waiting for this day for what seems to be an eternity. I finally am beginning "the credential program." I have wanted to be a teacher since I was a child. I have been up all night anticipating this day. It is so exciting, the first day of first grade. My master teacher told me she has been very nervous too. I found 
Figure 2: Creating a Learning Community

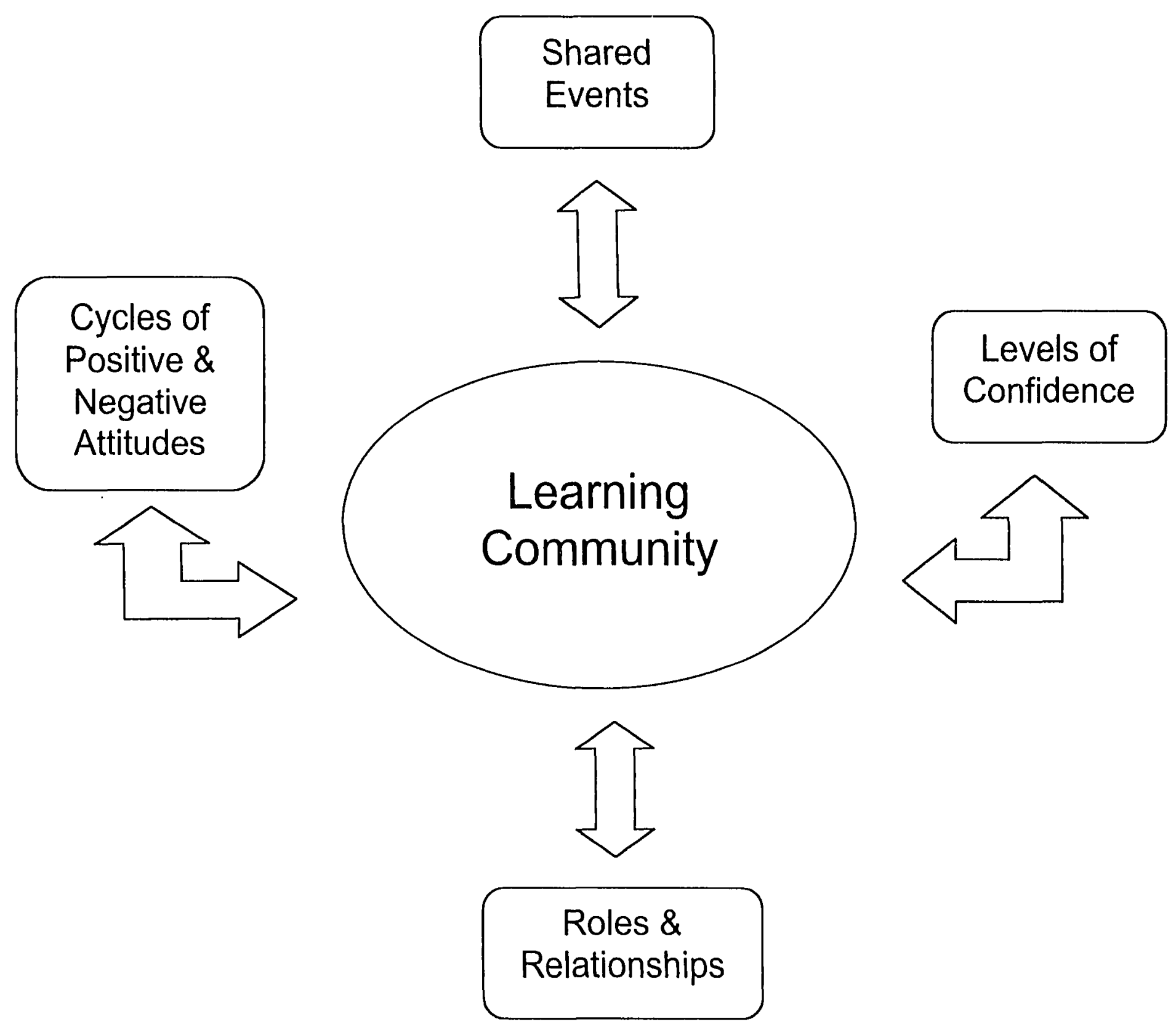


that so comforting, that after 20 years of teaching she still gets anxiety on the first day of school. (Dawn)

And so it begins. I feel nervous and excited to start the program. My master teacher is a super person, she really made me feel comfortable and at ease. I was put to work right away, which was great, because I hate to look like I'm doing nothing. (Alicia)

In response to the writing prompt "I felt welcomed at my school when ..." assigned during the first week in their student teaching classrooms, many of the students described the actions of their cooperating (master) teachers and their students that contributed to their feelings of comfort. Students noted that children gave them hugs and teachers took the time to provide introductions to other school faculty and staff. The following student described her welcome as setting the tone for her role in the classroom. I felt welcomed at my school when my master teacher introduced me to everyone that she saw. She also acted like I was a part of the classroom and implied to the kids I was just as important as she was. I also felt very excited and welcomed when all the teachers in the lounge made an effort to learn my name and asked me questions about myself and the program. (Lynn)

Not every student was completely satisfied with his or her first impressions, as expressed in the following selections. "The first weeks of school have been a little exciting, a little scary, and a little disappointing" (Sally). This student described how she offered ideas to her master teacher, but "whether she actually uses them will be another thing." This student teacher was excited about meeting her students and had the opportunity to meet many of their parents, but was afraid that she and her master teacher 
did not "have any connection with each other." Another student teacher expressed similar apprehension. "What a disappointment! My master teacher is stuck on her way back from Trinidad. I didn't know what to do, but [another teacher] gave me some things to do" (Jane). The next day she wrote,

Well, I met C. today. She seems nice, but she's really distracted. I guess she's tired from the long trip. I hope this works out. C. seems very low-key and she's not into formal lesson plans. I hope I know what I'm doing when it's time for me to start teaching the class. (Jane)

Yet another student expressed up front what many of the others did not acknowledge until later on in the semester. "Today was a sobering experience . . . in all my assisting today I finally realized how much work goes into teaching" (Jason).

The week before the students were to begin their first round of full-time student teaching, they were asked to write in their joumals about their feelings of confidence and anxiety. There was cautious optimism in some entries. "I'm not as nervous as I expected. I know I will have some problems getting started but I'm ready for them" (Cate). "I am confident that eventually all of this will come together, but I'm not sure when. I am confident that I will do my best" (Jane). "I also feel confident that my master teacher will help me if I have any problems" (Selena). "I am confident that I will be learning something new everyday!" (Nancy). Others stressed the relationships with their students and with their master teachers that helped to build their confidence. "I'm feeling very confident with my relationship with the students and my master teacher. I also feel that my master teacher is eager to set me free, not because she wants a break, but because she trusts me" (Dawn). "I am confident that my students like me and respect my authority - 
so far" (Jamie). "I feel comfortable about how well I know the students and their abilities" (Carol). "I feel confident that the kids like me. I am confident that the kids listen to what I say when I teach a lesson" (Lynn). "I have an open line of communication with my master teacher. This makes me confident in my abilities and the work I will be doing in the classroom" (Jacki). Most of them also referred to specific skills that they had learned from their Reading/Language Arts course and from their Math Methods course.

The most common response to "What I feel nervous about ..." referred to classroom management issues. Fourteen of 26 students (two students did not complete this entry) expressed their doubts about their ability to "successfully maintain the behavior in the classroom." "I'm nervous about keeping control of the students. The students in my class are hard for my master teacher to handle, so how am I going to do it" (Jane). "I am nervous that after the newness wears off, the kids will have discipline problems and I won't know how to handle them." (Lynn) "I don't want to be too harsh, but yet I don't want to be a pushover either" (Jacki). "I am nervous about the form of classroom management my master teacher used and the more relaxed ideas I have" (Jason). A number of them also expressed concern over being observed and/or evaluated. "The children I can handle but it's the aduits that make me nervous" (Alicia). "I'm dreading getting evaluated and people watching me!" (Rhonda). Only one student denied any apprehension and wrote that she felt nervous about "not feeling nervous" (Jill). One student shared the advice that she had received from her university supervisor.

Then my supervisor said that terrible thing, "Some teachers say they don't smile until Christmas." It is difficult to imagine an approach more out of step with 
everything we know about child development and learning! Nice teachers are highly effective - stern, cold teachers teach children to be stern and cold. I remember two stern elementary teachers I had - I hated them and they both made me feel bad about myself. (Lila)

By the time these students were ready to begin their second round of student teaching, the rise in the level of confidence was clear. Although they were not asked to respond to specific prompts of "I am confident about ..." and "I am nervous about ..." at that time, journal entries written the week before student teaching indicated much less anxiety and much more confidence. "I'll be happy next week when methods classes are done. I am looking forward to student teaching full time" (Mona). "I have supervised the classroom while Mrs. P. was out of the room. I can't wait until I am in the room full time." (Cate) "I've arranged to meet with my university supervisor and I'm interested in seeing what he expects from this semester. I've tried to take charge of what I'll be doing during full time teaching. I feel more confident about what my roles are." (Kay) "I can't wait until I get to go to my class everyday. Boy these kids are very loving and so happy to have me." (Sally)

The roles and relationships among the students changed throughout the program, adding to, or possibly resulting from, the cycles of positive and negative emotions. The students spent at least seven hours a day together during the first eight weeks of each semester, and often more if they were taking additional coursework, working on homework projects, or spending time at the same schools. As issues arose, the group members were challenged to solve problems and make decisions that ultimately affected 
their cohesiveness. Early in the first semester, almost half the students in the cohort addressed a dilemma about one of their classmates in their journal entries.

I feel that I need to talk about one of my fellow student teachers. I am not the type to go around talking about other people, but I have come to the point where I think something must be said. The first time I came into contact with her, my gut instinct told me to watch out. I filed this thought in the back of my mind and decided to give her the benefit of the doubt. I have since discovered that my instincts are correct. (Jan)

Jan went on to describe specific actions by this other student, including her "inappropriate comments," "interrupting classmates on a regular basis," and wearing "short shorts on days when she is in her assigned school." Less than two weeks later, Jan wrote, "I'm really trying not to be the Amy patrol, but I have to talk to someone. I don't want to talk about her with the other student teachers, because I am making a point to stay out of any and if possible, all of the gossip." She then added another paragraph commenting on Amy's tardiness. A number of other students echoed these sentiments. "I hate to make this journal a personal gripe session, but something should be said. Last week I wrote in my journal that a classmate was particularly annoying to me. I did not mention her name. But today ..." (Max). He described an incident for the next page and a half in which Amy's actions affected at least four other students. At the end of the entry, he wrote: "My biggest concern is that if she can so easily shut me out like what I have to say is invalid, what is she going to do as a teacher? More importantly how might this affect a third grade child?" Around that same time, one of the other students offered another perspective: “I see a problem with our attitude. Even though her [Amy's] 
speeches during class seem irrelevant and off the topic, we need to respect that she has the floor and not roll eyes, look away, talk among ourselves" (Nancy). About a month later, another one of Amy's "victims" wrote about her experiences, indicating that people had worked together to address the issues:

I got a phone call from the woman that offended me. She was actually very nice and apologetic. Apparently, someone told her that she was offending people and acting rude ... she said that she's unaware most of the time that she offends people. She mentioned that she needs to be more aware of those around her. She also said that she's quick to jump on other people for things they say, and that she does this in "defense" but needs to realize that maybe people aren't out to get her. I was so impressed with her statements, and hope that it makes a difference. I've noticed that she has been quieter in class and her statements since she called. We will see ... ( (Jackie)

Students also looked to one another for personal support and as well as for resources. "I seem to be joining others in the group in more social ways. We are doing group projects and stuff, so I think it's good to develop some of these friendships." (Kay) Or as one student said before beginning her second round of student teaching,

I'm getting excited about being in my class full time. But like last semester, I'm going to be sad to part with my friends. We've a!! become so close and gotten to know the ins and outs of everyone it's sad to separate! (Carol)

Other students viewed the separation as a welcome change. "I am getting so tired of coming to [host school]. I am tired of many of my classmates. I think we need a break from each other. There is far too much negativism. I'm ready to move on" (Sally). 
External pressures also magnified these emotions. A number of students wrote during the same period, about midway through second semester, after a particularly heated seminar session.

I don't know what to say. There's so much tension in this block right now that I dread coming here. I understand some of it. People are feeling under the gun to complete assignments. But mostly I think it's the stress of job search imminence. It's out there, it's coming. (Max)

The first thing I want to address is last week's seminar. I feel like it got a little bit out of hand. As a class, I feel like we acted a bit unprofessionally and if you guys felt attacked, I am sorry about that ... anyhow, thanks for working with us and I try to think of the whole day as hopefully increasing our teacher-student communication. It could have been handled better, but I think anxiety \& stress got the best of us! (Kim)

There was an element of the "groupthink" that emerged from the momentum of the discussion, as explained by the following entry:

I felt weird about the way that seminar class went. I felt like there was so much frustration in the room. It's hard for me to say how I feel about the whole situation. I think that the "stress" from students comes from worry about jobs, the future, etc. I had thought about it and asked myself, "should I be worrying more about my resume, interviews, etc." I think that people put this "worry" in my mind. (Jacki)

Summing up the experience from the perspective of being part of a learning community, one student offered her insights as to the membership of that community: 
We are more than a group of students. We are a community - one that you helped us build, in part. You have asked us to trust you, to share our reflections with you via our journal, to share concerns and ideas about our teaching. You've asked us, in essence, to allow you to be a part of our community. Perhaps even expected us to see you as a part of our community or maybe assumed that as our block leaders you were automatically a part of the group. The problem I see is that we're not a group but a community in which we have taken many risks together that have bonded us together more than any of us (including you) could imagine. (Nancy) Clearly, over the course of a year, this group of strangers emerged as a learning community. The shared events, successes, and challenges provided the context for their growth, both personally and professionally. In the following section, examples are provided that portray the students' individual development in awareness and understanding of the four strategic choices, e.g., technology, diverse learners, reflective practice, and collaboration. These examples were drawn primarily from their journal entries. Following the findings about awareness, examples of the ways in which students applied the choices in their internships are presented. These were collected from the group discussions held with the students at the end of the semester.

\section{$\underline{\text { Strategic Choices }}$}

When the students were introduced to the four strategic choices during the initial seminar meeting, they were asked to write their reactions to the prompt: "Describe your comfort level as a learner and as a teacher in the areas of technology and reflective practice, collaboration, and diverse learners." These entries, written over the following two weeks (two topics per week), provided a baseline of their level of awareness 
regarding each of the four themes. At the end of the first semester, the students were asked to respond to a second prompt: "Provide an example of how you've addressed the four themes in your student teaching classrooms." At the beginning of the second semester, they were given a third prompt: "Which themes do you plan to focus on this semester? What would help you to incorporate the four themes into your classroom?" Figure 3 lists these prompts as checkpoints that were used to determine indications of change over the year. In addition, journal entries written during each semester were examined. This time period was further defined by the two eight-week sessions during which students enrolled either in methods courses or participated in student teaching. Intersession (the period between first and second semester) was included in the checkpoint sequence to signify that students were assigned videos to review. The final checkpoint was designated for the student group discussions held at the end of second semester. As the students in one of the groups shared in these interviews, they attributed an additional meaning to the four themes, illustrated by the mnemonic they devised: "Teachers Do Really Care" (i.e., Technology, Diverse learners, Reflective Practice, Collaboration).

Technology. When students first wrote about technology, they were not provided a specific definition, yet 24 out of 28 included descriptions of their computer experience, referring to their exposure to the Internet, e-mail, and either word processing programs, games, or interactive software. The remaining four students referred to technology in general terms. Additional experiences listed included the use of video equipment, photography equipment, multi-media systems, laser dises, CD-ROMs, and overhead projectors. 
Figure 3: Checkpoints for Awareness \& Application

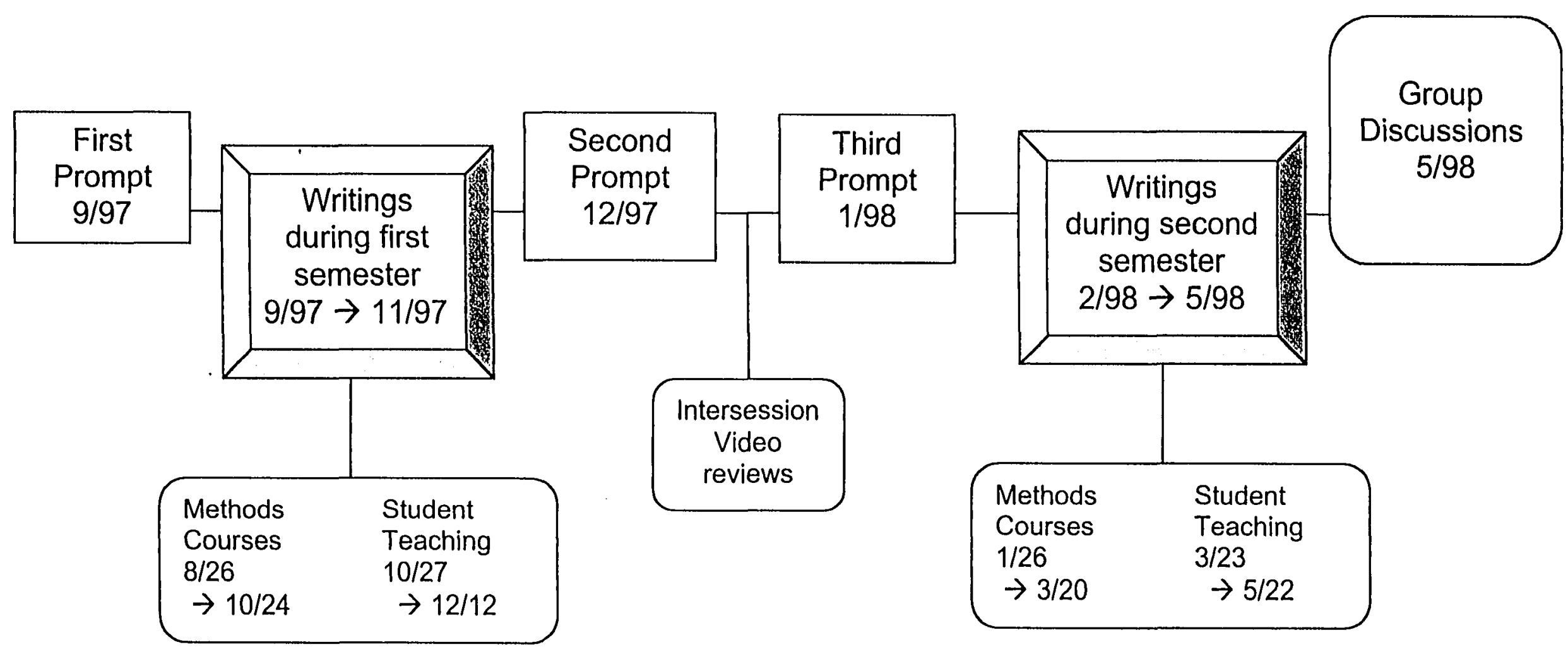


Figure 4 illustrates the influences that contributed to the students' increased awareness levels and their ability to apply their knowledge of technology.

In addition to clarifying their definitions of technology, students described their current comfort level for learning and teaching, and identified the need for more training and experience. The majority of the students felt comfortable with their knowledge and experience with computers and/or technology in general, but few felt that they had the skills to teach others. Comments such as, "As a teacher of technology, I feel very shaky" (Juanita), or "I can turn on the computer, it doesn't scare me ... as a teacher, I'm not comfortable at all" (Doris), illustrated their lack of confidence as a teacher. Others felt that their skills would be inadequate compared to those of their elementary students. "As a teacher, I am not nearly as confident. I feel like I am still behind many of the children I would be teaching" (Max). Or as another student described it,

My comfort level as a learner is good . . . as a teacher it's kind of a different story, because I know a lot of kids know much more than I do about computers. I could help a kid out with the basics, but otherwise I feel a little uncomfortable. (Lynn) Nearly all students mentioned that they wanted to pursue more training and acquire more experience, particularly before attempting to use it in the classroom. Nine students claimed confidence in both learning and teaching, even if they acknowledged that they needed more skills or experience. For example, one student had set a goal for himself "to be known by my school as the technology guy" (Dan) and another wrote, "Exciting! I need to get on the Net. I'd love to learn along with my students" (Lila). Overall the awareness level of the students seemed to be limited to basic uses of the computer. They referred to word processing, playing games, and accessing the Internet 
Figure 4: Technology

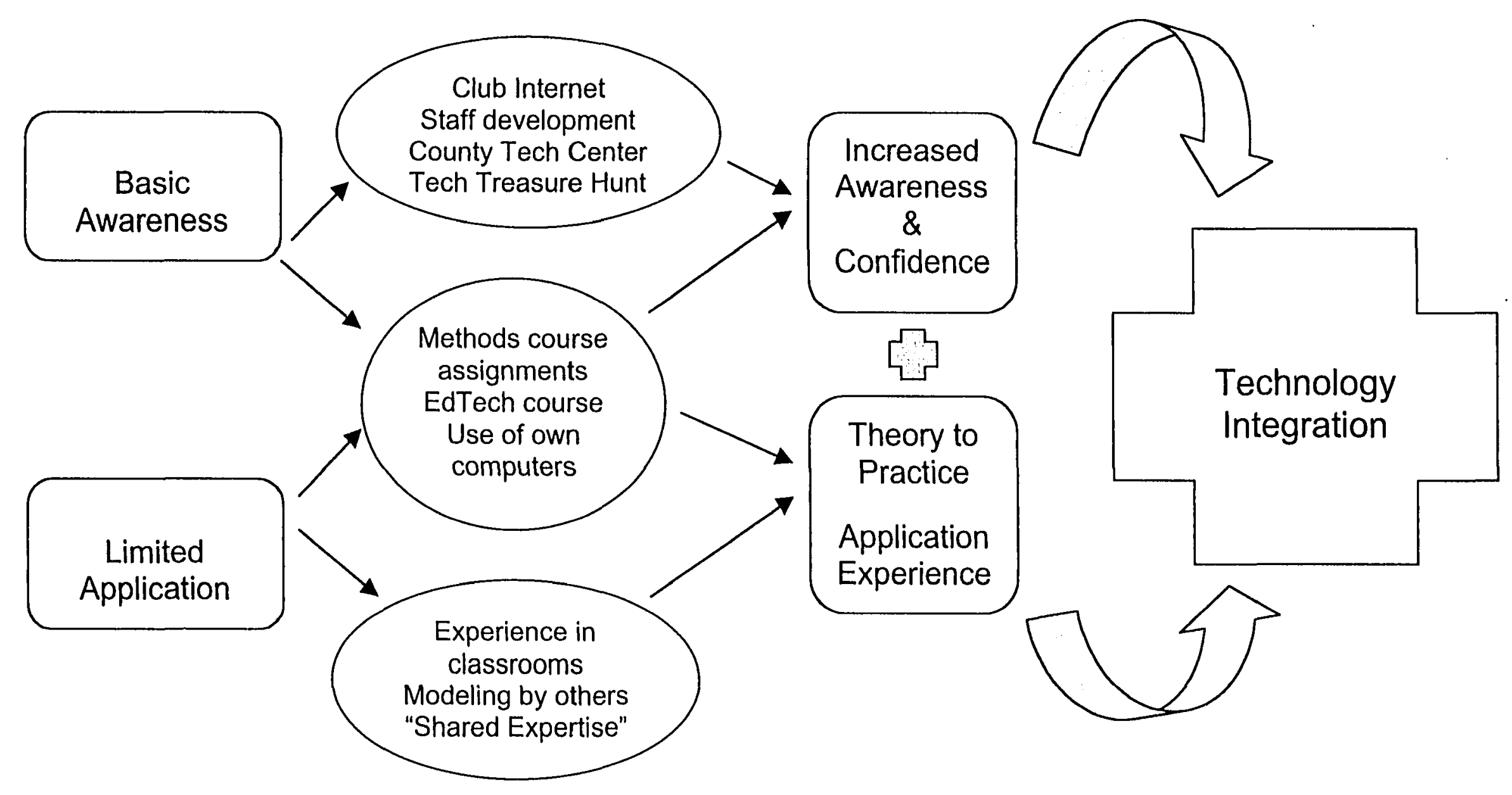


for references and resources. Only two students in the cohort indicated a level of awareness that referred to the use of technology as it might be integrated into the curriculum:

A concern I have is how to meaningfully integrate technology into the classroom so it serves a real useful purpose (not just for the sake of using technology). I have some ideas such as Internet searches or using certain CD-ROMs to enhance a unit or lesson, but hope to actually see it done in the classroom this year. (Kim) As an instructor I feel confident that I will access as many facets of technology that are available. I am excited about current information in technology and events in the world. I would like my students to feel as though they are a part of the world community, and I would like to use the Internet and other resources to make this happen. (Kay)

Over the next eight weeks, students were introduced to technology in a variety of ways. For example, they completed assignments in the seminar and other courses as well as observing it modeled by instructors and their cooperating teachers. One assignment, a Technology Treasure Hunt, required them to search out specific equipment that was available at their school sites. A number of students attended optional workshops to further their Internet skills. One session was offered by a computer business (e.g., Club Internet) located close to the host school, and the other was sponsored by a county computer educator group. A field trip was also arranged to the county technology center, where students saw examples of multi-media, distance education, and other "high tech" strategies for teaching and learning. 
A number of the students referred to their newly developing awareness of technology throughout the first semester. "If I had a computer at home, I know that I would spend all my free time searching for any kind of information I could get my hands on" (Alicia). "Most recently I have tried to bring myself into the technology age. I already had a computer but when I mentioned to a friend that I wanted to get the Internet, I was told how much I really needed" (Jill). She then described her investigations into modems, phone lines, and additional operating software, and summarized, "So technology has brought me a smaller checking account, a skeptical husband and a lot of frustration!" After completing an assignment that required use of the Internet, one student who in her first entry had written that she was "ambivalent" about technology, wrote, "I enjoyed this webquest. Since I have such a little amount of experience on the computer, what can be found on the computer always amazes me" (Cate). About two weeks later, Cate attended a staff development inservice at her school and heard a speaker talk about future trends and the implications for schools. Although she disagreed with some of the views presented, she noted that "I did get a sense for the importance of becoming technologically aware for my sake and for the sake of the children I will be teaching." Another student attended an inservice at her school that included ideas for using the Internet. "I can't wait to get on line at home so I can try it on my own. It's fun and the teacher showed how it could be used in the classroom to make a little presentation" (Jane).

Some students thought about the possibilities of distance education after checking out websites that had been used to supplement courses: 


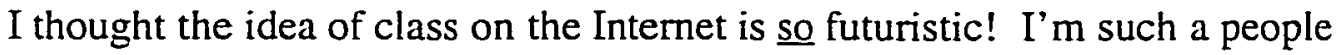
person. I like people interaction - face to face. I'm even uncomfortable staying on the phone with a person for a long time. So being separated by computers is just that much more uncomfortable for me. Could you imagine having child development courses over the Internet with no contact with even a child! Oh my!" (Doris)

I do think this is a great tool to connect people to places/people they ordinarily would not be able to interact with, but the idea of using the net as a reinforcer or source of knowledge we get in school is a better use than a full course with no human interaction. We can see that even within our block some people lack certain social skills, think of how more people would miss out on those skills. (Jamie)

Not all the experiences were "high tech." One student reported a new experience using the overhead projector.

I am learning where to stand, what colors to use and that I need to have a wet paper towel available or else my hands turn black. I have also learned a very easy way to make transparencies - on the copy machine. It's awesome. (Terri) The next journal prompt was given at the end of the first semester, "Provide an example of how you've addressed the four themes in your student teaching classrooms. If you have not addressed them, how do you plan to do so in the spring semester?" The majority of students ( 21 out of 28 ) described the ways in which they had used technology in their classrooms during their student teaching. These examples of application included teaching about and accessing the Internet for research by students and a source of ideas 
for their own lesson plans. They also wrote about using specific programs and games to introduce and reinforce skills in reading, language arts, math, art, and word processing; giving tests; and writing notes to parents. Several of the students who did not have sufficient access to computers at their school reported that they used the Internet at home to create lessons and activities for their students. Overall, as their awareness of, exposure to, and experience with technology increased, their confidence level rose. "So far my knowledge and familiarity with using computers has increased tenfold" (Jamie). "As a teacher, the computer and Internet are such useful tools it seems almost impossible to survive without them" (Nancy). "I really feel I've made great strides in the area of technology. I must admit I was apprehensive upon hearing that it was to be a focus of the program" (Lila).

I saved technology for last because it is what I've been the most excited about. I feel privileged to be at my school because of all the technological advantages they have. Since I've been there I have been involved with teaching my students how to e-mail and how to research a subject on the Internet. I have also involved the students in Hyperstudio projects, video taping interviews, finding things on the laser disc player, getting sound and video from Internet locations, etc. But the most exciting thing that I have been involved in is the fiber optic link that my classroom has with [a university]. Our students are involved in learning about the heart, circulatory system, their bodies, and how to keep fit through this link with pediatricians. We hook up with them every two weeks for at least one hour. This has been so great. I love to see my students so engaged in this type of meaningful learning. (Sally) 
One student demonstrated his newly developed awareness of technology as it related to the future needs of his students through the following entry:

It is becoming more important everyday that our students be comfortable and proficient users of rapidly advancing technology. In order to be competitive in tomorrow's job market, our students must be competent with computers, audiovisual equipment, and other electronic tools and equipment. Therefore we, as teachers, must also be familiar with these advances if we are to guide our pupils. (Max)

Regardless, or perhaps as a result of the advances in their awareness and ability to apply what they had learned about technology, 15 of the students listed working on technology as their top priority as they thought about their goals for second semester. More of them referred to the "integration of technology" at that point as opposed to simply learning or teaching basic skills. A number of students also enrolled in the Educational Technology course second semester, a requirement for earning their "clear" or permanent teaching credential. [Note: Teachers in California have up to five years to take this course after they have completed their provisional credential requirements, so students took this on their own, not as part of the Block.]

Entries during the second semester showed additional growth in skills and confidence, depending on their student teaching placement and the technology that was available at their site. Students wrote about lessons that featured their skills and knowledge with technology. "I'm so fortunate to be in a class where there's a lot of technology available and used daily" (Marisa). Students provided examples of the ways in which they integrated technology in a range of grade levels. One student described 
how she taught her kindergarten students to draw fish on the computer. She recorded the lesson on videotape to use for future interviews. Another student checked out a computer so that he could work on some lessons at home over the break. He was incorporating interactive software and accessing audio and video from the Internet. The following students demonstrate the advanced level of awareness that they had achieved.

I will be creating a center for the $5^{\text {th }}$ and $6^{\text {th }}$ grade classes that has the students find the weather report on the Internet. They will take down the forecast for this city and for another city in the USA. The students will take down the info and create a graph from the results. I'll also be creating a link between a one-room schoolhouse with our students that are studying Pioneers. (Kay) I started my computer newspaper projects this week. I divided the 64 students into 6 newspaper groups. They will be composing a newspaper that pertains to the Revolutionary War time period. We will be publishing the papers on the Student Writing Center and Publisher Program. I anticipate a lot of work ahead of me in terms of guidance, compilation, instruction, help, etc. I am excited to be doing this kind of project though. It was my idea and organization. (Jacki)

One student added some precautions as a result of her participation in a video conference that lost its connection during a broadcast between two schools and the county office of education. "The lesson here: technology is great, but we all must be ready for what doesn't go as expected" (Jill).

Each student appeared to have made notable advances in both the level of awareness about the use of technology as well as the ability to apply the information and skills in their internships. Most, if not all of them, indicated that they had developed an 
understanding of the meaning and importance of "technology integration" and maintained that they would be incorporating technology as professional educators. Interestingly, few students included descriptions of specific lessons that integrated technology in their journals, yet dozens of examples were shared during the discussion groups at the end of the second semester. These examples are included in the last section of this chapter.

Collaboration. As there is little consensus on the definition of collaboration (Welch, 1998), it is not surprising that when asked for their perspectives and experiences, the students in the cohort responded with a variety of interpretations. Most of them equated collaboration with group work, both as a learner and as a teacher. Other common threads emerged from the responses to the first journal prompt including: identifying purposes for collaboration; paying attention to fair distribution of the work load in group settings; meeting different learning styles through group work; and using collaboration to develop other skills. Figure 5 illustrates the changes in the students' awareness and experience with collaboration over the year.

A number of students described collaboration as "a useful tool for learning - a good way to gain knowledge from peers and others on tasks and information you may not previously have had access to" (Terri). Similar explanations about the value of collaboration from a leamer's perspective included: "Discussing ideas with peers is really helpful for me. It helps to clarify for myself how I feel about an issue" (Cheryl); "In my opinion, two heads are better than one. I enjoy using others as a sounding-board or as a resource for information" (Sally); "I view collaboration as an excellent means of grasping new information" (Jason). Overall, collaboration was seen as a positive strategy, although nearly half of the students cautioned that certain safeguards must be in 
Figure 5: Collaboration

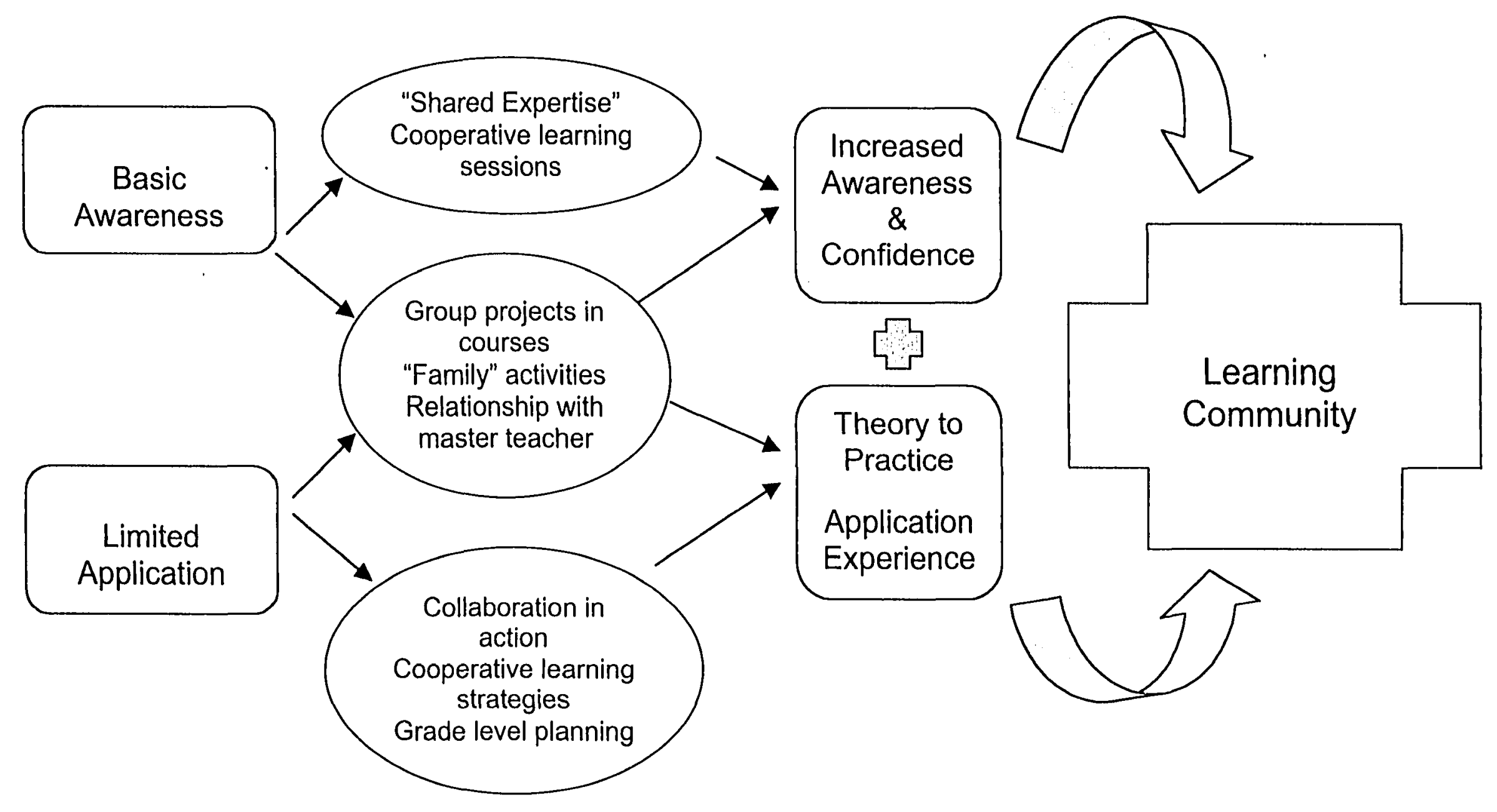


place, e.g., "each individual brings their fair share of work and time to the deeds at hand" (Juanita) and "it makes things easier to collaborate when people are delegated certain tasks" (Carol). The concern with fairness and equity was expressed in a variety of contexts, usually based on an experience that the student had when "someone always got left out or did all of the work or none of it" (Lila). A few students described their personal responses to past group work. "In the past I have almost always done activities on my own to eliminate any problems with others. I seem to take on most of the work load to make sure nothing goes wrong" (Dawn); and "I sometimes am concerned that things could be done a better, quicker way; but I suppose that's part of collaboration" (Nancy). While several students gave accounts of their leadership roles, others admitted that they may not have contributed their fair share of the work.

In college my first experiences working in groups (or partners) I rarely contributed very much because I was somewhat shy. Also, I often felt that what I had to contribute was not "worthy" of presenting. Over the years I have become more confident and I now voice my opinions and ideas. (Cate) It was only in college when I realized the power of collaboration. Since I was so uncomfortable in sharing my thoughts, I felt too anxious to fully participate in the activity. When I got more comfortable, I began to learn more about myself and others and how I learned. (Marisa)

When the students added their comments on how they would address collaboration as a teacher, again almost every student based their intentions on their previous experiences. For example, one student felt that she had received a lower grade in an undergraduate course as a result of being part of a group that did not work well 
together. She insisted that she would "take into account that not everyone in a group should be penalized because there is one lame duck in the group" (Jan). Another student wrote,

As a learner, I know I learn better with others. Everyone has strengths and weaknesses and everyone can bring those strengths to the group, and everyone's weaknesses can be strengthened with others' knowledge and input. As a teacher, I think collaboration is the best resource! Again, everyone has strengths and areas of interest that they can add! (Doris)

It also followed that when a student had not experienced much collaboration, she felt uncomfortable about incorporating it.

As a learner, I didn't have much experience with collaboration until I went back to school this year. I can see how it has positive aspects to it, but I'm still not that comfortable with the idea. As a teacher, I'm not sure that I know how to do it. (Jane)

Nearly all the students referred to how they would use collaborative strategies with their students, and about half of them also referred to ways that they would collaborate with other teachers. Comments about collaborating with other teachers included sharing materials, ideas, and resources. Only three students mentioned their plans to collaborate with families and other members of the community in order to create a supportive environment. When the students wrote about teaching collaborative skills to children, they referred to different learning styles that they might encounter in the classroom. As Terri noted, "In a group, students can share knowledge verbally, in this way it possibly reaches second language students more easily." Further, "those students 
with different learning styles and intelligences can profit from the ideas of others to share and reinforce their own ideas" (Sally). Student comments also focused on the importance of considering different viewpoints in their classrooms. "As being part of a group, a student is able to experience how others think differently from one another" (Mona) or as another explained: "My students should be able to see first hand that different people think differently. The students can also develop a stronger understanding when they have to think about presenting material to their fellow classmates" (Jason).

The intention of using collaboration to nurture the development of other skills was mentioned by almost half of the students. "I think collaboration is essential to survival in the world. It is a basic skill that is often overlooked" (Carol). "I think [collaboration] not only makes learning easier (or more clear) and more interesting, but it also allows the opportunity to develop interpersonal skills, such as cooperation" (Kim). Kim was the only student who referred to the need for these skills in the future "when they enter the workplace." Others had similar comments about skill development.

I'd like my students to have the opportunity to experience the benefits of collaboration. Like everything else, it takes practice to leam how to work together, to take the lead if necessary, to draw something out of a group member. Many interpersonal skills are developed in the process of collaboration, as well as the final product. (Dan)

Students need to collaborate with their classmates. It improves their communication skills, prepares them for group work, and allows them to feel that 
they have something valuable to give to other students. Collaboration will improve social skills. (Cheryl)

I believe that collaborative efforts could create magnificent productions. As a teacher, I would incorporate projects that involve independent projects as well as collaborative projects, to encourage skills that deal with cooperation, leadership, and social awareness. (Marta)

As the cohort members began their first semester of methods courses, they had opportunities to learn more about collaboration. They experienced collaborative learning in at least four contexts: group work required in their methods courses; weekly "family" activities at the host school; the development of relationships with their cooperating teachers; and exposure to collaboration in action with students in their classrooms and with faculty in their schools. In addition, a couple of the "Shared Expertise" sessions addressed aspects of creating community in the classroom. In addition to participating in group projects in seminar and in their methods courses, students attended a five-session seminar to learn more about the use of "cooperative learning" strategies. These interactive classes increased their awareness of collaborative possibilities and provided hands-on activities that they could use with children. Students in the cohort wrote only positive comments about the cooperative learning seminar, describing the activities that they tried with one another, and also the interactions that they had with children.

The team building activities we are doing within our groups are amazing. I've learned so much about the other 5 people in my group since we started and I've developed a camaraderie with them. I am sure that this works in a similar manner with children. (Sally) 
I wish we did some of these activities when I was in elementary school because I really struggled with social skills. Now I know how beneficial these activities are for building a classroom full of well-socialized and cooperative students. (Marisa) One student shared her thoughts after hearing a discussion about "collaborative learning being a fad that would be gone in a couple of years." She related the drawbacks that had been mentioned: "students do not learn as much because they sit back and allow a couple to do all the work; sometimes a leader emerges, takes control and doesn't allow the others a chance." She disagreed that these outcomes were inevitable and wrote that she hoped to learn more about this technique and "how to motivate all students" (Nancy)

Second, the students met weekly with their host school teacher and often conducted community-building activities with their assigned "families." [Note: At this school, elementary students are randomly grouped into "families" to include children from all grade levels $(\mathrm{K}-6)$ and remain in this group with the same teacher for all the years that they attend the school.] One student described building a "web of friendship" in which one child tossed a ball of yam to another child while saying something that they liked about him or her. Not all the cohort students were impressed with the structure. "I like the concept behind 'families' but don't know if I like the way it runs overall. It just seems like the kids don't become as 'bonded' as I thought they would through 'families" (Jacki). After a few more experiences with her family, Jackie modified her opinion.

Each older child is responsible for helping a younger child. I think that this system works out great. The older children like the responsibility and the younger children look up to the older children's guidance. Maybe "Families" isn't so bad. I'm not completely convinced about its success, but I do think more of it now. 
Third, students also had the opportunity to begin building rapport with their master teachers when they attended their assigned schools about twice a week while enrolled in their methods courses. Some discovered camaraderie right away, while others had to work harder at the relationship.

Things are not going so well for me with my master teacher. Yesterday I went to the "Curriculum Night" and everything was fine until my master teacher addressed the parents. She told them of all the programs and I stood in front of the room, helping her with the presentation. She didn't introduce me at all. (Sally)

Sally wrote that this type of interaction had happened repeatedly, but after thinking it over, decided that she had "allowed my insecurities to come forward." She decided to apologize to her teacher. The following week, things improved. "She accepted my apology whole-heartedly and today she seemed to make special attempts to make me feel welcome and needed." On the other hand, when one of the students found out that he would be working with two teachers due to a teaming situation, he thought it would be a "bonus" because,

I can observe, and get feedback from more than one teacher this semester. We sat down this afternoon and did overview planning, we also planned out the first day. I say "we" because they really made me feel a part of the process. I wasn't just an outsider observing. (Max)

Another student in a similar situation found some drawbacks to working with two teachers. "The hardest thing is developing my own style among two different models. 
Their teaching styles are quite different ... I have come to behave under different constraints on different days" (Kay).

By the third week into their student teaching, students were asked to respond in their journals to the prompt, "I'm beginning to feel like a member of my school because . .."For some, the feeling of membership grew from status symbols, like knowing the code to the copy machine or knowing where to find equipment. For others, it depended on the rapport and trust they built with their master teachers. For example, Dawn was asked to complete half the report cards, which made her feel that her opinion was valued. Jane noted that her master teacher "talks to me like I'm her partner in the classroom." Still others looked to student attitudes and responses to help them sense this feeling. This ranged from receiving candygrams for Halloween to being asked by children for help with their lessons. Max summed up the feeling of belonging that many of his peers experienced:

... seeing my name up on the white board under my cooperating teacher's name. Wow! I am one of the teachers in this class. Also, students at my school, who are not my students, recognize me on the playground and at lunch and after school. (Max)

Some students reported that they had not yet experienced feelings of membership. ... considering the recent addition [of another student teacher] to my classroom, I can't say I'm feeling more welcome. S. obviously didn't feel that I was important enough to be an active member in this decision. I feel like I am a convenience and sometimes a hindrance but not a welcomed member of a group. (Alexandra) 
I'm not really feeling like a member of the school, yet. Everyone is very polite and I guess the only time I really feel like a member is when I am in a meeting with the teachers and they are talking about all the different stuff going on in a way I do feel involved. (Juanita)

About a week later, after she described what was an "awesome" week, Juanita wrote, "My relationship with my master teacher is great! He's very supportive and always encourages me to bring in my own ideas. So far he has liked all of the lessons I have planned."

Finally, student teachers had the opportunity to see how their master teachers incorporated or did not incorporate collaborative learning experiences in the classroom. As one student noted after observing the math lesson that her teacher had presented, The class worked in pairs to measure different lengths of tape in the classroom. But V. does NO cooperative learning in her class. So, the children did not even come close to finishing the measuring. I had to intervene when one child was crying because the other would not let her do anything. Here I am aware of the frustration, but this is because the children have never been given the opportunity to really work together. (Dawn) Another witnessed how her master teacher introduced rules and expectations for the classroom. "She asks for the children's input on what rules and behavior they feel are important (Jacki). Early on, students began to understand that collaboration does not just happen. After observing his class's first efforts at collaborative work, another student realized that "the process needs to be discussed and taught" (Dan). Dan had many key 
questions on how to group the children, how to help them define roles and responsibilities, and how to build on each child's strengths.

One student saw collaboration in action among the faculty when the principal at her assigned school announced that a new class would be added. Because all the classrooms were already filled, a former work area was designated for one of the primary classes. Jacki's master teacher's name was drawn out of a bucket, requiring a move from a large room where she had taught for 10 years. "Ail the teachers eagerly helped her and abandoned their own plans for the day. I liked to see this kind of cooperation. The new room now becomes a "challenge" instead of an obstacle" (Jacki).

By the end of the first semester when the students wrote their responses to the second prompt "Provide an example of how you've addressed the four themes in your student teaching classrooms. If you have not addressed them, how do you plan to do so in the spring semester?" Their ideas about collaboration had clearly changed. In their recollections, the students referred to the collaboration they had tried with students as well as working together with their peers and their master teachers. A number of them also had experienced collaboration among the faculty at their schools, particularly with their grade level counterparts. The insights that they shared included recognizing the importance of: using collaborative strategies to meet the needs of mixed ability groups, e.g., "I try to pair up stronger learners with those who are a little bit lower" (Rhonda); teaching the skills required for collaboration, e.g., "It became very obvious to me early on that first graders do not know how to work together. It was my job to teach them" (Doris); and the mutual benefits and responsibilities of collaboration, e.g., "I will 
continue to use the amazingly generous and giving network of people and resources as I hope to add to it as well" (Lila).

Only four of the students listed collaboration as their top priority for second semester, as called for by the third journal prompt. Three students wanted to get more practice, as they had little opportunity to use it in their classroom first semester. The other student referred to her desire for a strong network of support and resources. She also was the only student who referred to the classroom community:

I want to feel more confident in my creation of community in the classroom. With this I am very interested in learning better ways to get parents involved in the education of their children and working with me and their children.

\section{(Alexandra)}

Jane, who had expressed her discomfort about collaboration in her initial entry, demonstrated a change of attitude in this last entry. She noted the importance of teaching children to work in collaborative groups as "preparation for life in the working world." She also wrote about the following benefits:

Brighter students have their knowledge reinforced when they help students of lower abilities. Both groups of students have increased self-esteem when they work in mixed ability groups. In the future, I plan to try more collaborative learning. (Jane)

The methods courses offered during second semester offered even more opportunities for collaborative group work, including working with each other as well as conducting these activities with children. Cate offered an insight early on in the second semester that illustrates the impact of this practice. She noticed a change in her approach 
to collaborative work, noting that before starting the program, she "hated this type of work."

Now, I've found my voice. A quote from the English Language Arts Framework describes what I am experiencing: “... when the thinker discovers that thinking needs to be made public!" I am experiencing by doing the importance of collaborative work. I hope that when I establish my classroom I find many ways to incorporate collaborative assignments often in order to give even the quietest student a voice. (Cate)

By the end of the second round of student teaching, students related many more collaborative experiences. For example, one student stated, "I did a lesson on Greek mythology. I incorporated cooperative learning groups and they all had a presentation. Students in each group had a chance to share their strengths" (Selena). Another student completed a large mural on an outside wall of the school with the help of 150 children. After hearing compliments from the Little League teams who use the school for practice, she wrote, "I realized how I was affecting the community" (Kay). Six of the students had an additional opportunity to teach for one week at a different school due to spring break schedules. Four of these students were placed in team teaching situations and were assigned to conduct a unit on China. They gained first-hand knowledge of the challenges and benefits of collaborative teaching. "Through collaboration, Cate and I have taken the best of both our ideas and organized an interesting week" (Jacki) Cate wrote in her journal that week as well:

Working with a partner has brought me new insight. I have mostly gained confidence. We were able to share the work load, and I am also trying to work 
harder because I care what Jacki thinks of my work. There is an element of peer pressure that makes me work just a little harder. (Cate)

Overall, most students finished the year with what appeared to be a greater understanding of collaboration. They had many opportunities to observe and practice collaboration with children, with their peers in the Block, and with colleagues at their schools. They expanded their definitions of collaboration to include the need for trust, sharing common goals, and maximizing everyone's potential, yet not all of them seemed to grasp the longitudinal process required to create a sense of community in the classroom or in the school.

Diverse leamers. When asked to write about "diverse learners," the cohort members again responded with their own interpretations, as a definition was not provided. Figure 6 illustrates the changes in the students' awareness and experience with diverse learners over the year. In their initial journal entry on this topic, the majority of students referred to the importance of recognizing a variety of learning styles or multiple intelligences and typically identified the styles with which they were most familiar. About half of the cohort also included within the meaning of diversity individuals who spoke languages other than English as well as those who were not white. Only four students, each of whom had previous experience with students who received special education services, specifically mentioned students with disabilities as a component of their definition of diverse learners. Many of the students admitted that they had little experience with students who were from cultures other than their own, but overall, most seemed open to the prospect. Themes that emerged related to diverse learners included the following: personal experiences as a learner; experiences with children who 
Figure 6: Meeting the needs of diverse learners

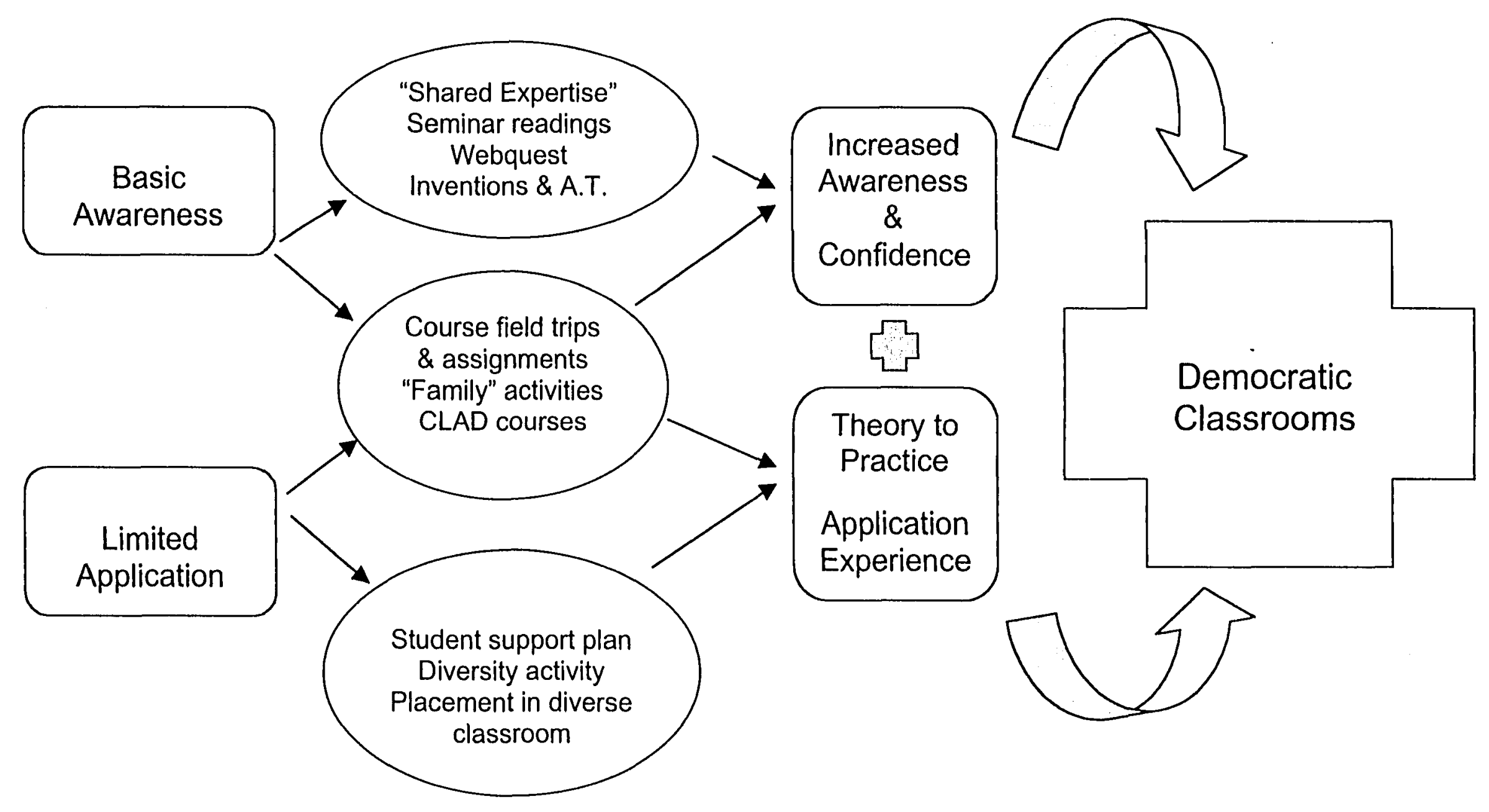


represented their definition of diversity; personal or professional goals to help broaden their skills and experience; and benefits or drawbacks to teaching a diverse group of students.

First, in describing their own strengths and needs as learners, a number of students referred to learning styles or multiple intelligences. For example, "I know how I learn different subjects in different ways so I have the sense that variety is essential" (Carol); "I learn skills by practicing them and going through each step physically" (Max); "I'm a better visual learner as opposed to auditory learner" (Jacki). One student who spoke Spanish as a child described her early school experiences before bilingual programs existed.

I came into the classroom where no one spoke Spanish and the teacher had a very hard time communicating with me. I was pulled out of the classroom and learned to speak by Flashcards. To me that was really boring. Often because I could not understand the instructions, I was not able to do the same activities as the rest of the class. (Alicia)

Second, students described experiences that they had with diverse populations. They wrote about a variety of situations, illustrated by the following entries: "I have spent the past two years teaching preschool in an inclusive environment. It was during this time that I truly became flexible in my teaching" (Dawn); "I have worked as an Instructional Aide and I served students who had been from China, Taiwan, and Puerto Rico. Being there for them and helping them made everything come together" (Selena); and "I have had some experience with cultures and language. I have worked in classrooms with students from Germany, France, Mexico, Ethiopia, Africa, Arabia, etc." 
(Terri). Several commented that they had little or no experience in this arena, causing them some anxiety. Even Selena, who had described her work positively as an Instructional Aide, commented "I do get nervous when a child and I cannot communicate well." The following entry indicated even more discomfort.

I'm not that comfortable with how to handle students with a lot of different backgrounds. It seems like it would be distracting to me and everyone in the class if you have to do a lot of reteaching to the various groups to keep everyone together. (Jane)

The majority of the cohort did not have personal experiences with diverse learners; however, they wrote about goals or strategies that they might use when faced with their own diverse classroom. For example, Jan planned to use a holistic approach, trying a "variety of ways and materials to teach all children, while considering each student's individual background." Kay noted a similar intention to utilize different methods, but also pointed out the necessity of "creating a comfortable space for individuals to find out how they learn the best." Some students were more specific about their goals, such as Kim's desire to learn Spanish and to have "a lot of multicultural resources and themes." Kim added that she wanted "to value each child." Lastly, Jamie described the importance of incorporating her own learning styles.

By nature each of us is different. I know how I learn and I will be very kinesthetic in my classroom. I will also investigate methods to use so my nonkinesthetic students will be able to grow and learn as well. (Jamie)

The last theme that emerged throughout this first writing was about the perceived benefits and, in some cases, drawbacks of diverse classrooms. Most described the 
contributions that each child had to offer because of his or her unique set of talents or strengths, e.g., "Diversity will make my class more interesting. It caii! help people to respect other cultures and interact with them" (Cheryl); "Each child is gifted in some way. Hidden or not, as teachers, those talents need to be challenged to grow!" (Marta). Although there were a handful of students who expressed some unfamiliarity or discomfort about their inexperience with diverse learners, only one student seemed to question the underlying philosophy:

I did not notice as a child that children learned in different ways. All I remember is that I was told to listen, then do what was instructed. Now, as an adult, I hear often about instruction that caters to learning intelligences, special learning disabilities and attention deficit disorders. I often wonder how children from my generation and before made it through school, or even life. I hope that we are going in the right direction and not just making excuses. (Jill)

Over the next several months while the student teachers attended courses and became familiar with their student teaching classrooms, they were exposed to scenarios that challenged them to expand their thinking about diversity. They met diverse groups of children in their schools and started to ask more questions about how to meet their equally diverse needs. As noted previously in the section on the context and culture of this cohort, a great deal of anxiety was expressed about classroom management issues. This topic was addressed throughout their journals, sometimes relating to aspects of collaboration and community, but more often in terms of grouping and "tracking" children according to ability, and questioning how rewards, punishments, and control 
were used in the classroom, especially given the range of skills and challenges that the children brought to the group.

Students were also introduced to materials that addressed multicultural and diversity issues. For example, in seminar one day they read a short story that stimulated an emotional discussion about growing up with the responsibilities of helping to raise younger siblings. That led to further debate about the assumptions and judgments teachers often make about the children who come to their classrooms. As one student described, "It was interesting how many different reactions everyone had to the story. It took on a whole new meaning when you read it out loud to us-what a powerful activity to do as a group!" (Jan). Second, when the students completed the last part of the Webquest assignment that required them to explore a specific website about diverse populations, many of them wrote their reactions to this resource. One of the areas that caught the attention of the students was the information on gender issues in education. As Dan wrote, "I read an astounding statement - girls begin to go underground with their talents and abilities sometime between fifth and sixth grade - Go underground!" He continued with other examples from this site, and ended, "Just by being a male do I subconsciously add to that pressure? I don't think so, but I'm sure as hell gonna be more aware of it!" Others made comments about other areas that they had explored, including gay/lesbian issues, students with disabilities, African-American culture, American Indian culture, and more.

Additional assignments related to classroom management strategies directed the students to design engaging lessons to prevent discipline problems and to create safe environments for all their students to learn in whatever way they learned best. 
Combining the principles of collaboration as well as paying attention to the diverse needs of children, the cohort students were challenged to consider their roles in balancing power in the classroom. Over and over they wrote about feeling the need to be "in control" of the classroom. They wrote reactions after a read-aloud of The Children's Story (Clavell, 1981), a short but powerful book that stimulated thoughtful journal entries, such as Lynn's reactions. She wrote that teachers "have so much influence over kids and must be careful not to take advantage of that." Dawn realized how much impact she was likely to have on each child. She continued,

It took less than 30 minutes to brainwash all the children. Children trust so much and this can be so easily distorted with a little coaxing. A teacher can make or break a child's whole life and thought process. The children's lives are basically in your hands as a teacher. (Dawn)

Additional assignments related to classroom management included developing student support plans that took into consideration all aspects of a child's life and environment. The cohort was presented with books and videos detailing different approaches that challenged traditional systems of rewards found in many of their classrooms. "Shared expertise" sessions (conducted weekly by teachers from the host school) for first semester also included topics that addressed diverse learning needs, e.g., interactive book reports using a range of formats, and integrating music, dance, and movement into the curriculum.

By the end of the first semester, the meaning of diverse learners as reflected in student responses illustrated a significantly deeper level of understanding. New categories of diversity were added, including children from different socioeconomic 
levels, children with health impairments, and those from various religious backgrounds. Students identified the range of diversity they encountered in their student teaching classrooms, which reinforced for them the need for using a wide range of strategies and accessing multicultural materials. They wrote about observing or implementing grouping strategies that included working individually with students who needed extra help or extra challenges; pairing students with complementary abilities; arranging students according to abilities, multiple intelligences, or interests; and grouping children randomly. Most commented on the need for flexible grouping approaches designed to meet different purposes or provide specific instruction.

After looking back on their coursework, assignments, and student teaching experiences, the cohort students in response to the second prompt listed many strategies that they had used to address the needs of diverse learners. Strategies included the use of complex instruction, multiple intelligences, modeling, building on children's strengths, communicating with parents, and providing a balance of structure and freedom. Students also included detailed descriptions of the children in their classrooms. For example, Sally's classroom included many children from "other than European (white) backgrounds, including students of Hispanic or Asian backgrounds." She also had at least five students who received special education services. She displayed respect to her students by "always addressing students in the way they want to be addressed." In addition, Max discovered that "reaching diverse learners may be one of the most difficult challenges teachers face on a daily basis." He found that "presenting lessons from a multitude of perspectives and in a variety of ways" was essential for meeting the needs of 
all students. Lila shared the following example regarding students who spoke languages other than English:

I have learned how to make sure the needs of second language/culture students are met in my classroom and in my family and how to highlight different activities and experiences so that everyone really shines their brightest at least once or twice every day! (Lila)

One student's entries demonstrated that some myths had been dispelled about the expectations for students who attended school in a lower socioeconomic area. Doris discovered that "students worked just as hard and they were just as smart" as the children who attended a school that had many more resources. She also realized that for some children, "being at school was the most stable and safest environment in their life." Moreover, Doris felt responsible for ensuring that "all students have the right to the best education that I can give them, no matter what 'side of the tracks' that they come from." When asked to identify their priorities for second semester, five of the students wrote that they wanted to focus on better meeting the needs of diverse learners. Jill, who had wondered at the beginning of the semester "if we are going in the right direction and not just making excuses," seemed to take another look five months later:

I think the area that I most want to work on is diverse learners. I am interested in learning and incorporating skills to reach as many students as possible. I also want them to be able to reach their goals. (Jill) These five students asked for more examples of how to accommodate the needs of all their children, were eager to see more videos and materials on the topic, and generally wanted "to reach as many students as possible in the best possible way" (Terri). 
When the second semester was underway, the students were more focused on multicultural issues and strategies for meeting the needs of their students as a result of course content, assignments, and activities. Specifically, they enrolled in the Social Studies methods course, attended three arts integration sessions, read and viewed more thought-provoking materials for seminar, and observed the way in which their cooperating teachers addressed diversity. A number of students also took additional courses to meet the Cross-Cultural, Language and Academic Development (CLAD) emphasis of the credential (included two required courses not scheduled as part of the block). In their journals throughout the first half of the second semester, they described experiences from Social Studies that had raised their awareness significantly. The following entry was written after the first class meeting that included a field trip to see a movie about slavery:

In our brief discussion about the importance of Social Studies, I learned a lot about [the instructor] as a person. She believed that in order to learn about our environment, we need to be out there to see and experience it. What a refreshing idea to hear from a teacher. Now, as a teacher, I know it is my responsibility to help children understand our past and how we can better our future by understanding our past. I can't avoid sensitive issues anymore because it hinders me from growth in all aspects of life. (Marisa)

In addition, the students attended three seminar sessions that offered materials and activities for integrating the arts (e.g., fine arts, music, drama, dance) throughout the curriculum. Not only learning about, but also experiencing these techniques served to raise both their confidence and competence. As one student described, 
I really enjoyed working on the performance. I've learned that through music, art, dance, drama, and other creative expression you get a full experience from a cultural perspective and you can empathize with people from other cultures. It was therapeutic also. (Cheryl)

Other second semester assignments included sharing their reactions to videos and readings that prompted some insightful entries in their journals. One day they saw a presentation about assistive technology devices and inventions that were used to support students with disabilities in general education classrooms. In addition, they read a vignette from a book called Bus People (Anderson, 1995), about a young woman with a disability named Rebecca who had been excluded from her sister's wedding.

Stories like this cause me to get upset but I think it is important to read things like this. I could never be like the people around Rebecca. I had an aunt who was severely retarded who lived next door when I was growing up. (Jason) The story is relevant to us as teachers because it should be a reminder that we should never set lower goals or expectations for certain students. Students with special needs shouldn't be treated differently or negatively because those students can achieve just as well as any other student. (Lynn)

When the students described the activities, curriculum, and particularly, classroom management and grouping strategies that they were observing in their classrooms, they often struggled to reconcile the concepts that they were learning in university coursework with the practices they were seeing in schools. Some of these entries included comments about reward systems and special services. For example, Lila described the incentives that her teacher used for children who solved puzzles most 
quickly. Lila thought that the children "would be just as excited to do the games (if not more excited) without the rewards. Not recognizing the first to solve puzzles would respect individual pace and ability." Other students also became more aware of the pervasiveness of reward systems in schools. Kim stated that she preferred to "intrinsically motivate children to want to learn." She continued with the following insight: "I know these may be the high hopes of a wide-eyed student teacher, but it just doesn't seem like reward systems are necessary, especially for the younger kids who want to please you anyway." Referring to another practice observed in many classrooms, Carol questioned the benefits of removing children from classrooms for special services. She noted how much is accomplished in one day, despite all the "added interruptions. You know I often wonder if pulling students out for RSP (resource services) is really beneficial!!"

The final assignment that the students were required to complete during their last round of student teaching was to teach a lesson from Activities for a Diverse Classroom (Katz, Sax, \& Fisher, 1998). They had the option of taking a lesson directly from the book, modifying a lesson to better fit the age level or specific needs of their children, or creating their own lesson that addressed similar issues. The main goal was to open the often difficult discussions about acceptance, tolerance, and understanding of one another's differences and challenges, and to do it within the framework of the core curriculum. In other words, implementing this activity was designed to build the comfort level of the student teachers so that when they have their own classes, they will think about using these activities throughout the year, not just on a special "diversity" day. Most of the students felt that the activity was successful and realized the benefits that 
such discussions might have when done on a regular basis. After conducting a lesson that required children to identify their strengths and goals, Dan wrote that not only was he happy with the results, but "the kids loved it." Dan referred to the way in which he talked with his sixth grade students about "how a person's strengths might enable them to accomplish goals." That led to more discussion about everyone being unique, and that “each person has different interests and abilities, and matures at different rates. It doesn't make anyone better or worse, just different. A person's goals will often reflect one's maturity as well as one's interests."

Topics addressed by the activities included friendship and the characteristics that friends should have; identifying unique qualities and being accepting of those differences; communication skills and how to express one's feelings; and the power of language, especially when it was in the form of insults and name-calling. Some of the students customized the activity to address concerns in the classroom. For example, one student teacher had a new child from Japan in her class who was having a hard time adjusting. According to the teacher, "other students are not taking into consideration how difficult these changes are for him" (Jill). Another situation prompted Lila to implement an activity on friendship, "because they have been having a difficult time getting along with one another for the past couple of weeks." Max chose a specific activity because of "four or five students who I am continually talking to about being respectful of others." He chose an activity that required his sixth graders to creatively and collaboratively solve a problem, using each of their individual strengths and talents. He concluded that "most of the students got the message" and enjoyed the activity. Jan created her own activity, 
"The crumple doll story," to demonstrate the long-lasting effects that insults can have on people:

I told a story about Amanda (a large paper doll) and how people were making fun of her. With each mean thing that was said, she crumples up a bit more. I based all of the "mean comments" on what I have heard during the past few weeks in my classroom. The students really looked sad as Amanda kept crumpling with each mean comment. Once Amanda was a ball of paper, I gave her a "friend" who gave her compliments which resulted in her "uncrumpling" bit by bit. As the students caught on to giving compliments, they started smiling again and began offering compliments to help uncrumple Amanda. Then we talked about how the wrinkles were like scars inside of us that you can't see but they are still there. We all still remember the mean things. (Jan)

Even at the kindergarten level, the children understood the concept and had an opportunity to put it into practice when one of their peers came to school the next day with new glasses. "No one laughed at him at all. Everyone told him how nice he looked! This was a great diversity activity."

Generally, the students in the cohort seemed to have broadened their understanding of diversity. They implemented a variety of strategies in the attempt to meet the wide range of children's needs. They seemed to understand that it was their responsibility to accommodate their children, not the other way around. Once again, more experience led to a higher confidence level which in turn built their expertise in this area. The students sounded much more impassioned about this area in their group 
interviews than their writings indicated. The discussions are described in the final section of this chapter.

Reflective practice. When asked to write about their interpretations of reflective practices, over half of the students (19 of 28 ) in the cohort wrote that being reflective either "comes naturally," "is part of my nature," or is "something I always do." While one student seemed to have misunderstood the concept (she wrote about reward systems), the remaining eight students either expressed some discomfort with the process of being reflective, little understanding of the process itself, or were inexperienced with implementing the practice but interested in learning more about it. In addition to describing their experience and comfort level with reflective practices, the students' responses to the first journal prompt could be organized under three major themes: the purposes of and vehicles for reflection, the ways in which they might employ reflective practices regarding their own teaching, and how they might teach these skills to children. Figure 7 illustrates the changes in the students' awareness and experience with reflective practice over the year. The following examples provide a baseline of their level of awareness and experience as they began the school year.

First, of the 19 students who had referred to reflection as a familiar routine, almost half of them mentioned using journals as a vehicle for this practice. At least three students shared that they kept personal journals, and a number of them referred to journals that they had kept for other classes. They also explained that whether they wrote, talked about, or just thought about their actions, reflecting served many purposes. For example, it helped them to "sort out what happened that day, my thoughts about it, and how I could improve my actions or attitudes" (Cate); "to think of things in the big 
Figure 7: Reflective practice

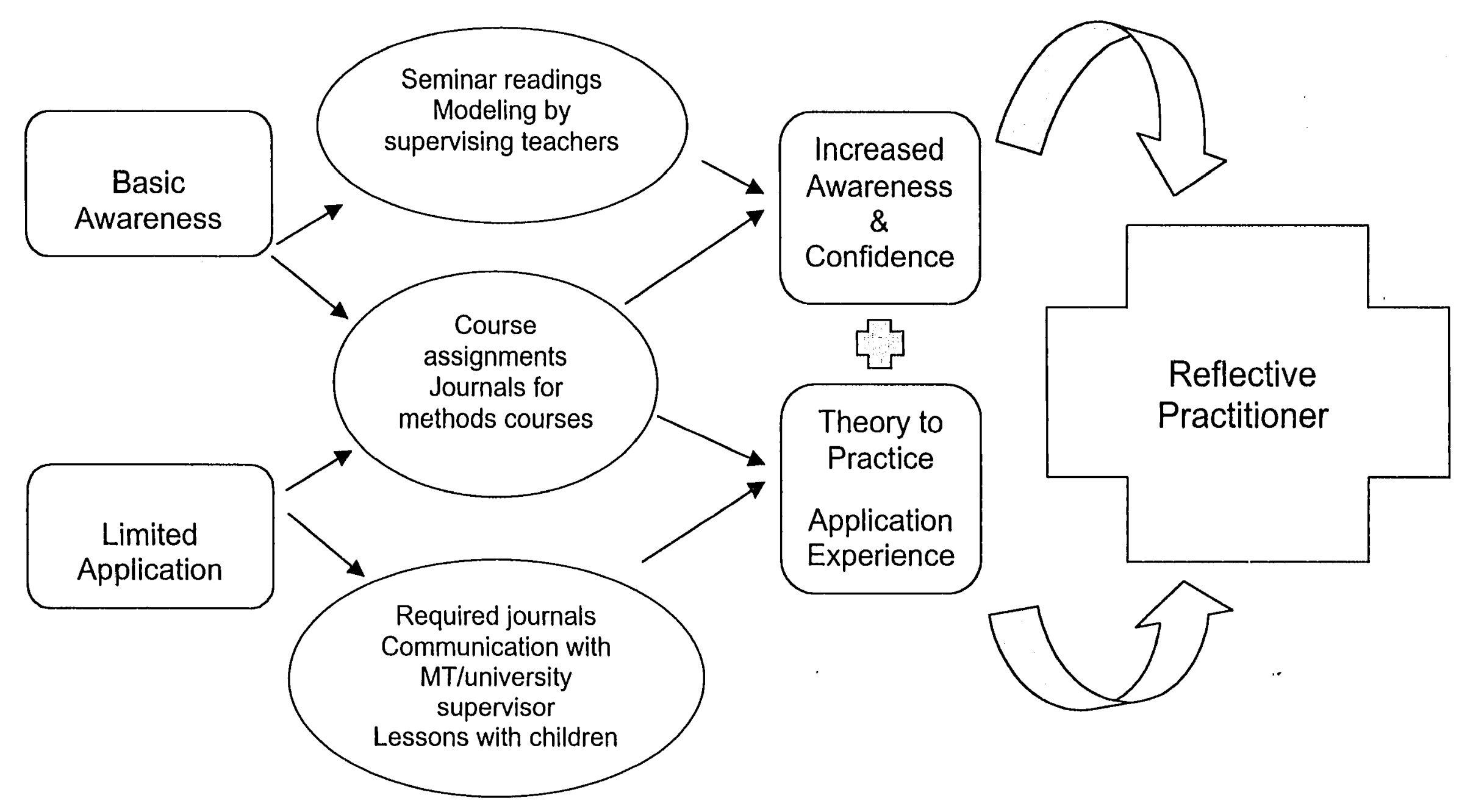


picture" (Kay); "solidify ideas and questions in my mind" (Alexandra); and "internalize what I have learned and experienced" (Marisa). At least three of the 19 also admitted the tendency to become overly critical of themselves during reflection, "picking it apart for the good and the not so good" (Dan). Overall, reflection was seen as necessary and beneficial in order for them to improve as professionals. All students, including those who were not as familiar or comfortable with the concept or practice of reflection, acknowledged its value.

Second, entries that described their intentions for using a reflective approach as they began teaching included the use of it as a "tool for my learning and teaching, to look back to find patterns, things that worked and didn't work, and as a good measure to see improvement" (Nancy). Others expressed similar intentions for using reflection as a method for evaluating their teaching on a continual basis, e.g., "I will need to pinpoint where problems arise and modify my instruction at that point" (Jason).

Third, most of the students referred to the importance of teaching reflective practices to their future students, "as an important piece of language development and self awareness" (Max); and "to give students a chance to decide how they feel about things and to give them a chance to form opinions" (Alicia). While referring primarily to the use of journals to encourage reflection, several students were interested in finding additional methods to use for expressing their thoughts and reactions. Most of the students wrote that they were eager to learn more reflection techniques to use for their own professional development as well as for teaching children.

Students in the cohort were required to keep journals throughout the year as an assignment for the seminar. At the beginning of the semester when students were visiting 
their student teaching classrooms once or twice a week, the journals were filled mostly with accounts of events that occurred during the day. For example, entries described schedules, specific lessons, instructional strategies being implemented in the classroom, as well as comments about activities and assignments from their methods courses. One student began to question early on the discrepancy between the "do as I say, not as I do" approach to teacher training.

It's crazy (and wonderful) how many times we've read and have been told to make it real for our students. Don't teach skills in isolation - build on prior knowledge - involve students in active learning - don't stand in front of the class lecturing - don't teach how to do $\mathrm{X}$ without applying it to $\mathrm{Y}$ and providing handson $Z$. These ideas are ingrained in my mind forever. It seems as though our teachers have some trouble keeping these ideas in mind when teaching us. (Lila) Another category of entries included descriptions of their newly developing relationships with children, cooperating teachers, administrators, and their peers (see also Context and Culture of the Cohort). Most were eager to describe their initial interactions with children and were very honest about the success and failure of these attempts. As students began teaching lessons, they described the results, e.g., "I taught the first solar energy lesson. I learned that I should script the entire lesson and give over-explicit directions, rather than relying on a basic lesson plan and the outline in the science kit" (Jan); “Today's math lesson was AWFUL! I just gave them too much information - too much for a first grader to handle" (Rhonda). Another student described her first attempt at leading a creative writing lesson. 
It went pretty well, but I know there are lots of things to improve upon too. I think I did a pretty good job this time of setting and stating my expectations and objectives and modeling. I think I could have explained what I wanted them to do more clearly, like how much or how long I expected them to write, whether they could write on more than one topic, what to do when they finished. I think writing out a lesson plan would make me think through everything better. (Kim) A third category included impressions of the philosophy of the school or the implications of certain rules that the school imposed. For example, after accompanying the children on a field trip, one student described her frustration with the "no talking on the bus" rule.

The children wanted so much to talk and comment about what they had seen during the field trip. I learned in my communication disorders class that children need to practice talking and conversing with each other. Bus rides are great places for great conversation that would give children better speaking skills. (Selena)

Many of the assignments they did for seminar or for their methods courses required them to take a deeper look at the implications of their initial impressions. As detailed in examples in the previous sections (e.g., technology, collaboration, diverse learners), they were asked to think about all these topic areas in relationship to their continuing professional development. These thoughts occupied more than class time, as the following entries illustrate:

I had some heated debates about education over the weekend. Topics that came up included voucher programs and whether to use cultural identity to shape the 
classroom or to make sure the class is equal for all, ignoring the element of culture. I can tell these are issues where I need to clearly internalize my own philosophy so that I can defend it! (Kay)

One of the students attended a reading seminar with her cooperating teacher. Being the only student teacher in "a room full of experts," she felt a bit intimidated but was also reassured that she was familiar with the assessments that were being discussed. She added,

I can see the difference between student teachers' ideas and thoughts and feelings and those of seasoned teachers. I am sure you are thinking "duh!" but the ambiance and mood here are so different. I hope when I am twenty years into the profession I have somewhat the same emotions for teaching. (Jamie)

When they began the first eight week session of student teaching, each cohort student was assigned a university supervisor who observed them weekly. A total of five supervisors assigned by the university participated in this block. Students did not necessarily have the same supervisor first and second semesters and only two of the supervisors worked both semesters. Supervisors were assigned randomly to student teachers, but typically were responsible for all the students who were placed at any school. The supervisors observed weekly and set up initial, midterm, and final triad meetings with each student and his or her cooperating teacher. Supervisors also completed a final evaluation at the end of each semester in collaboration with the cooperating teacher. Supervisors were expected to engage in a "reflective supervision" model with student teachers that included the following components: pre-conference to clarify objectives; direct observation to document lesson delivery; lesson analysis to 
reinforce strengths and identify target behaviors to change; post-conference to encourage reflection and provide feedback; and post-conference analysis to plan self-improvement. As they began developing relationships with their supervisors, students had more opportunities to engage in reflection with added support. Entries about their supervisors' visits included positive descriptions of the interactions. The students received encouragement, compliments, and constructive comments. After conducting what she described as an "outstanding" lesson, Marta wrote that "both my master teacher and supervisor wished they videotaped me doing this lesson."

As student teaching began, most students continued to write summaries of the day's events. In attempting to provide some reflection on their performance that day, most entries included basic evaluations, including comments that certain lessons had gone more smoothly than they had expected. For example, Doris noted, "It went pretty well for my first time - that's the point of trying all of this - and I'm trying!" On the other hand, they were honest about lessons that were not as successful: "I started teaching PE on Friday and that went, well, not so good" (Juanita). After the first week or so, entries indicated that students were considering causes, effects, and motivations as to why the behavior of the students seemed to be different. Jane stated: "The honeymoon is over! These students were really good for a few days and now they've got to test me to see what they can get away with." Max realized that he needed to modify his own behavior by "talking less at the children." He hoped that "those classroom management skills will come as I have more practice." While students made attempts to be more reflective about their teaching, the majority of entries consisted of more summaries than reflections. 
When the students responded to their second journal prompt near the end of the first round of student teaching, it seemed that they had developed more of an understanding of reflective practice and stated that they were using it on a regular basis to analyze and improve their teaching. None of the teachers wrote that they needed more information on the definition or practices associated with reflection. Over two-thirds of them claimed to engage in reflective practices after every lesson or at least every day, some on their own via their journals while others wrote about discussing their reflections with their master teachers or university supervisors. One student even wrote, "I have sleepless nights because of reflecting, reflecting, and reflecting on my day's work" (Selena). Some students offered techniques that helped them to improve their reflective practices. The following examples illustrate the changes in their skill levels as they mastered techniques for reflecting on lessons and on other classroom situations:

I made it a habit to reflect on each and every lesson that I taught. I always asked myself the following questions: How did the lesson go? Did I meet my objectives? Did the students meet my objectives? Would I do the lesson again? If so, what would I change next time? How could I make it better? (Doris) Every time I teach a lesson, my master teachers encourage me to write in my journal. I'm to find three positive things that I did, and list three things I need to work on. After the lesson or after school, my teachers sit down with me and we go over my journal. (Terri)

Only three students described the practice of "reflecting during the lessons to assess for understanding" (Marisa), demonstrating "reflection-in-action" that Schön (1983) described. 
As a teacher, reflective thinking has helped guide my decisions, practices, and attitude. As I teach a lesson I can think to myself which components are creating success and which components are preventing it. I can then act on these reflections and prevent further incidents of weakness. (Jacki) This is an aspect that I have incorporated into my lifestyle. Recently, during a math lesson, the concept was not getting across the way I felt it needed to. I reevaluated the presentation and changed part of the activity to better suit the students. (Jamie)

While all of the students referred to their own development of becoming reflective practitioners, only four mentioned using this approach with children. Each of these students mentioned having observed the use of journals in the classroom to reflect on a specific lesson or activity.

When the group was asked to write about their priorities for second semester, one student co-listed "reflective practice" with "technology," claiming that she wanted "to write about what worked and what didn't" so that she would have a "visual reference" as a record (Rhonda). Only two other students placed reflective practice at the top of their lists. Their reasons are as follows:

I should work on all four [themes], but the one I will focus on the most is reflective practice. I feel like I didn't do enough reflecting last semester and I don't go deep enough into why I feel the way I do at times. (Cheryl) This semester I will work on reflective teaching. This means that I will dutifully spend time writing my reflections and analyzing my accomplishments and my weaknesses. Even though I wrote a great deal of notes last semester, I did not 
spend much time analyzing my thoughts. I believe that when I write, I learn. (Sally)

During the second semester, students did not write as many entries as they had during first semester, but overall, their journals included more of their perspectives and less running accounts summarizing their day. They compared their new student teaching classrooms and schools with the placements from first semester, as reported earlier in the section, Context and Culture of the Cohort. The remainder of the entries included employment-related issues (e.g., attending career fairs, applying for jobs, going through interviews); reflections and evaluations of specific lessons or interactions with children; and indications of developing their own approaches to teaching and classroom organization. While the employment-related issues did not involve much reflection, the entries written about the success and failure of lessons demonstrated that they were improving their ability to view their own teaching with increasing objectivity, building on skills acquired during the first semester. The major difference noted this semester related to the ways in which students developed their own approaches to teaching and classroom organization. Sub-themes that emerged included: a sense of taking responsibility for their own learning; and further development of their own philosophy of education. Taking responsibility for their own learning is illustrated in the following entry, written after a student had questioned the appropriateness of her placement. "I have come to the conclusion that my own personality and attitude are going to be what makes or breaks this experience" (Dawn). Another student came to her own realizations.

I am really starting to change my focus from myself (what I'm learning, teaching, what I did right or wrong) to a more child-focused mentality. I am now trying to 
think from the child's perspective. I am now free to really devote myself to teaching $\rightarrow$ facilitate learning. (Cate)

Some of the students shared thoughts that demonstrated their attempts to "make sense of an uncertain situation that initially makes no sense" (Schön, 1983, p. 40) by evaluating the actions they observed in their classrooms as compared with their own evolving educational philosophy. Max could not understand why his "master teacher hands out candy like it's going out of style." Max thought it was odd because, on one hand, she was using "modern ideas like picking playing cards to call on students with new math ideas," but on the other hand, she was "feeding kids sugar for random correct responses to mental math questions." Other students made similar observations about other discipline issues. For example, Juanita described the discipline plan at her school as relying on a "a lot of public humiliation, the raising of voices and putting kids in the corner." She also noted that "once a child is labeled difficult, that child is seldom given a chance to really change." Juanita hoped that she would not be forced to employ such practices, writing that, "I hope though that as I get older, I won't let exhaustion and frustration make me lash out at my students." Lastly, Marta provided another perspective of how she had decided to handle her less than perfect classroom.

I'm beginning to like the classroom more. I think my attitude toward it has changed my perspective. This classroom of disorganization and undisciplined children can only better me, because it will allow me to figure out how to work with this class when I finally have the classroom to myself. It may be good that I don't have such a perfect classroom this semester. I think it's a blessing in disguise ... (Marta) 
Because all students were required to maintain a journal throughout the year, they had the opportunity to demonstrate their understanding of reflective practices simply by writing entries. Their ability to engage in deeper reflection, or reflection-in-action, was illustrated by the way they wrote observations, expressed opinions, presented questions, and generally made sense of what they were seeing and doing. Their own recollections of their reflective practices were more detailed during the group interview sessions, described in the next section.

\section{$\underline{\text { Realizations in Retrospect }}$}

At the end of the semester, four group interviews structured around five questions were conducted with the cohort related specifically to the application of the four strategic choices: technology, collaboration, diverse learners, and reflective practice. Students were given the opportunity to contemplate their professional development year and to articulate ways in which they had incorporated the four core areas into their internships. They were also asked to discuss ways in which they planned to do so as future professionals. This forum enabled students to express themselves verbally instead of writing in journals, as they had done throughout the year.

As they discussed each of the four core areas, many students came to new or different realizations than ones that they had described in their journals. Hearing from their peers often prompted them to remember additional incidents or insights. By "looking at the big picture," they were able to synthesize what they learned from a different perspective than writing about their experiences and reactions on a daily basis. The findings from the interviews may be more easily understood by categorizing comments into two time frames: how they had experienced the four core areas (i.e., 
recollections), and how they intended to incorporate them into their professional lives (i.e., projections).

Recollections. All of the students spoke enthusiastically of the successful ways in which they experienced technology, collaboration, diverse learners, and reflective practice. They provided dozens of examples of specific lessons, interactions, responsibilities, and opportunities from both semesters that related to one or more of these core areas. Across all the discussions, two themes emerged that seemed inherent to all the accomplishments that they described. The first was the sense of confidence that was reflected in their conversations. The cycle of confidence and competence building on one another was clear: their confidence increased with their experience, their successful experiences opened doors to acquiring new skills, and their confidence continued to grow. They gave examples of skills they had mastered, support they had received from colleagues and mentors, and strategies for incorporating others' recommendations into their own teaching styles.

Some students provided examples of confidence as related to learning skills in specific areas, like reflective practice:

And now that I have a second semester behind me, it's much easier to think about how I didn't like the way that something went, that it could have gone better, and to think that right away. Where last semester, it would take me a little longer to reflect on what went wrong, but now I can see easier what goes wrong and save it beforehand. (Group \#1)

I think I'm really good at looking at what I did, and in my head I'm just saying "next time I'll do this, and this." Every single thing I do, no matter how tiny, 
even if it's a little transition thing, or anything. I can always see so clearly how I could have done it differently, and how to make it that much better next time, next one, next one. (Group \#4)

Others were dismayed about the underutilization of technology but demonstrated their confidence by instructing their cooperating teachers, e.g., "I' ve sparked my master teacher into being interested in technology and using it in her classroom" (Group \#3); and My master teacher knows nothing about computers. She barely even knows how to do any typing on the computer. So, finally I've been trying, it's taken beating down the door a lot, just these last two weeks, she finally decided that she really really likes me. But, the kids all had to do mission reports. I told her, why don't you have each kid bring their report that's written and write it on the computer? So now I've noticed that she's letting them go on the Internet to look up about mountain men, so I thought, light turning on for her! (Group \#4)

Some students found out that their predictions about learning technology strategies from students came true. As one of the students in the first interview group explained, "Sometimes it's easier to learn from a child because it's in easier terms." Others echoed this sentiment.

I'm learning a lot about technology. I was never the big computer whiz before, I could basically just survive on Microsoft Word before. And now I'm getting a lot more familiar with the programs, like Publisher and Student Writing Center because I implemented an activity in which six newspapers are occurring in the classroom for 60 children. And so it's been a big learning experience for me because I had to learn from the students themselves, the whizzes of the classroom, 
which I think is fine for me to tell them that I don't know how to do this and I need to learn from them. (Group \#1)

Many students referred to their confidence boost as a result of the support and encouragement from their master teachers and university supervisors.

I think that just being in this environment with my master teacher, compared to where I was last semester, has been really successful and I've gained a lot of self confidence and a lot of confidence in the classroom because she has high expectations. Attainable high expectations. But you know, you work towards what she expects and in my last classroom, I don't think my teacher had quite such high expectations, she expected me to fall on my face. (Group \#1) I think that reason that I'm able to feel [successful] is because I had feedback. I had reflections from the people who watched me, my master teacher reflected on my work, my advisor reflected on my work, people told me how they felt, they told me specifically what they felt I was strong in. (Group \#3) I think the supervisor, our supervisor this semester is so wonderful that I think the interaction is there more, he's there all the time, he's very supportive. He really encourages the honest interaction and I think that's one of the successes that this semester compared to last semester for me too. It's that interaction, he encourages us to do that reflection. (Group \#1)

These students had enough confidence to "pick and choose" from the strategies they had observed, and felt comfortable asking for more information. Several students from Group \#1 noted that collaborating with other teachers did not necessarily mean that they were in agreement with everything the other teachers did. Each felt that she would 
be able to "take the best parts and then incorporate our own ideas." As students recognized their own levels of tolerance for noise or activity levels, they realized that as teachers, each of them would set their own standards. In addition, one student described her heightened confidence related to asking for help.

I think most of what I've used in my classroom at this point, is because I've gone out and asked or I've seen, because of interest or seeing what's out there and say, how do you do that? I'm not afraid to ask questions. (Group \#3)

A student from Group \#4 described her new level of confidence, and attributed it to successful experiences. She commented that she felt confident even when "the principal brings in five parents and a couple of teachers at the same time into my classroom and I continue going on with my work." In response, another student in the same group revealed her source of confidence:

All the teachers at least once a week get together and they share everything and it's been a really good experience, because now that I've taken over the class since my master teacher's out, they treat me as their equal and they like my ideas and they're using them in their classrooms as well, so it's been a really good experience. (Group \#4)

The second theme that emerged emphasized the importance of relationships as the students progressed toward their professional goals. Tied closely to their sense of confidence, they referred to a variety of relationships, including those they had with each other (peers), their master teachers, university supervisors, children, and other faculty in the schools. One student from Group \#3 discussed the support and materials that she received from her peers to get started in a new grade level. She also referred to the 
cooperation that she received from teachers who were in the same grade level at her site. Another student in that group did not limit the creation of a potential support network to her school. She stated:

You don't have to restrict yourself to collaborating with the people at your school, you've made a lot of connections through this last year so those are still people that you will know, and we have our block stars list of the people in our block. All the teachers that you have worked with and made connections with, those are people that will collaborate with you if you don't have a lot of support. (Group \#3)

Many also talked about the importance of teaching children to build and value relationships, and that creating a sense of community in the classroom had to start early and be nurtured throughout each year. Some of the ways in which the students thought about helping children build relationships with one another included facilitating cooperative leaming, cross-age tutoring, and conducting activities that would help create a safe and secure environment. For example, a student in Group \#4 described an insect unit that she designed with "sixth graders coming in teaching the lessons to the kindergartners. The sixth graders were so patient and so wonderful with the kids. It was nice to see them working in the groups and rotating and doing it all together." Several students from Group \#2 also talked about the importance of building a positive environment from the beginning of the year. One of them commented:

If you start these kinds of activities in the beginning of the year, at this time of the year they're going to be working more as a team, they're going to be over the 
silliness stage, and working better. They're going to be cooperating rather than fighting. (Group \#2)

Projections. When students were asked about intentions for incorporating these four core areas into their own classrooms, there seemed to be no question that "these themes will ensure success for us in the future." The following examples indicate their intentions of "making them a part of the classroom, by incorporating all of them into all the subject matter and into everything you do everyday" (Group \#4).

I think that we've already found the ways that we're going to implement them in our classroom, and that at this point, it's a matter of how will you continue to commit yourself to maintaining these values in your classroom. (Group \#3) See, I think for me they are already there. I mean they are already part of, that's the way I work now. I am already collaborating and I know strategies to improve collaborative skills with my students and with my colleagues. Reflection happens automatically, to write it down is really useful for me at this point, you know, but reflection is totally already there. (Group \#3)

Other sub-themes that emerged included the intention to pursue their professional development; maintain and build their personal and professional networks; as well as consciously incorporate all four areas, that is, employ the use of technology ("Technology is definitely going to be part of my classroom"), create a collaborative environment for children and aduits (e.g., "When I have my classroom, I would like to have tables so everyone, people are able to talk to each other and work in groups"), continue reflective practices (e.g., "It's asking the right kind of question -- are you asking surface questions or are you getting into the heart of the matter?"), and advocate to meet 
the needs of all learners (e.g., "I have more to learn on diverse learners, but I'm convinced of the validity of the theory and I see ways to implement it"). Many students expressed these goals specifically, talking about the four areas as "values," "tools," and "philosophy."

Often students referred to a combination of strategic choices and models for teaching and learning, and stressed the importance of having been exposed to the choices in their program. For example, a student in Group \#3 addressed collaboration and lifelong learning. She was resolute about not becoming "an isolated teacher." She discussed the importance of joining with her colleagues to pursue professional development opportunities and to incorporate "the part that works for you and really use it." A student in Group \#3 focused on diversity and reflective practice. She noted that she had developed her own ideas about diversity and that her involvement in the block had given her the "opportunity to really begin to develop a philosophy." Moreover, she realized that her "philosophy was likely to change over time and probably always be in change" but that her exposure to all the reflections had helped her become more aware of how to develop a philosophy. A student from Group \#4 noted that "our group is much more sensitive to diverse learners." She described an incident in her school when teachers had resisted including certain children in their classrooms due to the children's ethnicity or language. This student was certain that she "wanted children of different ethnicities in her classroom" and that it was important for her to do so.

Another student in Group \#3 discussed the encouragement she received about expanding her technology skills. She stated, 
I think the use of technology and the information that were given in the program, has made me a lot more willing and able to explore those things in the classroom that, had we not talked about them in seminar and had I not gotten myself involved with multi-media academy and had things not been made available to me, I would be just as stand-offish about the computers in my classroom, because it wasn't made an easy thing. (Group \#3)

The following comment by a student in Group \#4 summed up her intent to incorporate all the strategic choices:

I think that's really important, to make sure that you keep that connection, so that you are reflective, so that you are remembering about diverse learners, technology, all of it. Because if you don't keep connected, and that means continuing your education, make sure you go to professional development and build your rapport with your own staff. And if you don't have that, then you have to go somewhere else. You really do. (Group \#4)

\section{Summary}

This chapter began with a portrayal of the context and culture of this cohort of students. A description of the students and their courses, experiences, interactions, and relationships helped toward an "understanding of the whole." In an attempt to address the research questions, journal entries about each of the strategic choices were examined for emerging themes across the time span of the two semesters. Finally, the group interviews were analyzed for additional evidence of changes that occurred in the students' awareness and experience with technology, collaboration, diverse learners, and reflective practice. 


\section{CHAPTER FIVE}

\section{DISCUSSION}

The qualitative researcher seeks to "describe, explain, and make understandable the familiar in a contextual, personal, and passionate way" (Janesick, 1994, p.217). Toward this end, the data reported in Chapter Four were contextualized to provide a look at "the larger picture, the whole picture, beginning with a search for understanding of the whole" (p. 212). Student voices were also included to illustrate their personal and often passionate expressions of understanding. Further, the data were displayed in graphic forms in order to make sense of the patterns and relationships that emerged through analysis. This final chapter provides a discussion of the findings in light of existing research, notes limitations of the study, and offers implications for educators and administrators in professional education programs. Recommendations for future research are also included.

The purpose of this study was to investigate student experiences in a yearlong professional education program that was focused by four strategic choices: diversity, collaboration, reflective practice, and technology. The objectives were twofold: 1) to explore students' perceptions of their experiences with the four strategic choices and how they applied these choices to their professional education practice; and 2) to identify implications for educators and administrators related to the translation of theory to 
practice. More specifically, two research questions were investigated: 1) How, if at all, did the students' awareness of the four strategic choices change over time?; and 2) How, if at all, did the students apply the four strategic choices during their internships? The following discussion addresses each of these questions.

Question 1: Changes in Awareness

\section{How, if at all, did the students' awareness of the four strategic choices change over time?}

When the students wrote their initial journal entries about each of the four strategic choices, most of them expressed a limited understanding of these concepts as related to teaching and learning. At that time, they wrote mostly about personal experiences as learners, using that experience to ground their understanding. This starting point can be viewed as a baseline. The students were then exposed to information, activities, discussions, and other experiences through coursework and classroom interactions. The content of their journal entries and their final group discussions indicated that the level of their awareness and understanding had indeed changed. Entries reflected that they expanded their definitions of each of the four choices, identified relationships among the choices, and utilized the underlying values of these choices to begin developing their personal philosophies of education. Further, reaching the "last box" was considered an advanced level of awareness and understanding, as illustrated in Figures 4-7 (see Chapter Four). These "last boxes" included: technology integration (technology); democratic classrooms (diverse learners); learning community (collaboration); and reflective practitioner (reflective 
practice). While not all students reached that level in each of the areas, findings suggested that every student made notable changes.

Technology. In their initial journal entries, students in this cohort described their familiarity with types of technology (e.g., computers, multi-media equipment, audiovisual equipment) but rarely referred to the application and integration of technology in the classroom. All but four of the students entered the teacher credentialing program with basic computer skills; however, every student understood that incorporating computer use into the classroom would be and should be expected. At least nine students expressed fear that children in their classrooms would likely know more than they would about computers. In addition, two students referred to the possibility that they would have more technology-related skills than their supervising teachers. Technology was unique in this respect, that is, it seemed to evoke the most fear. As it turned out, nearly all of the students reported learning from the children in their classrooms and at least half of them also provided instruction for their supervising teachers. As they were exposed to information, materials, and models of technology use through their coursework and initial visits to classrooms, the students' awareness of the range of possibilities for technology integration also increased. Their understanding expanded more dramatically as they were given opportunities to try it themselves during their internship experiences. Clearly, the relationship between competence and confidence was a factor. As all of the students became increasingly competent in using computers and other technologies, their entries reflected more confidence about their experiences and their willingness to try new activities. 
Technology integration, according to the professional literature, implied that technology was used to affect how instruction was delivered, how students accessed education, and how resources were made available (Thornburg, 1994). Further, new ways of utilizing technology transformed not only the way the curriculum was delivered but how learning took place (Reich, 1992). Skills related to technology will be necessary for children who are entering a world where lifelong learning means survival and where self-directed learners will have the advantage over others who rely on more traditional ways of learning (Thornburg, 1994). According to these definitions, only a few of the students did not grasp the full meaning of technology integration. Specifically, three students continued to refer to computers as a scheduled activity rather than as a tool that should be accessed throughout the school day. On the other hand, 25 students developed a more comprehensive understanding of technology, as evidenced by their ability to design and implement lessons that integrated technology.

By the end of the year, all of the students expressed the intention to pursue additional training so that they could more effectively access and utilize technology. They referred to the need for keeping up with the advances in equipment and strategies. Even those who did not have as much hands-on experience due to the lack of technology at their schools seemed to have increased their level of understanding and comfort and fully expected to integrate technology into their future classrooms. Further, they all indicated a strong belief in the importance for children to acquire technology skills and that they, as future teachers, had some responsibility in this process. The students also realized the value of having been exposed to technology during their education, and 
seemed determined to pursue more training for their own use and for enhancing the lessons that they would present to children.

As students' awareness and understanding of technology integration increased, references to the other strategic choices also appeared. For example, as students realized that they could learn about technology from the children and also share their skills and knowledge with their supervising teachers, they added to their understanding of collaboration. They began to understand more fully the ways in which expertise can be shared, consistent with the multi-directional approach supported by Freire (1970) and others. The students also had the opportunity to develop some awareness of the role that technology plays in leveling the playing field for learners with a range of needs and abilities (Matthews, 1997). All of them completed at least one of their internships in a school that had little or no technology available for daily use by children. After being in a school that offered state-of-the-art technology, the students saw the clear advantage that technology can offer to all children, breaking down barriers for students who cannot afford or who cannot otherwise access the technology (Jones \& Young, 1997). Regardless of their personal comfort level with technology, all students developed a clearer understanding of the necessity to address technology integration as an issue of access and equity for the children whom they would be teaching.

Diverse learners. When they first wrote about meeting the needs of diverse learners in their journals, most students offered a narrow definition of diversity. Only four referred to children with disabilities or those from lower socioeconomic status. About half of the cohort referred to children who spoke languages other than English. By the end of the year, they had all amended their definitions to include the full range of 
human experience. Not only had they expanded their awareness, but they also indicated a higher level of comfort and confidence in their ability to meet the diverse needs of children. While it is likely that not all of them developed the ability to create truly democratic classrooms, it is safe to say that they exited their professional development program with higher expectations for all children.

When students shared their perspectives on diversity, they often referred to questions of power and control in the classroom or classroom management issues. As they developed a better understanding of the importance of addressing all learning styles and of incorporating differentiated instructional strategies to do so, they questioned the practices that they were observing in the classroom. Consistent with research that indicates beginning teachers display a strong tendency to become increasingly controlling of their students (Jones, 1996), most of the students in this cohort also expressed the desire to be "in control" of their classroom, and often equated that ability with being a good teacher. For example, several students expressed anxiety about teaching in a classroom that was "already out of control" and that they would receive a poor evaluation for a situation they had little or no opportunity to remedy. In fact, three students requested changes in placements based on this justification. However, by the end of the year, many students found that the use of engaging lessons was an effective and proactive strategy for maintaining a positive classroom environment. Most believed this to be true, but not all had confidence that they would be immediately successful using this approach. Another aspect of diversity related to grouping and tracking students. It seemed that initially students were familiar and comfortable with the practice of grouping children according to their perceived abilities. At least half the students had reported 
experiencing ability grouping in their own education and therefore assumed that some value existed in using this practice. Few, if any, remained comfortable with this approach after reading and discussing literature that challenged its soundness. While the area of technology evoked the most fear, the area of meeting the needs of diverse learners seemed to result in the most cognitive dissonance. In other words, students were continually shaping their philosophies about interacting with children and organizing classrooms, yet they were often obliged to implement strategies that conflicted with their new ideas. They were challenged to consider the effects that low expectations might have on a group of children and that they had responsibility for creating an environment in which all children could feel successful. The students demonstrated increased sensitivity to these issues in their journal entries as they began to understand the implications of their actions and the degree of influence that they actually had in the classroom. Some of them realized the importance of not only believing all children had a right to learn but also the necessity of modeling that behavior in the classroom. At least two students described their shock in hearing teachers at their schools make derogatory comments about certain "types" of children whom they would rather not include in their classrooms. Increasingly, all the students in the cohort gained a deeper understanding of their roles and responsibilities in shaping a learning community that provided a safe and secure environment in which all children felt a sense of belonging.

Again the relationship among the strategic choices served to reinforce learning about each of the others. The goal of creating a classroom community required not only sensitivity and awareness about the diverse needs of children, but also required collaboration between and among children and adults. As studerits raised their 
expectations of what might be possible for all children, they indicated an understanding of the benefits of creating both a learning community and a democratic classroom. More than half the cohort implied that their comfort level had increased and that they were interested in schools that included studenis who represented a wide range of needs, abilities, and talents. At least five of them explicitly shared the conclusion that it was their responsibility to increase their own exposure to diverse learners in order to truly increase their own capacity to meet the diverse needs of these children.

Collaboration. Similar to their writing about the other strategic choices, the journal entries about collaboration were based initially on the students' personal experiences. They wrote mostly about the support that they had given to one another as members of a cohort but did not immediately make the connection to the importance of a support network that they would need as professionals. Their understanding of the uses and implications of collaboration was also limited at the time they entered the program. Descriptions of collaboration for classroom use were mostly limited to incorporating cooperative learning strategies with children. When they wrote their first impressions, students did not tend to refer to other aspects of collaboration, such as team teaching, sharing common goals, or creating a learning community with children and adults (Fullan, 1993; Senge, 1990).

As they were exposed to examples of collaboration, both among children and adults, the students began to attribute more importance to its use. Five students noted that children needed to learn collaborative skills to perform effectively in school as well as in their future workplaces. As the students spent more time in their assigned schools, they were often surprised at the limited opportunities that were available for cooperative 
learning or collaboration in general. At least eight students described frustration in conducting these types of activities when the children had little or no experience working in groups. As a result, the students developed a greater understanding for the necessity of purposefully teaching these skills. They were beginning to grasp the essence of community, that is, people working together and sharing responsibility that required everyone's unique and individual talents (McKnight, 1995).

The majority of the students observed effective cooperative learning for children in at least one, if not in both, of their student teaching placements. However, they saw far fewer examples of teacher collaboration, which added to their cognitive dissonance. Those who became part of a grade level planning team at their schools wrote about the support and camaraderie that they were experiencing with their new colleagues. Others who had few if any opportunities for this type of networking or collegiality wrote more often about their desire to see such collaboration and stated their intentions to help facilitate this approach when they became employed as teachers. They seemed to understand that it would take great effort on their part not to become an "isolated" teacher, as described in the group discussions. Many studies have identified teaching as an isolating profession (Guyton \& McIntyre, 1990; McIntyre, Byrd, \& Foxx, 1996); however, these students do not see teacher isolation as inevitable. Rather, they expressed interest in learning more about collaboration, both for themselves and for the children in their classrooms. They planned to identify others in their schools who valued collaborative approaches in order to expand their own expertise. Seven members of one discussion group demonstrated their new depth of understanding on this topic as they 
offered advice to one another for connecting with their future colleagues, even if it had to be accomplished with one person at a time.

By the end of the year, the students had been exposed to information about and models for collaboration that increased their understanding of the concept. After the emotional writing that occurred after one of the seminar discussions, many of them obviously realized the extra time and effort required for effective collaboration. Their new perspectives echoed the claims made by some of the leading thinkers on change who have stated that collaboration includes developing a shared vision, building trust, communicating effectively and honestly, and creating a learning community (Bergquist, 1993; Drucker, 1989; Fullan, 1993; Senge, 1990). In other words, at least $85 \%$ of the students gave strong indications through written or verbal comments that they were determined to become teachers who would make a difference.

Reflective practice. Compared to entries about the other strategic choices, the initial journal entries about reflective practice revealed a much greater familiarity and comfort level. Over half of the students perceived themselves as being reflective by nature and indicated that applying this to teaching would happen without much effort. Even those who were less familiar with the reflective process expressed interest in learning more about it. However, for at least the first few weeks (and for eight students an even longer time period), the majority of the students provided a running record or summary of events rather than reflecting on themselves and their teaching activities. Given the nature of reflective thinking, a number of reasons might be considered. First, there was likely a period of time necessary for building trust, i.e., that the information from their journals would be kept confidential and that they would not be judged or 
penalized for writing their honest reflections. Second, if reflective thinking is embedded in the decision-making process, as John Dewey (1933) claimed, then it followed that as the students faced more decisions, they became more reflective. Dewey noted that reflection often begins in doubt or when facing conflict. As the students accumulated more knowledge and faced increasing cognitive dissonance, they used their journals as a vehicle to reflect on new dilemmas. Third, skills and understanding aside, journal writing was time-consuming. Due to the often demanding schedule of a full-time professional education program, all of the students expressed frustration at not having enough time to record as many thoughts as they would have liked.

Journal entries on reflection were interwoven with the other strategic choices, that is, their reflections often addressed thoughts, doubts, and questions about diversity, collaboration, and technology. They wrote many entries about their attempts to reconcile the discrepancy they perceived between coursework theory and practical application. They cited examples related to curriculum areas as well as to each of the strategic choices. Students also described the difficulty in reflecting on their own teaching in a realistic manner without being overly critical of themselves. As they were provided written feedback in their journals and verbal comments from their supervising teachers and university supervisors, they developed more effective techniques for reflection and added to their understanding of the concept as an important strategy for their continued professional development.

Only two of the students never seemed to get beyond the "I did this in my classroom today" type of entry. It was likely that journaling would not necessarily be the preferred mode of reflection for all of the students. The discussion groups at the end of 
the year confirmed this expectation. During the group discussions, at least seven students specifically described their ability to think about what they were doing as they were doing it, and to then act immediately on the reflections, or "reflection-in-action" described by Schön (1983). Overall, the entries from 26 of students indicated a deeper understanding about reflection. They also employed this approach to make sense of situations that initially made no sense, another use suggested by Schön. Those who excelled in this area demonstrated increased self-knowledge and seemed to understand their relationships with others from a more holistic perspective. By the end of the year, all the students developed their own philosophies, based on the cumulation of all their reflections. Their progress was consistent with research that suggested the importance of not only engaging students in reflection and inquiry, but also teaching the skills and insights required to employ reflection effectively (Boyd, Boll, Brawner, \& Villaume, 1998; Guillaume \& Rudney, 1993; Rodriguez \& Sjostrom, 1998).

In sum, the level of student awareness changed. Moreover, all students seemed willing to have their beliefs challenged, at least to some degree. They were exposed to many perspectives and encouraged to draw their own conclusions. As their confidence increased, so did their willingness to implement new practices. Their increased awareness and understanding led to increased self-knowledge, higher expectations for children, deeper appreciation for personal and professional relationships, and the willingness to assume responsibility for creating classrooms that were consistent with their beliefs and values. Research about the potential for change in beliefs is divided. Some scholars maintain that beliefs are extremely difficult if not impossible to change (Richardson, 1996), while others are optimistic that teacher education programs can help 
students change beliefs in "significant and worthwhile directions" (p. 110). The changes noted in the students in this study add support to the latter point of view.

\section{Question 2: Application during Internship}

\section{How, if at all, did the students apply the four strategic choices during their internships?}

Regardless of the increased level of awareness of the four strategic choices, it cannot be assumed that all students in the cohort applied the choices during their internships to the same degree. However, each of the students did provide numerous examples of practical application. The discussion in this section focuses on how the students applied the choices, that is, in the context of teaching and learning models.

A review of the literature indicated that experiential activities were an integral component of coursework that provided students with opportunities to construct knowledge in a real context (Morey \& Kitano, 1997). Further, field experiences were often listed as the most important part of the educational programs by teachers (McIntyre, Byrd, \& Foxx, 1996). However, until recently studies supported assertions made by researchers that most field experiences lacked a theoretical framework or clear set of goals (Guyton \& McIntyre, 1990). Educational efforts since that time have attempted to integrate theory and practice through the creation of a "model and knowledge base that undergird the purpose, processes, and outcomes of their teacher education program, [and that] unify all components of a program, including campus courses and field experiences" (McIntyre, Byrd, \& Foxx, 1996, p. 172). The application of the four strategic choices by the students in this cohort demonstrated at least some degree of theory and practice integration and supported the approach of using: 1) a model to guide the program (i.e., 
the four strategic choices); and 2) "real" experience to guide and reinforce learning. Included in this section are ways in which students applied the four choices that were consistent with the models of teaching and learning described in Chapter 2, e.g., lifelong leaming, learner-centered education, and practice-oriented or experiential learning. Examples illustrated the different levels of application, including activities considered "above and beyond" the minimum standards. When these activities were combined with advanced levels of awareness, the integration of theory and practice was indicative of any or all of the "last boxes" (e.g., technology integration, democratic classrooms, learning communities, and reflective practitioners).

Lifelong learning. The concept of lifelong learning has been a dominant theme in US education since the 1930s. Even at that time, the process of "learning how to learn" was seen as an essential skill for children and adults (Knowles, 1990). Lifelong learning has also been included as a fundamental principle of teacher education (Griffin, 1991). Students in this cohort referred explicitly and implicitly to their interest in and commitment to lifelong learning in their joumal entries as well as during the group discussions. For example, all students intended to increase their skills and comfort level with technology in order to facilitate these skills with children. For some students, that translated into buying their own computers to ensure continued access to the Internet for resources and for networking. Most notably, those who had the opportunity to participate in lessons that integrated technology at a more complex level (e.g., connecting to experts via a fiber optics link) were determined to access technology for their own classrooms. Many of the students also expressed interest in participating in distance learning to enhance their own professional education and at least three students applied to a graduate 
program scheduled to begin right after the end of the semester. Each of these actions indicated that students had gone "above and beyond" the minimum expectations and had initiated steps characteristic of professional educators.

About half of the students also referred to the relationship between collaboration and lifelong learning. For example, those who had experienced collaborative efforts during their internships were hopeful that they would have similar support when they taught in their own classrooms. Not all of the students fully understood their own roles and responsibilities in creating collaborative partnerships. Those who initiated these connections moved "above and beyond" the minimum expectations and benefited from their efforts. For some, this happened when they offered resources to others, such as organizing a particular activity or project that was valued in the school (e.g., drawing a mural, coordinating a science club). Regardless of the extra work that collaboration typically involved, all students appreciated the benefits that were realized from pooling resources and expertise.

Another dimension of collaboration as a vehicle for lifelong learning included the development of mentoring relationships (i.e., "a mutually respectful and highly personal relationship in which the mentor's responsibility is to help shape the growth and development of his or her protégé" [Gold, 1996, p. 572]). While the majority of students formed a positive rapport with their supervising teachers, ten of them experienced a mentoring relationship with teachers and/or administrators at one of their school sites. For example, one principal encouraged a student teacher who had the same ethnic background as herself to attend a conference for Pilipino educators. During the conference, the principal asked the student to facilitate a session and to join the 
association that sponsored the event. The principal continued to mentor this student throughout the semester. As a result of this relationship, the student realized that she could make valuable contributions to her community. Other students discovered mentors who guided them in areas such as music and movement, storytelling, and technology. Reflective practice was important to the pursuit of lifelong learning. Students who became very skilled at reflective thinking realized that they also needed feedback from others. This varied with the degree of confidence that students possessed. Those who felt confident about their skills appreciated the constructive criticism and compliments that observers offered, while those who were nervous about their own teaching seemed threatened about being observed. Students who integrated reflective practices into their teaching noted that they intended to use these strategies with children when they had their own classrooms. They also predicted that they would seek out colleagues who had similar viewpoints on reflection.

Lifelong learning included the continued awareness and additional skills that would be required to meet the needs of diverse learners. About a third of the students did not fully associate the importance of their own values about equity and democratic classrooms until they were placed in a classroom that included children with diverse needs. When students were placed at two schools that had very different populations of children (e.g., socioeconomic levels, language proficiency, family involvement), the contrast was especially evident. The majority of the cohort questioned their own values and recognized the inequity that might be perpetuated in classrooms. Those who went "above and beyond" actualized their beliefs by assuming the role of advocate. As they learned more about the individual needs of the children in their classrooms, they 
recognized that certain children needed extra time and support that no one else was likely to provide. As a result, more students were determined that they would consider these equity issues when they were teachers.

Learner-centered education. Studies have demonstrated that placing students in the center of the learning process encouraged active participation, increased self-esteem, and improved interpersonal relationships (Jones \& Young, 1997). Students in this cohort were in the unique position of being learners as well as teachers. They often evaluated the performance of their university instructors on the instructors' ability to model learnercentered approaches. In other words, the students wanted to experience the instructional techniques that they were expected to use with children, and in many cases, this occurred. Because the students were based at an elementary school site for their university methods courses, they had access to children. For some of the methods courses, the students designed lessons that they implemented with children. Immediately after conducting the lesson, the students reflected, revised, and re-taught the lesson to another child or group of children. In their dual roles as learners and teachers, they helped to guide the multidirectional instruction to meet their own needs and to better meet the needs of children.

All of the students to varying degrees discovered the relationship between utilizing a leamer-centered approach and issues of power and control, both of which affected the creation of a learning community and a democratic classroom. Learnercentered education relies on "principles of collaborative learning and egalitarian relationships" (Rohfeld \& Hiemstra, 1995, p. 1). These relationships were readily apparent when technology was involved. For example, one of the student teachers set up a discussion via email for the children in his classroom to converse with children and 
adults across the country about one of their assigned books. All the children had the same opportunity to participate and technology leveled the playing field for those who needed extra help in submitting their messages. Similarly, the students in the cohort experienced the clear disadvantages of not having access to technology. Whether it was for their own assignments or for planning a lesson with children, the students who had access to technology resources often designed and implemented lessons that were more engaging, interactive, and motivating. A third of the students also participated in efforts that attempted to involve families and community members in using technology. Doing so helped them develop a clearer idea of the barriers and benefits to opening these lines of communication. Overall, all students became better equipped to advocate for the integration of technology at their future schools.

Learner-centered education requires teachers to understand not only what their children know but also how they think. Teachers need "a rich knowledge base about learning and an array of tools for accessing student thinking, understanding students' prior knowledge and backgrounds, and connecting their families and communities" (Darling-Hammond \& Sclan, 1996, p. 95). The students in the cohort realized that by utilizing a learner-centered approach they could learn much more about the children's strengths and needs. Those who went "above and beyond" implemented child-centered assessments that would take into consideration cognitive, social, physical, and psychological development. Rather than expecting all children to react in the same way to a lesson or blaming the children for not learning, they saw it as their responsibility to offer a variety of instructional strategies that reached children through their best learning modes. All students, to varying degrees, employed strategies that incorporated and 
addressed multiple intelligences to help all children reach their potential. These experiences helped students understand the importance of creating a learning community in their own classrooms.

Another aspect of learner-centered education referred to the development of "teachers as the managers of their own inquiry" (Darling-Hammond \& Sclan, 1996, p. 95). This perspective was a departure from earlier assumptions that beginning teachers needed to focus only on basic concepts and processes and that "teachers in general should be the recipients of knowledge rather than the generators of knowledge" (p. 95). Consistent with Freire's (1970) criticism of the banking approach to teaching, this earlier approach is being replaced with the perspective that "teachers must be empowered to own, use, and develop knowledge about teaching and learning as sophisticated and powerful as the demands of such work require" (p. 95). Students who went "above and beyond" in this aspect were those who took responsibility for their own learning. For some this meant that they attended additional professional development inservices and workshops. For others it included initiating professional networks that could lead to employment.

Practice-oriented/experiential learning. Internships, student teaching, or similar field practica are typically a component of professional education programs. Cohorts are often organized to help establish a learning community (Bullough \& Gitlin, 1995), and can enhance the internship experience by helping students learn about the conventions or culture of a given field (Schön, 1987). Being a member of a cohort also "encourages a more communal perspective and a weakening of the extreme form of individualism common to traditional approaches to student teaching placement" (McIntyre, Byrd, \& 
Foxx, 1996, p. 174). The culture of the student cohort in this study provided a safe environment in which to learn, experiment, and even fail. It was important to maintain communication and contact within the cohort, especially during the two sessions of student teaching when they were not meeting regularly for methods courses. This was accomplished in two ways. First, at least two, and up to six students were placed at a school site in order to maintain a support network at each school. Second, the students continued to meet for seminar every week, even during student teaching. Because it was the only opportunity to meet as a whole group, time was allotted for them to share experiences. They commented on the importance of these meetings to maintain their learning community. Many noted that they intended to keep this network active as they applied for jobs and when they began setting up their own classrooms.

As described in Chapter 4, the culture of this cohort thrived on both taking risks and providing support. When they applied the four strategic choices in their classrooms, the students were eager to compare notes with one another for help and reinforcement. Many of the students also shared materials with one another when they switched grade levels from one semester to the next. The combination of being part of a cohort and participating in an internship were mutually beneficial. The students depended on one another to share experiences and insights that being placed at different schools offered, particularly as they encountered students with a variety of learning needs. For example, some schools included children with disabilities in classrooms while others operated "pull-out " programs (Fisher, Sax, \& Pumpian, 1996). When they encountered different models, the students struggled to clarify their values and philosophies. Those who went "above and beyond" in their reflections developed strong philosophies that included their 
perspectives on equity, inclusion, and social justice. Although they questioned how much control they were likely to have over such important decisions when they eventually were in charge of their own classrooms, they intended to keep certain values uncompromised.

Another important feature of an internship includes the opportunity to benefit from others' experiences (Schön, 1987). The focus on reflective practice enabled students to "see through a teacher's eyes and to consider responses in light of practical, social, and ethical consequences" (McIntyre, Byrd, \& Foxx, 1996, p. 172). Students had been encouraged to study and critique the context of their classrooms and their schools. As a result, students developed a more holistic perspective about their placements and, by the end of the year, most of them expressed appreciation for the responsibility that teachers must assume. Although many of the students often felt overwhelmed by pressures from being in the teacher preparation program, it is unclear how many of them understood that, in reality, they had not assumed all of the responsibilities that their supervising teachers faced daily. For example, not one student directly referred to the fact that the supervising teacher was ultimately responsible for ensuring that children met educational standards even when the children were receiving instruction from student teachers. Interestingly, no one specifically mentioned the desire or intention to eventually take on the supervision of student teachers themselves. Whether that was a situation too far in the future, or that becoming master teachers at some point was inevitable, was not clear.

Another issue that arose during the internship portion of the program focused on the quality of the supervising teachers and the school sites in general. Classroom 
placements were coordinated by the leader of the block who contacted principals for names of teachers interested in supervising a student teacher. After the principal submitted a list of teachers, placements were designated with consideration given to grade level, teacher experience, and other environmental and cultural factors. Even with this process, at least three students faced assignments in classrooms in which the supervising teachers claimed they had not requested (or wanted) a student teacher. Research indicated that this was not uncommon. One study found that some school principals placed student teachers with weak teachers, anticipating that the student teachers would provide assistance (Guyton, Paille, \& Rainer, 1993). Other studies suggested that often the supervising teachers were not prepared for the responsibilities of educating and supervising their student teachers, nor were they certain of their roles or expectations in a student teacher triad (i.e., student, supervising teacher, university supervisor) (Guyton \& McIntyre, 1990).

Students in this cohort were assigned to supervising teachers who had a wide range of skills and personal characteristics. Some teachers were especially skilled at modeling effective instructional strategies. Others varied in the way that they provided feedback and allowed opportunities for students to be innovative. Most students also discovered that, consistent with the research, not all teachers who were effective with children in the classroom were necessarily effective as teacher trainers (Koemer, 1992). Regardless, students in this cohort were encouraged by their university instructors and supervisors as well as by one another to learn as much as possible from their supervising teachers. Those who went "above and beyond" learned to analyze and evaluate the practices that they observed to determine which of those they might eventually 
incorporate into their own classrooms. They also demonstrated the maturity to avoid becoming judgmental about their supervising teachers or about practices that saw as less effective or appropriate.

In sum, the ways in which these students applied the four strategic choices in their internships clearly reflected effective models of teaching and learning. The ability and opportunity for the students to apply all that they had learned from coursework, materials, activities, and other resources varied from site to site and from semester to semester. Key factors included their supervising teachers, the culture and climate of their schools, and relationships that they created and maintained with one another and with other colleagues at their schools. Twenty-six of 28 students went "above and beyond" the minimum standards and expectations in one or more of the areas and demonstrated characteristics of professional educators. In addition, indications were that the theoretical framework and knowledge base (i.e., the four strategic choices) provided a unifying force for more effectively integrating theory and practice.

\section{Conclusions and Implications}

This study explored students' perceptions of their experiences with four strategic choices and how they applied these choices to their internships. The findings demonstrated that the students in this cohort experienced significant changes in their awareness and that they applied their increased understanding in their practica. More specifically, this study demonstrated the following:

1) Infusing strategic choices into the coursework of a professional education program helped encourage students to challenge their own beliefs and clarify their own values. 
2) Coordinating the goals and activities of the coursework and internship experiences helped to reinforce effective models for teaching and learning.

3) Using a cohort structure throughout a professional education program facilitated the creation and maintenance of a learning community.

4) Structuring a seminar class held regularly throughout a professional education program provided a safe environment in which students synthesized the information from their coursework, shared experiences and strategies for translating theory to practice, and developed a clearer understanding of their roles and responsibilities as future professionals.

5) Incorporating reflective practices in a professional education program encouraged students to examine their skills as well as their beliefs about teaching and learning.

Given these conclusions, a number of implications for administrators and faculty of professional education programs are worthy of consideration.

1) Faculty and administrators must have the opportunity to help articulate the mission, vision, and strategic choices for a professional education program. If the faculty are expected to infuse the choices within their curriculum and instruction, they must first be involved in the creation of this framework. In addition, the participants may need any or all of the following supports: time for collaborative planning; additional training regarding effective strategies; access to technology and multimedia equipment; supplemental resources to enhance teaching activities (e.g., field trips, guest speakers). 
2) The internship sites should be selected based on criteria that match or complement the theoretical framework of the professional education program. While not every internship site is expected to provide ideal models of each aspect of the framework, placements should be carefully chosen to provide effective models of teaching and learning associated with the four strategic choices (or other model identified by the professional education program). This might require that faculty, staff, and site administrators at internship sites be provided additional training, resources, and/or equipment. Criteria should be more formalized so that students are placed in sites that demonstrate collaborative efforts, attention to the needs of diverse learners, technology integration, and the use of reflective practices.

3) Faculty and administrators at both the university and the internship sites must coordinate efforts to help students apply knowledge and information from coursework to their professional practice. Coursework, experiential activities, and supervision must infuse the strategic choices and incorporate effective models for teaching and learning. Students must acquire knowledge in their coursework, but they must also develop reasoning skills, decision-making strategies, and reflective thinking approaches in order to apply this knowledge during their internships and throughout their professional lives. Again, additional time and training may be required to enable this type of collaboration.

4) Efforts to support the cohort structure beyond the end of the professional education program should be initiated. As students leave the support and 
camaraderie of the cohort, they may find it difficult to transfer the effective practices that they have learned in their program to their new schools. They often face being the only new teacher on staff and may not always find colleagues who hold similar beliefs or value systems. Facilitating an ongoing support network for members of the cohort, either by electronic communication or face-to-face meetings, could help new teachers transition more easily into their first year of teaching.

5) The options for learning and applying reflective practices should be expanded. Journal writing during internship experiences has been demonstrated to be an effective mode for some students to learn and practice the skills required for reflection. However, some students need more opportunities to apply the art and skill of reflection in other settings. In addition, not all students necessarily find writing to be their preferred method. In order to accommodate a wide range of learning styles, a variety of reflective strategies should be incorporated into different aspects of the professional education program. Students should be encouraged to explore many avenues for reflection and expression, including the use of technology, e.g., videotapes, audiotapes, interactive computer media, etc. In addition, students should experience reflective thinking throughout their program and should be encouraged to express their reflections through artistic interpretation as well as intellectual writing. 


\section{Recommendations for Future Research}

Although empirical work has been conducted that links beliefs to practices, it cannot be assumed that all changes in beliefs translate into changes in practices (Richardson, 1996). This study adds to the research in this area, as many of the changes in awareness and understanding that students experienced directly translated into practices that they applied during their internships. A longitudinal study of the students in this cohort might investigate a number of aspects. Such studies might include conducting both observations and interviews to determine how, if at all, their awareness of the four strategic choices has changed since they were employed as teachers; and how, if at all, they have applied the four strategic choices into their own classrooms. It would also be interesting to determine if the students have maintained communication with their former cohort members, and if so, what means they have used and what information they have shared.

Another direction of future research might examine cohorts of students in other professional education programs to determine if they experienced similar changes in awareness and if they applied this understanding to their internships. Special attention should be devoted to determine if the needs of nontraditional students or traditionally underrepresented groups of students were met through this approach. Future studies might also include interviews or focus groups with the cohort instructors to identify how each of them addressed the four strategic choices in their courses. Another perspective might be obtained by completing a content analysis of the syllabi for each of the courses, and conducting observations in university classes in order to identify the strategies that instructors used for infusing the four choices. 


\section{$\underline{\text { Limitations }}$}

This study had three major limitations. The first limitation was related to the size of the sample. The study was limited to the experiences of one cohort of students who completed a yearlong professional education program. However, given the nature of the findings in light of the existing research, transferability to other professional education programs seems likely. The strategies that were successful in this study could be easily incorporated into not only other teacher education programs, but also into professional education programs that include a combination of coursework and experiential practices. The innovations could be applied to any university or college program, regardless of size, geographical location (e.g., rural, urban), student profile, or structure (e.g., private, public). A theoretical framework, focused by values-based strategic choices could be designed by faculty and administrators wishing to do so and willing to take the time and effort to participate in the process.

Second, the research was limited to the use of existing data. Although data were collected from two sources (i.e., journals and interviews) and a member check was conducted for credibility, the study did not include gathering additional data from the students. Nevertheless, the findings of this study provided a baseline for a future investigation of the students' perceptions after they have been employed as professionals. Interviews with and observations of the participants at least one or two years after employment as teachers may inform the College of Education as to how, if at all, the students' perceptions changed over a longer period of time, and how, if at all, they continued to apply the four choices in their own classrooms. 
The third limitation referred to researcher bias. While most qualitative researchers accept that "research is ideologically driven" and that "there is no value-free or bias-free design" (Janesick, 1994, p. 212), the influence of the researcher as an instructor in the credential program cannot be ignored. Safeguards were taken to ensure continued attention to the question of subjectivity and objectivity. To balance this possible influence, the researcher requested that two other colleagues examine the data display and data analyses to provide an "outside" perspective that the findings did indeed appear to be an authentic representation of reality. Checking with a number of participating students after the major domains, displays, and relationships were identified

provided an additional measure of authenticity. All those who were asked were satisfied that the data were representative of their recollections.

\section{Conclusion}

The use of a theoretical framework focused by four strategic choices provided a vehicle by which students in a professional education program acquired knowledge and, at the same time, were challenged to clarify their beliefs and values as they applied theory to practice. Findings indicated that changes in awareness occurred and that students applied what they learned to their internships. Moreover, the cohort of students in this study incorporated these strategic choices in effective models of teaching and learning. Further investigation is warranted to determine the effects on other students in this program or on students in other professional education programs, particularly those who are considered nontraditional or who are from traditionally underrepresented groups.

As a new vision of higher education emerges, faculty and administrators are implementing new ways of thinking that include attention to the content and form of the 
curriculum as well as to the delivery of instruction (Boyer, 1990; Tierney, 1998; Young, 1997). Faculty and administrators from the professional education program in this study participated in the reexamination of the vision of the College of Education and infused the four strategic choices in coursework and practica experiences: diversity, collaboration, reflective practice, and technology. In an attempt to respond to the newly defined needs of students, as well as to the changing political, economic, and social contexts that contribute to those needs (Braskamp \& Wergin, 1998; Coate, 1995), such efforts as those demonstrated in this study, may result in significant changes in the existing system of professional education programs. 


\section{References}

Academy for Educational Development. (1991). Teacher development in schools: A report to the Ford Foundation. New York: Author.

American Psychological Association Task Force on Psychology in Education and the Mid-continent Regional Educational Laboratory. (1992, August). Learner-centered psychological principles: Guidelines for school redesign and reform. Washington, DC: APA.

Anderson, R. (1995). Bus people. New York: Henry Holt.

Ashbaugh, C. R., \& Kasten, K. L. (1995). Educational leadership: Case studies for reflective practice $\left(2^{\text {nd }}\right.$ ed.). New York: Longman.

Association of American Colleges. (1985). Integrity in the college curriculum: A report to the academic community. Washington, DC: Author.

Babbie, E. (1990). Survey research methods ( $2^{\text {nd }}$ Ed.). Belmont, CA: Wadsworth.

Bardwick, J. M. (1996). Peacetime management and wartime leadership. In F. Hesselbein, M. Goldsmith, \& R. Beckhard (Eds.) The leader of the future: New visions. strategies, and practices for the next era (pp. 131-139). San Francisco: Jossey-Bass.

Bellah, R., N., Madsen, R. Sullivan, W., Swidler, A., \& Tipton, S. W. (1992). The good society. New York: Vintage Books.

Bennis, W. (1989). Why leaders can't lead: The unconscious conspiracy continues. San Francisco: Jossey-Bass.

Bergquist, W. (1993). The postmodern organization: Mastering the art of irreversible change. San Francisco: Jossey-Bass. 
Bogdan, R. C., \& Biklen, S. K. (1992). Qualitative research for education (2nd ed.). Needham Heights, MA: Allyn \& Bacon.

Botkin, J. W., Elmandjra, M., \& Salitza, M. (1979). No limits to learning. New York: Pergamon Press.

Boyd, P. C., Boll, M., Brawner, L., \& Villaume, S. K. (1998). Becoming reflective professionals: An exploration of preservice teachers' struggles as they translate language and literacy theory into practice. Action in Teacher Education, 19(4), 61-75.

Boyer, E. L. (1987). College: The undergraduate experience in America. New York: Harper \& Row.

Boyer, E. L. (1990). Scholarship reconsidered: Priorities of the professoriate. Princeton, N.J.: Carnegie Foundation for the Advancement of Teaching.

Boyer, E. L. (1993). Campus climate in the 1980s and 1990s: Decades of apathy and renewal. In A. Levine (Ed.), Higher learning in America: 1980-2000 (pp. 322-332). Baltimore: Johns Hopkins University Press.

Bradshaw, L. K. (1997). Technology-supported change: A staff development opportunity. NASSP Bulletin, 81(593), 86-92.

Braskamp, L. A., \& Wergin, J. F. (1998). Forming new social partnerships. In W. G. Tierney (Ed.), The responsive university: Restructuring for high performance (pp. 62-91). Baltimore: Johns Hopkins University Press.

Bullough, R. V., Jr., \& Gitlin, A. (1995). Becoming a student of teaching: Methodologies for exploring self and school context. New York: Garland. 
Bullough, R. V., Jr., \& Stokes, D. K. (1994). Analyzing personal teaching metaphors in preservice teacher education as a means for encouraging professional development. American Educational Research Journal, 31, 197-224.

Calderhead, J., \& Robson, M. (1991). Images of teaching: Student teachers; early conceptions of classroom practice. Teaching and Teacher Education, 7, 1-8.

Calhoun, E. F. (1993). Action research: Three approaches. Educational Leadership. 51(2), 62-65.

Calhoun, E. F. (1994). How to use action research in the self-renewing school. Alexandria, VA: Association for Supervision and Curriculum Development.

Capra, F. (1983). The turning point: Science, society, and the rising culture. New York: Bantam Books.

Carnegie Forum on Education and Economy. (1986). A nation prepared: Teachers for the $21^{\text {st }}$ century. New York: Carnegie Forum.

Carter, D. J., \& Wilson, R. (1994). Twelfth annual status report: Minorities in higher education. Washington, DC: American Council on Education.

Chaffee, E. E. (1998). Listening to the people we serve. In W. G. Tierney (Ed.), The responsive university: Restructuring for high performance (pp. 13-37). Baltimore: Johns Hopkins University Press.

Chrislip, D. D., \& Larson, C. E. (1994). Collaborative leadership: How citizens and civic leaders can make a difference. San Francisco: Jossey-Bass.

Clemson-Ingram, R. L., \& Fessler, R. (1997). The Maryland redesign of teacher education: A commitment to system reform. Action in Teacher Education, 19(1), 1-15. 
Clift, R. T., Houston, W. R., Pugach, M. C. (1990). Encouraging reflective practice in education: An analysis of issues and programs. New York: Teachers College Press.

Coate, L. E. (1995). The big questions in higher education today. In B. D. Ruben (Ed.), Quality in higher education (pp. 127-136). New Brunswick, NJ: Transaction Publishers.

Clavell, J. (1981). The children's story. New York: Dell.

Darling-Hammond, L. (1994). Professional development schools: Schools for developing a profession. New York: Teachers College Press.

Darling-Hammond, L. (1996). The quiet revolution: Rethinking teacher development. Educational Leadership. 53(6), 4-10.

Darling-Hammond, L., Bullmaster, M. L , \& Cobb, V. L. (1995). Rethinking teacher leadership through professional development schools. Elementary School Journal, 96, 87-106.

Darling-Hammond, L., \& Sclan, E. M. (1996). Who teaches and why: Dilemmas of building a profession for twenty-first century schools. In J. Sikula, T. J. Buttery, \& E. Guyton (Eds.), Handbook of research on teacher education $\left(2^{\text {nd }}\right.$ ed., pp. 67101). New York: Macmillan.

Davis, M. D., \& Zaret, E. (1984). Need in teacher education: A developmentai model for evaluation of teachers, preservice to inservice. Journal of Teacher Education. $\underline{25}(5), 18-22$.

Denzin, N. K. (1978). The research act: A theoretical introduction to sociological methods ( $2^{\text {nd }}$ ed.). New York: McGraw-Hill. 
Dewey, J. (1933). How we think. Boston: D. C. Heath.

Dreher, D. (1996). The Tao of personal leadership. New York: HarperCollins.

Drucker, P. (1989). The new realities. New York: HarperCollins.

Dryfoos, J. G. (1994). Full-service schools: A revolution in health and social services for children, youth, and families. San Francisco: Jossey-Bass.

Education Commission of the States. (1986). Transforming the state role in undergraduate education: Time for a different view. Denver: Author.

Etzioni, A. (1993). The spirit of community. New York: Crown.

Feinberg, W. (1987). The Holmes Group report and the professionalization of teaching. Teachers College Record, 88, 366-377.

Fisher, D., Sax, C., \& Pumpian, I. (1996). From intrusion to inclusion: Myths and realities in our schools. The Reading Teacher, 49, 580-584.

Fisher, D., \& Sax, C. (in press). A technology-enhanced learning environment. In S. Totten, C. Johnson, L. Morrow, \& T. Briegel (Eds.), Preparing middle level educators: Practicing what we preach. New York: Garland.

Foa, L., Schwab, R. L., \& Johnson, M. (1996, May 1). Upgrading school technology. Education Week, 52.

Freire, P. (1970). Pedagogy of the oppressed. New York: Continuum.

Fullan, M. (1993). Change forces. London: Falmer.

Fullan, M., Galluzzo, G., Morris, P., \& Watson, N. (1998). The rise and stall of teacher education reform. Washington, DC: American Association of Colleges for Teacher Education. 
Futrell, M. H. (1987). The Holmes Group report: A teacher's perspective. Teachers College Record, 88, 378-383.

Garland, C., \& Shippy, V. (1991). Improving the student teaching context: A research-based program for cooperating teachers. Action in Teacher Education, 8(1), 3741 .

Gay, G. (1997). Multicultural infusion in teacher education: Foundations and applications. In A. I. Morey, \& M. Kitano (Eds.), Multicultural course transformation in higher education: A broader truth (pp. 192-210). Boston: Allyn \& Bacon.

Geiger, R. L. (1993). Research universities in a new era: From the 1980s to the 1990s. In A. Levine (Ed.), Higher learning in America: 1980-2000, (pp. 57-85).

Baltimore: Johns Hopkins University Press.

Ghorpade, J. (1998, May 17). An ever-widening meaning of diversity. The San Diego Union-Tribune, p. G-3.

Glaser, B. (1978). Theoretical sensitivity: Advances in the methodology of grounded theory. Mill Valley, CA: Sociology Press.

Glassick, C. E., Huber, M. T., \& Maeroff, G. I. (1997). Scholarship assessed: Evaluation of the professoriate. San Francisco: Jossey-Bass.

Glickman, C. D. (1992). The essence of school renewal: The prose has begun. Educational Leadership. 50(1), 24-27.

Glickman, C. D. (1993). Renewing America's schools: A guide for schoolbased action. San Francisco: Jossey-Bass.

Goetz, J. P., \& LeCompte, M. D. (1984). Ethnography and qualitative design in educational research. New York: Academic Press. 
Gold, Y. (1996). Beginning teacher support: Attrition, mentoring, and induction. In J. Sikula, T. J. Buttery, \& E. Guyton (Eds.), Handbook of research on teacher education ( $2^{\text {nd }}$ ed., pp. 548-594). New York: Macmillan.

Goodlad, J. I. (1990). Teachers for our nation's schools. San Francisco: JosseyBass.

Griffin, G. A. (1991). Toward a community of learning: The preparation and continuing education of teachers. East Lansing, MI: Holmes Group, Inc. (ERIC Document Reproduction Service No. ED 330 650).

Guest, L. (1993). Improving teacher preparation: What the reform reports recommend. Denver, CO: Education Commission of the States. (ERIC Document Reproduction Service No. ED 364 518).

Guillaume, A. M., \& Rudney, G. L. (1993). Student teachers' growth toward independence: An analysis of their changing concerns. Teacher and Teacher Education. $\underline{8}(1), 65-80$.

Guyton, E., \& McIntyre, D. J. (1990). Student teaching and school experiences. In W. R. Houston (Ed.), Handbook of research on teacher education, (pp. 514-534). New York: Macmillan.

Guyton, E., Paille, E., \& Rainer, J. (1993). Collaborative field-based urban teacher education program. Action in Teacher Education, 15(3), 7-11.

Harthern, A. T., \& Rolle, G. E. (1991). Teachers' perceptions of acquiring understanding of and competency in selected teaching skills. Action in Teacher Education, 8(1), 51-56.

Helgesen, S. (1995). The web of inclusion. New York: Doubleday. 
Hollingsworth, S. (1989). Prior beliefs and cognitive change in learning to teach. American Educational Research Journal, 26, 160-189.

Holmes Group. (1986). Tomorrow's teachers. East Lansing, MI: Author. Holmes Group. (1990). Tomorrow's schools. East Lansing, MI: Author. Holmes Group. (1995). Tomorrow's schools of education. East Lansing, MI: Author.

Huberman, A. M., \& Miles, M. B. (1994). Data management and analysis methods. In N. K. Denzin \& Y. S. Lincoln (Eds.), Handbook of qualitative research (pp. 428-444). Thousand Oaks, CA: Sage.

Janesick, V. J. (1994). The dance of qualitative research design: Metaphor, methodolatry, and meaning. In N. K. Denzin \& Y. S. Lincoln (Eds.), Handbook of qualitative research (pp. 209-219). Thousand Oaks, CA: Sage.

Jansen, G., \& Peshkin, A. (1992). Subjectivity in qualitative research. In M. D. LeCompte, W. L. Millroy, \& J. Preissle (Eds.), Handbook of qualitative research in education (pp. 681-725). San Diego: Academic Press, Inc.

Johnson, W. R. (1990). Inviting conversations: The Homes Group and “Tomorrow's Schools." American Educational Research Journal, 27, 581-88.

Jones, V. (1996). Classroom management. In J. Sikula, T. J. Buttery, \& E. Guyton (Eds.), Handbook of research on teacher education ( $2^{\text {nd }}$ ed., pp. 503-521). New York: Macmillan.

Jones, T., \& Young, G. S. A. (1997). Classroom dynamics: Disclosing the hidden curriculum. In A. I. Morey, \& M. Kitano (Eds.), Multicultural course 
transformation in higher education: A broader truth (pp. 89-103). Boston: Allyn \& Bacon.

Joyce, B., Wolf, J., \& Calhoun, E. (1993). The self-renewing school.

Alexandria, VA: ASCD.

Kagan, D. M. (1992). Professional growth among preservice and beginning teachers. Review of Educational Research, 62, 129-169.

Katz, L., Sax, C., \& Fisher, D. (1998). Activities for a diverse classroom:

Connecting students. Colorado Springs, CO: PEAK Parent Center, Inc.

Kitano, M. (1997). A rationale and framework for course change. In A. I.

Morey, \& M. Kitano (Eds.), Multicultural course transformation in higher education: A broader truth (pp. 1-17). Boston: Allyn \& Bacon.

Knowles, M. (1990). The adult learner: A neglected species (4th ed.). Houston: Gulf Publishing Company.

Koerner, M. (1992). The cooperating teacher: An ambivalent participant in student teaching. Journal of Teacher Education, 43(1), 46-56.

Kouzes, J. M., \& Posner, B. Z. (1987). The leadership challenge: How to get extraordinary things done in organizations. San Francisco: Jossey-Bass.

Kozol, J. (1991). Savage inequalities: Children in America's schools. New York: Harper Perennial.

Labaree, D. F., \& Pallas, A. M. (1996). Dire straits: The narrow vision of the Holmes Group. Educational Researcher, 25(4), 25-28.

Levine, A. (Ed.). (1993). Higher learning in America: 1980-2000. Baltimore: Johns Hopkins University Press. 
Lincoln, Y. S., \& Guba, E. G. (1985). Naturalistic inquiry. Beverly Hills, CA: Sage.

Lucas, C. J. (1994). American higher education: A history. New York: St. Martin's Griffin.

Matthews, A. (1997). Bright college years: Inside the American campus today. New York: Simon and Schuster.

Maxon, M., \& Sindelar, R. (1998). Images revisited: Examining preservice teachers' ideas about teaching. Teacher Education Quarterly, 25(2), 5-26.

McIntyre, D. J., Byrd, D. M., \& Foxx, S. M. (1996). Field and laboratory experiences. In J. Sikula, T. J. Buttery, \& E. Guyton (Eds.), ㅂandbook of research on teacher education ( $2^{\text {nd }}$ ed., pp. 171-193). New York: Macmillan.

McKnight, J. (1995). The careless society: Community and its counterfeits. New York: BasicBooks.

Meyen, E. L., Lian, C., \& Tangen, P. (1998). Issues associated with the design and delivery of online instruction. Focus on Autism and Other Developmental Disabilities, 13, 53-60.

Miles, M. B., \& Huberman, A. M. (1984). Qualitative data analysis: A sourcebook of new methods. Newbury Park, CA: Sage.

Mitchell, S. (1988). Tao te ching: A new English version, with foreward and notes. New York: Harper \& Row.

Morey, A. I., \& Kitano, M. (Eds.). (1997). Multicultural course transformation in higher education: A broader truth. Boston: Allyn \& Bacon. 
Murray, F. B. (1996). The narrow and broad readings of "Tomorrow's Schools of Education." Educational Researcher. 25(4), 28-31.

National Association of State Boards of Education (NASBE). (1995). Winning ways: Creating inclusive schools, classrooms, and communities. Report of the NASBE Study Group on Special Education. Washington, DC: Author.

National Commission on Excellence in Education. (1983). A nation at risk: The imperatives for educational reform. Washington, DC: Author.

National Council for Accreditation of Teacher Education (NCATE). (1995). NCATE standards, procedures, and policies for the accreditation of professional education units manual. Washington, DC: Author.

O'Brien, G. D. (1998). All the essential half-truths about higher education. Chicago: University of Chicago Press.

Owston, R. D. (1997). The world wide web: A technology to enhance teaching and learning? Educational Researcher. 26(2), 27-33.

Patton, M. Q. (1997). Utilization-focused evaluation: The new century text. Thousand Oaks, CA: Sage.

Reed, T. K. (1997). Leadership to match a new era: Democratizing society through emancipatory learning. The Journal of Leadership Studies. 4(1), 58-77.

Reich, R. (1992). The work of nations: Preparing ourselves for 21 st century capitalism. New York: Vintage Books.

Richardson, V. (1996). The role of attitudes and beliefs in learning to teach. In J. Sikula, T. J. Buttery, \& E. Guyton (Eds.), Handbook of research on teacher education (2 $2^{\text {nd }}$ ed., pp. 102-119). New York: Macmillan. 
Rifkin, J. (1995). The end of work: The decline of the global labor force and the dawn of the post-market era. New York: G. P. Putman's Sons.

Rodriguez, Y. E. G., \& Sjostrom, B. R. (1998). Critical reflection for professional development: A comparative study of nontraditional adult and traditional student teachers. Journal of Teacher Education, 49, 177-186.

Rohfeld, R. W., \& Hiemstra, R. (1995). Moderating discussions in the electronic classroom. [Online]. Available: http://star.ucc.nau.edu/ mauri/moderate/rohfeld.html Rosenholtz, S. J. (1989). Teachers' workplace: The social organization of schools. White Plains, NY: Longman.

Ross, D. D., \& Smith, W. (1992). Understanding preservice teachers' perspectives on diversity. Journal of Teacher Education, 43, 94-103.

Rost, J. C. (1993). Leadership for the twenty-first century. Westport, CT: Praeger.

Sacks, P. (1996). Generation X goes to college: An eve-opening account of teaching in postmodern America. Chicago: Open Court.

Sax, C., Fisher, D., \& Pumpian, I. (1996). Outcomes for students with severe disabilities: Case studies on the use of assistive technology in inclusive classrooms. Technology \& Disability, 5, 327-334.

Schön, D. A. (1983). The reflective practitioner: How professionals think in action. New York: Basic Books.

Schön, D. A. (1987). Educating the reflective practitioner. San Francisco: Jossey-Bass. 
Senge, P. (1990). The fifth discipline: The art and practice of the learning organization. New York: Doubleday.

Sergiovanni, T. J. (1994). Building communities in schools. San Francisco: Jossey-Bass.

Shapiro, J. (1993). No pity: People with disabilities forging a new civil rights movement. New York: Times Books.

Spradley, J. P. (1980). Participant observation. New York: Holt, Rinehart \& Winston.

Stringer, E. T. (1996). Action research: A handbook for practitioners. Thousand Oaks, CA: Sage.

Sykes, G. (1990). Fostering teacher professionalism in schools. In R. F. Elmore and Associates (Eds.), Restructuring schools: The next generation of educational reform (pp. 59-96). San Francisco: Jossey-Bass.

Tatto, M. T. (1998). The influence of teacher education on teachers' beliefs about purposes of education, roles, and practice. Journal of Teacher Education, 49, 6677.

Thornburg, D. D. (1994). Education in the communication age. San Carlos, CA: Starsong.

Tierney, W. G. (Ed.). (1998). The responsive university: Restructuring for high performance. Baltimore: Johns Hopkins University Press.

US Department of Education. (1993). Digest of educational statistics 1993. Washington, DC: National Center for Educational Statistics. 
Van Manen, M. (1990). Researching lived experience: Human science for an action sensitive pedagogy. London, Ontario, Canada: The State University of New York.

Welch, M. (1998). Collaboration: Staying on the bandwagon. Journal of Teacher Education, 49, 26-37.

Wheatley, M. J. (1994). Leadership and the new science: Leaming about organization from an orderly universe. San Francisco: Berrett-Koehler.

Wheatley, M. J., \& Kellner-Rogers, M. (1996). A simpler way. San Francisco: Berrett-Koehler.

Wilson, D. L. (1992, January 29). Colleges pressured on computer access for the handicapped. The Chronicle of Higher Education, 38(21), A1, A21-22.

Wise, A. E., Liebbrand, J. A., \& Williams, B. C. (1997). NCATE's response to critical issues in teacher preparation today. Action in Teacher Education, 19(2), 1-6.

Young, R. B. (1997). No neutral ground: Standing by the values we prize in higher education. San Francisco: Jossey-Bass.

Zehr, M. A. (1997). Teaching the teachers. Education Week, 17(11), 24-29. 


\section{APPENDICES}

\section{Appendix A: Consent form}

\section{Appendix B: Student journal writing prompts}

Appendix C: Student group discussion questions 


\section{University of San Diego School of Education \\ CONSENT FORM}

Caren Sax, a doctoral student in USD's School of Education, is conducting a study to explore students' practical application of the four themes identified by San Diego State University's College of Education: collaboration, reflective practice, diverse learners, and technology.

1. I consent to having my seminar journal entries reviewed for the explicit purpose of identifying how I addressed the four themes in the past academic year, 1997-98, as a student in the Multiple Subject Credential Program. I also consent to the use of my feedback that was audiotaped during seminar discussions in May 1998, with the understanding that the tape and its transcription will be used only for purposes of this study as related to the application of the four themes.

2. I understand that only the journal entries directly related to the four themes will be used, and that no other entries will be used for this study. I have completed my credential program and am at no risk that the use of this information will affect my grades or standing in the program. I understand that I have the opportunity to review the information that will be used for the study. I further understand that only the researcher will have access to the journals and audiotapes. The copies that are made of the journals and the audiotapes will be destroyed after the information is used. My original journal will be returned to me. Until that time, the information will be kept in a locked file cabinet at the Interwork Institute (not in the School of Teacher Education). 
3. I understand that my participation in this project will provide information about how university students learn and apply core concepts, as identified by the College of Education. My participation will provide the opportunity for student voices to be heard, so that instructors, administrators, and future students in professional education programs may benefit from the feedback.

4. I understand that my participation is completely voluntary. I may choose to withdraw my consent at any time during the research process, and if I do so, that decision will have no impact on any future interaction with San Diego State University.

5. Prior to signing the consent form, I will be given an opportunity to ask questions about how the data will be used, to which the researcher will respond openly (via phone at 619/594-7183, email to csax@mail.sdsu.edu, or fax to 619/594-8810).

6. I agreed verbally (at the time) to participate in class discussion groups that were audiotaped, and I understand that I will have access to the completed transcription, as well as the analysis, if I request it. Any future participation on my part will not be required unless I request it.

7. I understand that care will be taken to protect my identity and to ensure the confidentiality of all information utilized in the research. Names will not be used, nor will any other references to field sites or specific situations that might inadvertently reveal my identity.

8. There is no additional agreement, verbal or written, beyond that expressed in the consent form. 
I, the undersigned, understand the above explanations and on that basis, I give consent to my voluntary participation in this research.

Signature of Subject

Date

Location

Signature of Principle Researcher

Date

Signature of Witness

Date 


\section{Student Journal Writing Prompts}

9/3/97: Complete the phrase: "I felt welcomed at my school when ..."

9/1 1/97: Describe your comfort level as a learner and as a teacher in the areas of technology and reflective practice.

9/18/97: Describe your comfort level as a learner and as a teacher in the areas of collaboration and diverse learners.

10/6/97: In reference to The children's story by James Clavell: Write your assumptions about power, control, and influence in the classroom.

11/6/97: Complete the phrase: 'I'm beginning to feel like a member of my school because ..."

12/4/97: Provide an example of how you've addressed the four themes in your student teaching classrooms. If you have not addressed them, how do you plan to do so in the spring semester?

1/28/98: Which themes do you plan to focus on this semester? What would help you to incorporate the four themes into your classroom? 
$\underline{\text { Student group discussion questions }}$

1. How were you able to put the four core concepts into practice?

2. What specific activities did you do?

3. What success did you experience?

4. What challenges or questions remain?

5. How do you expect to incorporate these core concepts into your professional life? 